\title{
The course of chronic disease, depression and health behaviour in longitudinal perspective : findings concerning the epidemiology of aging
}

Citation for published version (APA):

van Gool, C. H. (2005). The course of chronic disease, depression and health behaviour in longitudinal perspective : findings concerning the epidemiology of aging. [Doctoral Thesis, Maastricht University]. Maastricht University. https://doi.org/10.26481/dis.20050610cg

Document status and date:

Published: 01/01/2005

DOI:

$10.26481 /$ dis.20050610cg

Document Version:

Publisher's PDF, also known as Version of record

Please check the document version of this publication:

- A submitted manuscript is the version of the article upon submission and before peer-review. There can be important differences between the submitted version and the official published version of record.

People interested in the research are advised to contact the author for the final version of the publication, or visit the DOI to the publisher's website.

- The final author version and the galley proof are versions of the publication after peer review.

- The final published version features the final layout of the paper including the volume, issue and page numbers.

Link to publication

\footnotetext{
General rights rights.

- You may freely distribute the URL identifying the publication in the public portal. please follow below link for the End User Agreement:

www.umlib.nl/taverne-license

Take down policy

If you believe that this document breaches copyright please contact us at:

repository@maastrichtuniversity.nl

providing details and we will investigate your claim.
}

Copyright and moral rights for the publications made accessible in the public portal are retained by the authors and/or other copyright owners and it is a condition of accessing publications that users recognise and abide by the legal requirements associated with these

- Users may download and print one copy of any publication from the public portal for the purpose of private study or research.

- You may not further distribute the material or use it for any profit-making activity or commercial gain

If the publication is distributed under the terms of Article $25 \mathrm{fa}$ of the Dutch Copyright Act, indicated by the "Taverne" license above, 
THE COURSE OF CHRONIC DISEASE, DEPRESSION, AND HEALTH BEHAVIOR IN LONGITUDINAL PERSPECTIVE

Findings concerning the epidemiology of aging

HET BELOOP VAN CHRONISCHE ZIEKTE, DEPRESSIE, EN GEZONDHEIDSGEDRAG IN LONGITUDINAAL PERSPECTIEF

Bevindingen aangaande de epidemiologie van veroudering 
The studies described in this thesis were performed at the Care and Public Health Research Institute (CAPHRI) of the Universiteit Maastricht, which partakes in the Netherlands School of Primary Care Research (CaRe), re-acknowledged by the Royal Dutch Academy of Sciences (KNAW) in 2000.

The studies described in this thesis were financially supported through research grants from the J.W. Fulbright Association, Stichting Anna Fonds, Nationaal Reumafonds, and Wake Forest University, which are gratefully acknowledged.

Financial support for printing this thesis by the Faculty of Health Sciences of the Universiteit Maastricht, the Care And Public Health Research Institute (CAPHRI) is gratefully acknowledged.

The course of chronic disease, depression, and health behavior in longitudinal perspective: Findings concerning the epidemiology of aging. C.H. van Gool. Doctoral dissertation, Universiteit Maastricht - with references - with summary in Dutch. MeSH subject headings: Chronic disease, Depression, Health Behavior, Lifestyle, Adherence, Longitudinal studies, Aging.

Lay out by C.H. van Gool; printed by Ipskamp PrintPartners. Cover design by Ivorm Concept \& Design, Tilburg (www.Ivorm.nl). ISBN: 90-9019432-0

Copyright (C) 2005, C.H. VAN GOOL, Universiteit Maastricht, Department of Health Care Studies, PO Box 616, 6200 MD Maastricht, The Netherlands, Telephone: (+31) 0433882204 ; Facsimile: (+31) 043 3884169, E-mail: Coen_v_Gool@yahoo.com 


\title{
THE COURSE OF CHRONIC DISEASE, DEPRESSION, AND HEALTH BEHAVIOR IN LONGITUDINAL PERSPECTIVE
}

Findings concerning the epidemiology of aging

\author{
PROEFSCHRIFT \\ ter verkrijging van de graad van doctor \\ aan de Universiteit Maastricht, \\ op gezag van de Rector Magnificus, \\ Prof. mr. G.P.M.F. Mols, \\ volgens het besluit van het College van Decanen, \\ in het openbaar te verdedigen \\ op vrijdag 10 juni 2005 om 12.00 uur.
}

door

CORNELIS HENRICUS (Coen) VAN GOOL

Geboren te Goirle op 12 november 1974 
Promotores:

Prof. dr. J.Th.M. van Eijk

Prof. dr. G.I.J.M. Kempen

Co-promotor:

Dr. B.W.J.H. Penninx (Vrije Universiteit Amsterdam)

Beoordelingscommissie:

Prof. dr. J.A. Knottnerus (voorzitter)

Prof. dr. J.J. Jolles

Prof. dr. J. van Os

Prof. dr. R. Sanderman (Rijksuniversiteit Groningen) 
"He who is of calm and happy nature will hardly feel the pressure of age, but to him who is of an opposite disposition youth and age are equally a burden" (Plato, 427bc - 347bc)

"I enjoy research more than eating"

(Curt P. Richter, 1894-1988) 


\section{Contents}

CHAPTER 1

General introduction

CHAPTER 2

Determinants of attendance to diet and exercise interventions among overweight and obese older adults: results from the Arthritis, Diet, and Activity Promotion Trial

CHAPTER 3

Effects of exercise adherence on physical function among overweight older adults with knee osteoarthritis

CHAPTER 4

Chronic disease and lifestyle changes: results from the Longitudinal Aging Study Amsterdam

CHAPTER 5

Protective effects of healthy lifestyles on the development of depressed mood: Iongitudinal results from the Maastricht Aging Study

CHAPTER 6

Relationship between changes in depressive symptoms and unhealthy lifestyles in late middle aged and older persons: results from the Longitudinal Aging Study Amsterdam

CHAPTER 7

Impact of depression on disablement in late middle aged and older persons: results from the Longitudinal Aging Study Amsterdam

CHAPTER 8

General conclusions and discussion

CHAPTER 9

SUMMARY (SAMENVATTING)

ACKNOWLEDGEMENT (DANKWOORD) AND CURRICULUM VITAE 
CHAPTER 1

General introduction 


\subsection{Determining the framework: the epidemiology of aging}

W

estern society's industrial revolution had several important

consequences, one of which is still ongoing: the medical revolution. Inventions, like penicillin, radioactivity, and Röntgen radiation, had the important consequences that all kinds of life threatening diseases, such as tuberculosis and poliomyelitis, could be detected earlier, and, eventually, could be turned from life threatening into recovery or life lasting. Together with improved sanitary conditions, this has lead to a decrease in infant mortality and increase in life expectancy, resulting, ultimately, in the proportion of people aged 65 years and older constituting an increasingly part of populations in Western society. In the Netherlands, for example, this proportion will have increased from $7.7 \%$ in 1950 to an expected $23.4 \%$ in 2040 [1].

The earlier detection of certain diseases in combination with the life lasting character of diseases (instead of life threatening) also has the consequence that persons are more likely to be struck by chronic disease as they age. Therefore, an increasingly great part of the aging population will spend an increasingly great part of their life with chronic diseases.

As shown in the table with percentages of reported chronic diseases in the Dutch population [2], the one-year prevalence of musculoskeletal disorders in persons aged 25 through 54 years was 8.3\%, while the one-year prevalence in persons aged 55 years and over was 36.1\% (Table 1.1). For high blood pressure the one-year prevalence in persons aged 25 through 54 years is $6.8 \%$, while the one-year prevalence in persons aged 55 years and over is $24.4 \%$. As a last example, only $1.2 \%$ of persons aged $25-54$ years reported to have (had) heart disease, while almost $10 \%$ of the persons aged 55 years and over indicated to have (had) a serious heart condition or myocardial infarction. In the age group 25 through 54 years only $15.8 \%$ has two or more chronic diseases, whereas $35.5 \%$ of the age group 55 years and over reported two or more chronic disease. This suggests not only that aging is associated with an increased risk of being struck by chronic diseases, but also that being struck by chronic disease is associated with an increased risk of more chronic conditions.

Being struck by a chronic disease can be the start of a natural sequence of events that occurs as a consequence of disease and that culminates in disability [3]. This disease-disability pathway has been described before $[4,5]$, 
Table 1.1: Estimated one-year prevalence ${ }^{\mathrm{a}}$ of reported chronic diseases in the Dutch population, stratified by age categories.

\begin{tabular}{|c|c|c|}
\hline Chronic diseases & $25-54$ years & $>54$ years \\
\hline Musculoskeletal disorders ${ }^{b}$ & $8.3 \%$ & $36.1 \%$ \\
\hline High blood pressure & $6.8 \%$ & $24.4 \%$ \\
\hline Back injury & $10.1 \%$ & $15.4 \%$ \\
\hline Heart disease ${ }^{c}$ & $1.2 \%$ & $9.6 \%$ \\
\hline Lung disease $^{d}$ & $7.5 \%$ & $9.0 \%$ \\
\hline Diabetes mellitus & $1.3 \%$ & $7.1 \%$ \\
\hline Cancer or malignancies & $0.8 \%$ & $3.9 \%$ \\
\hline Vertigo (with falling) & $1.0 \%$ & $3.8 \%$ \\
\hline Gastrointestinal disorder ${ }^{\mathrm{e}}$ & $1.9 \%$ & $3.5 \%$ \\
\hline Thyroid disorder & $1.4 \%$ & $3.3 \%$ \\
\hline (Consequences of) Stroke & $0.2 \%$ & $2.6 \%$ \\
\hline$\%$ with 2 or more chronic diseases & $15.8 \%$ & $35.5 \%$ \\
\hline
\end{tabular}

but has been extended and innovated by Verbrugge and Jette [6] in their disablement process, where 'disablement' refers to "the impact that chronic (...) conditions have on the functioning of specific body systems and on people's abilities to act in necessary, usual, expected, and personally desired ways in their society", and 'process' refers to "the interest in the dynamics of disablement; that is the trajectory of functional consequences over time and the factors that affect their direction, pace, and patterns of change". Specifically, the disablement process is initiated by disease or pathology. When confronted by disease (e.g., arthritis), a person may encounter impairments of the disease: the body mobilizes its' resources and defense mechanisms (e.g., pain, joint inflammation) against the abnormal state of disease in an attempt to return to its' normal state. Because of these impairments, a person may be 
limited functionally in performing routine tasks in a usual way (e.g., difficulty in grasping and rotating fixed objects). The persistent functional limitation in routine tasks can cause a person to be no longer able to adequately perform a functional or social role, and can qualify a person as disabled. For example, no longer being able to turn on a water faucet hinders the role of self-care.

The pathway from disease to disability is not inexorable [7]. Each of the steps in the disablement process can be modified by predisposing risk factors (present before disease manifestation: e.g., biological, lifestyle, demographic factors, socioeconomic status), extra-individual factors (e.g., health insurance, surgery, medication), and intra-individual factors (e.g., coping style, lifestyle changes, symptoms of depression).

Traditionally, medicine used to focus on causes of diseases, and reducing incidence of diseases by eradicating etiologic factors (primary prevention). However, as medicine is being confronted with an increasingly great part of the aging population spending an increasingly great part of their life with more chronic diseases, the need arises for reducing chronic disease burden by early detection and effective initial treatment (secondary prevention). As there is no cure (yet) for chronic diseases, tertiary prevention, aimed at preventing additional morbidity as a consequence of initial chronic disease, seems the strategy indicated to follow in order to add life to years of older people, instead of only years to life $[6,8,9]$. An example of tertiary prevention is promoting healthy lifestyles, such as giving up smoking, moderate alcohol intake, being physically active for at least 30 minutes per day on average, and following a well-balanced diet.

So, gradually, a different way of thinking is noticeable in medicine regarding chronic diseases. Whereas medicine traditionally was focused on preventing or eliminating causes of each disease (model of primary causality), nowadays the focus is on the model of circular causality, in which causes and consequences of diseases are difficult to distinguish: the consequences of the one disease may be the cause of another disease, the consequences of which may be the cause of yet another disease, and so on... Effective tertiary prevention of chronic diseases should foremost aim at assessing all aspects of chronic disease. Which chronic diseases are more common? What kind of comorbid conditions can be distinguished? The epidemiology of aging tries to 
explore what diseases become more prevalent as people age, what determinants are facilitating for being struck by diseases typical of old age, and what factors are protective for being struck by these diseases. Knowing this, tertiary prevention of chronic diseases can then investigate possibilities to intervene on this negative circular chain, and prevent or diminish negative consequences of disease in terms of impairments, limitations, or even disability [10].

\subsection{Associations between chronic disease, depression, and health behavior}

Chronic diseases differ greatly regarding onset (acute vs. gradual), course (progressive decline vs. constant or episodic), functional incapacitation (disabling vs. no incapacitation), prognosis (fatal or life-threatening vs. recovery or life lasting), and illness controllability (low vs. high; [11]). As described before, aging is associated with an increased risk of all kinds of potentially disabling chronic diseases. Chronic diseases not only negatively influence physical functioning, but can also have an unfavorable influence on (symptoms of) depression [12]. Depression, in its' turn, can provoke (or worsen the course of) chronic disease $[13,14]$. In both cross-sectional and longitudinal studies, people with specific diseases reported more symptoms of depression, as compared to those without chronic diseases [15-19]. Moreover, a higher number of chronic diseases is strongly associated with more depressive symptomatology $[20,21]$. Bearing in mind the earlier mentioned higher numbers of chronic diseases in older people, this places persons of 55 years and over at increased risk of more symptoms of depression related to chronic diseases.

There are several possible mechanisms to explain the association frequently found between chronic diseases and depression. First, structural or neurochemical changes of the brain, or immune system deficiencies may be the cause of depression $[18,22]$. Second, psychosocial consequences of the disease, such as decreased quality of life, may lead to depression [23]. There are also several possible mechanisms through which depression can lead to chronic diseases. A biological mechanism in the case of heart disease is that depression goes together with elevated plasma norepinephrine, increased 
heart rate, and reduced heart-rate variability [24,25], ultimately leading to heart disease. Another mechanism through which depression can lead to chronic diseases is that more symptoms of depression could lead to an increase in smoking behavior, an increase in alcohol intake, and a decrease in physical activity, and less adherence to medical regimen. These unhealthy behaviors are well known risk factors for chronic disease incidence or worsening $[26,27]$. Finally, both chronic disease and depression could well be symptoms of mutually shared underlying latent pathology or disease [28], as for example too high levels of the thyroid hormone thyroxine and symptoms of depression are both symptoms of hyperthyroid disorder. Ultimately, one can say that the mechanisms of chronic disease causing depression and the mechanisms of depression causing or worsening chronic disease seem to increase the risk of each other over time.

Chronic diseases and health behavior, which we defined in our study as smoking behavior, alcohol intake, physical activity, body composition, and the extent to which people adhere to health advice or medication (regimen adherence) are unmistakably intertwined. Chronic disease incidence, for example arthritis, may cause a physically active person to transcend to an unhealthy sedentary lifestyle, as the pain of his or her condition is too much of an impediment in being physically active. Also, healthy lifestyle changes may be indicated to prevent chronic disease incidence or worsening [29]. Chronic disease prevention is a good example of how changing lifestyles (e.g., quit smoking) or enhancing regimen adherence (e.g., attending smoking cessation classes) can contribute to the prevention of chronic disease incidence or worsening (preventing myocardial infarction incidence, or preventing atherosclerosis from worsening).

There are a number of studies available that have examined the association between depression and unhealthy lifestyles, particularly in older people. It seems that depressed persons are more likely than non-depressed persons to engage in unhealthy lifestyles, such as smoking, excessive alcohol intake, physical inactivity, unhealthy eating habits, and intervention noncompliance [30-32]. About the effect of health behavior on depression, it can be said that regular physical activity was protective for both prevalent as well as incident depression [33]. Also, in a prospective study physical inactivity was 
found to be a risk factor for symptoms of depression [34]. Regarding the other health behavior concepts and their association with depression: nicotine dependent as to non-nicotine dependent, but also smokers as to non-smokers had higher depression scores [35,36]; alcoholics as to non-alcoholics were at higher risk of depression, whereas non-alcoholics experienced mood-enhancing effects when using alcohol [37]; and being extremely obese was associated with the increased risk for depression [38].

\subsection{Study objectives}

The primary objective of this study is to gain more insight into the reciprocal associations between depression, health behavior, and the course of chronic disease among late middle aged and older persons, as depicted in the conceptual model (Figure 1.1). In order to attain this primary objective, the data of three different longitudinal studies were made available to us, with which specific research questions will be answered. The Arthritis, Diet, and Activity Promotion Trial (ADAPT) is a randomized controlled trial that compared effectiveness of three interventions with a control group on physical function of 316 overweight and obese older adults with knee OA, carried out by Wake Forest University in Winston-Salem (NC, United States). The Longitudinal Aging Study Amsterdam (LASA) is an ongoing, population-based cohort-study on predictors and consequences of changes in well-being and autonomy among 3107 late middle- and older aged adults, carried out by the Vrije Universiteit of Amsterdam. Finally, the Maastricht Aging Study (MAAS) is an ongoing,

Figure 1.1: Conceptual model of our study

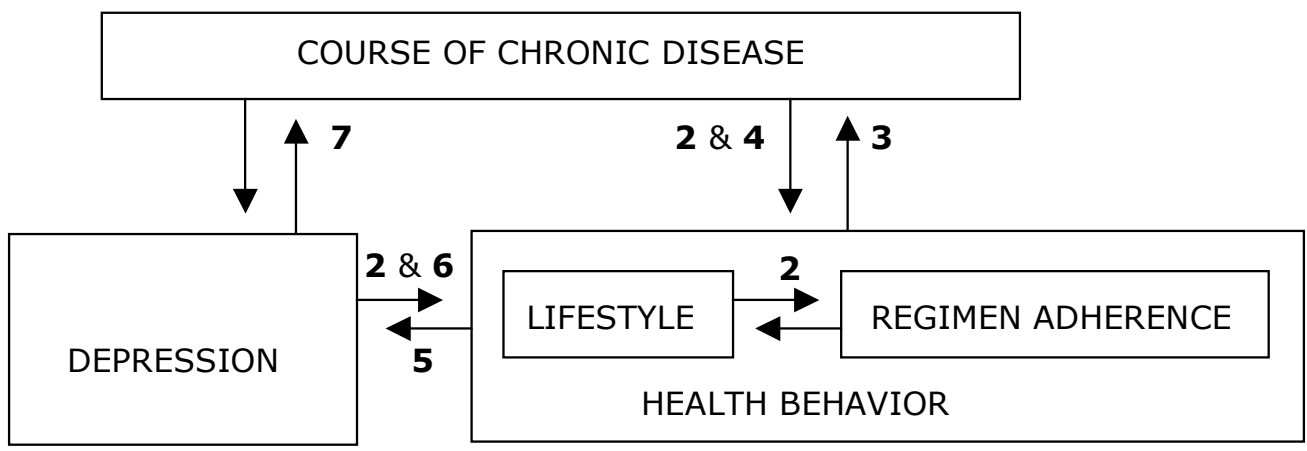

Note: The numbered arrows in the figure refer to the different chapters in this dissertation 
population-based cohort-study on determinants of successful (cognitive) aging among 3449 adults, aged between 24 and 81 years, and carried out by the Universiteit Maastricht.

Specifically, our research questions - which correspond both with the respective numbered arrows in the conceptual model and with the chapter numbers in this dissertation - are:

2) What determinants predict high and low intervention adherence to an 18-month intervention program in the Arthritis, Diet, and Activity Promotion Trial? In this study we examined whether determinants from the domains of chronic disease, lifestyle, and mental health, amongst others, could predict the extent of attendance to intervention sessions among older respondents with knee osteoarthritis;

3) Is exercise adherence to an 18-month intervention program associated with improvements in physical function in the Arthritis, Diet, and Activity Promotion Trial? In this study we examined whether the extent of attendance to intervention sessions was predictive of improvements in physical function and self-reported disability among older respondents with knee osteoarthritis; 4) Is chronic disease status associated with changes in unhealthy lifestyle in the Longitudinal Aging Study Amsterdam? In this study we analyzed whether lifestyle patterns changed during a six-year period, and whether these changes were different among specific chronic diseases among late middle aged and older community-dwelling respondents;

5) Are (changes in) lifestyle associated with symptoms of depression in the Maastricht Aging Study? In this study we analyzed the effect of smoking, alcohol use, level of physical exercise, and body mass index, and the changes herein over a six-year period, on subsequent depression among adult respondents from the general population;

6) Are (changes in) symptoms of depression associated with lifestyle in the Longitudinal Aging Study Amsterdam? In this study we examined the effect of being depressed, and changes in being depressed over a six-year period, on smoking, alcohol use, level of physical exercise, and the changes herein over a six-year period among late middle aged and older community-dwelling respondents; 
7) What is the impact of depression on the process of disablement in the Longitudinal Aging Study Amsterdam? In this study we analyzed whether the process of disablement could be identified in our sample of late middle aged and older community-dwelling respondents and whether or not depression accelerated this process.

Results may provide insights into determinants of the associations between depression, health behavior, and the course of chronic disease that are amenable to change, which can potentially be used in intervention research, and may therefore be relevant for clinical practice. Additionally, the outcome may contribute to improvements in public health policy and to costeffective health care. 


\subsection{References}

1. Nationaal Kompas Volksgezondheid. Bilthoven: RIVM , 2002.

2. Statistics Netherlands. Reported health and lifestyle. Retrieved June 3, 2004, from http://statline.cbs.nl/StatWeb/start.asp?lp=Search/Search.

3. Escalante A, Del Rincon I. The disablement process in rheumatoid arthritis. Arthritis Rheum 2002; 47: 333-42.

4. World Health Organization (WHO). International Classification of Impairments, Disabilities, and Handicaps. Geneva, Switzerland: WHO, 1980.

5. Nagi SZ. Some conceptual issues in disability and rehabilitation. In: Sussman MB, editor. Sociology and rehabilitation. Washington, D.C: American Sociological Association, 1965: 100-13.

6. Verbrugge LM, Jette AM. The disablement process. Soc Sci Med 1994; 38: 1-14.

7. Guccione AA. Arthritis and the process of disablement. Phys Ther 1994; 74: 408-14.

8. Fries JF. The compression of morbidity: near or far? Milbank Q 1989; 67: 208-32.

9. Spitzer WO. State of science 1986: quality of life and functional status as target variables for research. J Chronic Dis 1987; 40: 465-71.

10. Wagner EH, Austin BT, Von Korff M. Organizing care for patients. Milbank Q 1996; 74: 511-544.

11. Rolland JS. Chronic illness and the life cycle: a conceptual framework. Fam Process. 1987; 26: 20321.

12. Bisschop MI. Psychosocial resources and the consequences of specific chronic diseases in older age: the Longitudinal Aging Study Amsterdam [dissertation]. Enschede, the Netherlands: Febodruk, 2004.

13. National Academy on an Aging Society. Depression: A treatable disease. Challenges for the $21^{\text {st }}$ Century: Chronic \& Disabling Conditions 9. Retrieved May 31, 2004 from http://www.agingsociety.org/profiles.

14. Depression Guideline Panel. Depression in primary care, Vol 1. Detection and diagnosis. Clinical Practice Guideline, Number 5. Rockville, MD: Department of Health and Human Services, Public Health Service, Agency for Health Care Policy and Research. AHCPR Publication No. 93-0550, 1993.

15. Bisschop MI, Kriegsman DM, Deeg DJ, Beekman AT, van Tilburg W. The longitudinal relation between chronic diseases and depression in older persons in the community: the Longitudinal Aging Study Amsterdam. J Clin Epidemiol 2004; 57: 187-94.

16. Borson S, Barnes RA, Kukull WA, Okimoto JT, Veith RC, Inui TS, Carter W, Raskind MA. Symptomatic depression in elderly medical outpatients. I. Prevalence, demography, and health service utilization. J Am Geriatr Soc 1986; 34: 341-7.

17. Cassileth BR. Psychosocial problems and support of the advanced cancer patient. Rays 1985; 10: 131-4.

18. Shimoda K, Robinson RG. The relationship between poststroke depression and lesion location in longterm follow-up. Biol Psychiatry 1999; 45: 187-92.

19. Terry DJ. Stress, coping and coping resources as correlates of adaptation in myocardial infarction patients. Br J Clin Psychol 1992; 31 (Pt 2): 215-25.

20. Black SA, Goodwin JS, Markides KS. The association between chronic diseases and depressive symptomatology in older Mexican Americans. J Gerontol A Biol Sci Med Sci 1998; 53: M188-94.

21. Palinkas LA, Wingard DL, Barrett-Connor E. Chronic illness and depressive symptoms in the elderly: a population-based study. J Clin Epidemiol 1990; 43: 1131-41.

22. Zautra AJ, Burleson MH, Matt KS, Roth S, Burrows L. Interpersonal stress, depression, and disease activity in rheumatoid arthritis and osteoarthritis patients. Health Psychol 1994; 13: 139-48. 
23. Aneshensel CS, Frerichs RR, Huba GJ. Depression and physical illness: a multiwave, nonrecursive causal model. J Health Soc Behav 1984; 25: 350-71.

24. Hughes JW, Stoney CM. Depressed mood is related to high-frequency heart rate variability during stressors. Psychosom Med 2000; 62: 796-803.

25. Pitzalis MV, Iacoviello M, Todarello O, Fioretti A, Guida P, Massari F, Mastropasqua F, Russo GD, Rizzon $P$. Depression but not anxiety influences the autonomic control of heart rate after myocardial infarction. Am Heart J 2001; 141: 765-71.

26. Gohlke H. Lifestyle modification - is it worth it? Herz 2004; 29: 139-44.

27. Meigs JB, Hu FB, Rifai N, Manson JE. Biomarkers of endothelial dysfunction and risk of type 2 diabetes mellitus. JAMA 2004; 291: 1978-86.

28. Penninx BW, Leveille S, Ferrucci L, van Eijk JT, Guralnik JM. Exploring the effect of depression on physical disability: Iongitudinal evidence from the established populations for epidemiologic studies of the elderly. Am J Public Health 1999; 89: 1346-52.

29. Ellingsen I, Hjermann I, Abdelnoor M, Hjerkinn EM, Tonstad S. Dietary and antismoking advice and ischemic heart disease mortality in men with normal or high fasting triacylglycerol concentrations: a 23-y follow-up study. Am J Clin Nutr 2003; 78: 935-40.

30. Aneshensel CS, Huba GJ. Depression, alcohol use, and smoking over one year: a four-wave longitudinal causal model. J Abnorm Psychol 1983; 92: 134-50.

31. Stephens T. Physical activity and mental health in the United States and Canada: evidence from four population surveys. Prev Med 1988; 17: 35-47.

32. Slymen DJ, Drew JA, Elder JP, Williams SJ. Determinants of non-compliance and attrition in the elderly. Int J Epidemiol 1996; 25: 411-9.

33. Strawbridge WJ, Deleger S, Roberts RE, Kaplan GA. Physical activity reduces the risk of subsequent depression for older adults. Am J Epidemiol 2002; 156: 328-34.

34. Farmer ME, Locke BZ, Moscicki EK, Dannenberg AL, Larson DB, Radloff LS. Physical activity and depressive symptoms: the NHANES I Epidemiologic Follow-up Study. Am J Epidemiol 1988; 128: 1340-51.

35. John U, Meyer C, Rumpf HJ, Hapke U. Depressive disorders are related to nicotine dependence in the population but do not necessarily hamper smoking cessation. J Clin Psychiatry 2004; 65: 169-76.

36. Daniel M, Cargo MD, Lifshay J, Green LW.Cigarette smoking, mental health and social support: data from a northwestern First Nation. Can J Public Health 2004; 95: 45-9.

37. Freed EX. Alcohol and mood: an updated review. Int J Addict 1978; 13: 173-200.

38. Dong C, Sanchez LE, Price RA.Relationship of obesity to depression: a family-based study. Int J Obes Relat Metab Disord 2004; 28: 790-5. 


\title{
CHAPTER 2*
}

\section{Determinants of high and low attendance to diet and exercise interventions among overweight and obese older adults}

\author{
Results from the Arthritis, Diet, and Activity Promotion Trial \\ Coen H. van Gool, Brenda W.J.H. Penninx, Gertrudis I.J.M. Kempen, \\ Gary D. Miller, Jacques Th.M. van Eijk, Marco Pahor, Stephen Messier
}

\begin{abstract}
Background: Determinants of compliance to lifestyle regimens are not well understood. Attendance to intervention sessions is crucial for patients to acquire knowledge and skills regarding the core elements of an intervention, and can be seen as a prerequisite of intervention compliance. We explored demographic, health-related, and social determinants of high and low attendance to diet and exercise sessions among overweight and obese persons ( $\geq 60$ years; $N=206$ ) with knee osteoarthritis. Methods: The Arthritis, Diet, and Activity Promotion Trial was an 18-month randomized controlled trial on the effectiveness of dietary weight loss and exercise interventions. We conducted chi-square and t-tests, and logistic regression analyses on categories of short- and long-term attendance to intervention sessions. Results: Over the 18-month duration of the study, $60.7 \%( \pm 28.5)$ of diet sessions, and 53.2\% ( \pm 29.0$)$ of exercise sessions were attended. Not being married, low social participation, and single intervention randomization predicted high attendance to diet sessions during months 1 to 4 . Exercising at home (versus at the facility), and single intervention randomization predicted high attendance to exercise sessions during months 5 to 18 . For both interventions high attendance to intervention sessions during months 1 to 4 was a significant determinant of high intervention session attendance thereafter. Conclusions: Among overweight and obese knee osteoarthritis patients, determinants of diet and exercise session attendance differ. Giving people a choice to do their exercise at least partly at home and stimulating early intervention session attendance can be effective in improving long-term attendance to both interventions.
\end{abstract}

Keywords: knee osteoarthritis, obesity, patient compliance.

"As submitted to Controlled Clinical Trials. 


\subsection{Introduction}

nee osteoarthritis (OA) is a leading cause of decreasing physical function among older adults [1-3], which ultimately may limit a person's independence of living. Study outcomes have prompted the American College of Rheumatology to recommend weight loss and exercise for obese patients with knee OA [4]. There is evidence that obesity is strongly associated with knee OA [5-7], and that weight loss may prevent the worsening of this degenerative joint disease [8]. Exercise programs have demonstrated improvements in mobility among patients with knee OA [5,9-11]. However, success of efforts for pain relief and improvement of clinical outcomes in patients with OA is largely dependent on intervention compliance [12]. Attendance to intervention sessions is crucial for patients to acquire knowledge and skills regarding the core elements of an intervention. Hence, attendance to intervention sessions can be seen as an important prerequisite of intervention compliance.

Recent reviews on physical activity interventions identify advanced age, female gender, low educational level, smoking, being overweight, low social support and medical concerns as determinants of poor intervention session attendance [13-16]. However, as these determinants were derived from studies using short-term interventions and short follow-up durations in young and healthy samples, it remains unclear whether these determinants apply to older, more diseased persons. Determinants of attendance to diet intervention sessions are less well studied [17-19]. To our knowledge, no study has examined the impact of the same set of determinants on both diet and exercise session attendance.

We explored determinants of high and low attendance to an 18-month dietary weight loss and an 18-month exercise intervention. We selected a broad range of determinants - demographics, health-related, and social variables - since it has been indicated by previous research that all of these domains may be important for intervention session attendance $[14,15]$. Understanding determinants of high and low diet and exercise session attendance may be helpful to tailor future therapies to maximize intervention session attendance among overweight and obese older people with knee OA, which is pivotal in developing effective interventions [16,20-22]. 


\subsection{Methods}

\section{Design}

The Arthritis, Diet, and Activity Promotion Trial (ADAPT) was a randomized controlled trial to compare effectiveness of three 18-months interventions - a dietary weight loss program (WL), an exercise program (EX), and a dietary weight loss plus exercise program $(W L+E X)$ - with a healthy lifestyle control group on physical function of overweight and obese adults with knee OA. Main study findings indicated that especially participants in the WL+EX program improved their physical function and health-related quality of life over time. Detailed information on all interventions as well as sampling and datacollection procedures, and main study outcomes can be found elsewhere [2325]. The current study reports on determinants of high and low attendance to sessions of the intervention programs.

\section{Study sample and Intervention}

Inclusion criteria for study participation were: 1 ) age $\geq 60$ years; 2 ) body mass index $(B M I) \geq 28 \mathrm{~kg} / \mathrm{m}^{2}$; 3) knee pain on most of the days; 4) sedentary activity pattern for the past 6 months with less than 20 minutes of formal exercise once a week; 5) self-reported difficulty ascribed to knee pain in at least one activity of daily living; and 6) radiographic evidence of tibia-femoral OA. Potential participants were excluded if they: 1 ) had a serious medical condition that prevented safe participation in the exercise intervention program; 2) had a mini-mental state examination (MMSE [26]) score $\leq 23 ; 3$ ) could not finish the 18 month trial due to severe psychiatric morbidity or terminal illness; or 4) were unable to walk without an assistive device. After pre-screening 2,209 persons, written informed consent was obtained from 316 participants. They were randomly assigned to one of four study groups: 82 in the WL intervention, 80 in the EX intervention, 76 in the WL+EX intervention, and 78 in the healthy lifestyle control group. Since we wanted to explore determinants of intervention session attendance, only the three intervention groups $(N=238)$ were included in our secondary data analyses. The study was conducted at the Claude D. Pepper Older Americans Independence center of Wake Forest University with the approval of the institutional review board. Participant progress during the study is depicted in Figure 2.1. 
Figure 2.1: Flowchart of participant progress in ADAPT study.

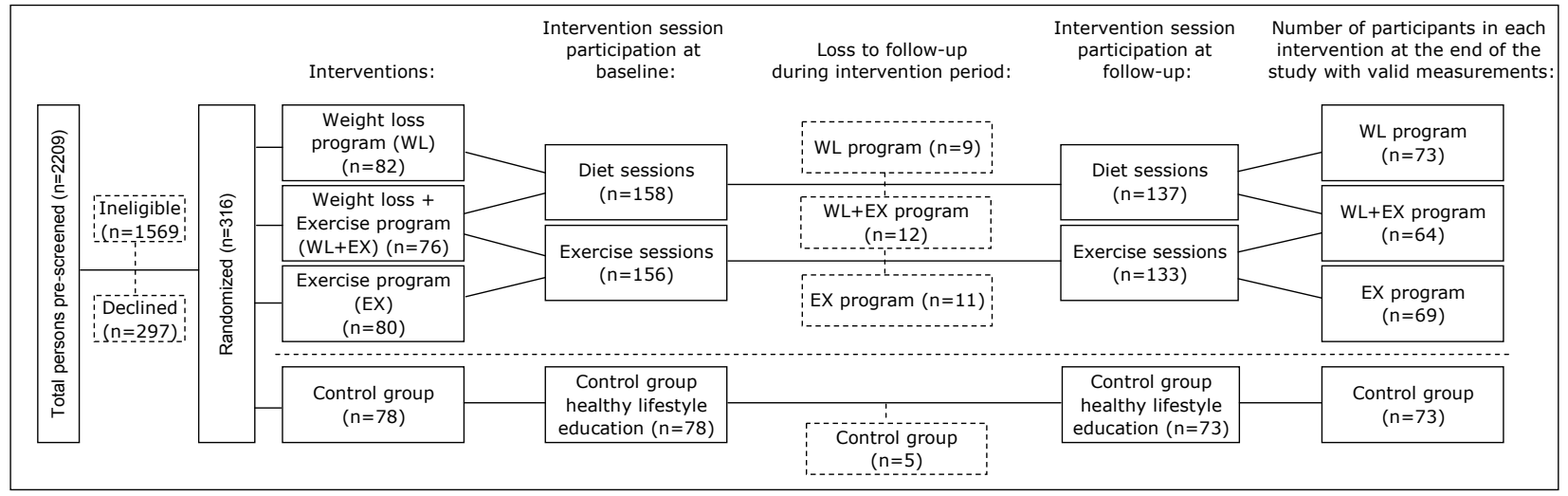

The goal of the $W L$ program was to achieve and maintain an average weight loss of $5 \%$ during 18 months. This was done through diet sessions. During the first four months (initiation phase) an individual introductory session was followed by 16 weekly sessions in a 1:3 ratio of individual versus group sessions. The transition and maintenance phase (maintenance phase; months 5 to 18 ) started with one individual and three group sessions bi-weekly over an eight-week period. Hereafter, meetings were held monthly, also in a $1: 3$ ratio of individual versus group contact, followed by telephone contacts, initiated by a study interviewer, two weeks after the meeting.

The EX program intended to expand aerobic and resistance-training capacities. The three days per week exercise program -the exercise sessionsconsisted of two 15 minutes aerobics phases, during which participants walked within a range of $50-75 \%$ of their heart rate reserve, and were separated by a 15 minutes resistance-training phase, which consisted of two sets of 12 repetitions of the following exercises: leg extension, leg curl, heel raise, and step up. Ankle cuff weights and weighted vests provided resistance. Fifteen minutes of cooling down ended each session. The initiation phase was held at the facility. In the maintenance phase participants could either choose to exercise at home, exercise in a facility-based program, or in a combined facility-home-based program. Those who had opted for the (combined) homebased program were expected to exercise as much as the facility-based participants - 60 minutes, three days a week - and had to keep daily exercise logs, in which they were asked to carefully report on exercise frequency, duration, and achieved heart rate.

Participants in the $W L+E X$ program underwent an exact combination of the aforementioned WL and EX interventions. During the first four months diet 
sessions and exercise sessions were done consecutively and on the same day. Transportation to intervention sessions, and to baseline, six-, and 18-months post-randomization assessment visits was provided for all participants when needed. Intervention participation was stimulated by reminder telephone calls. Additionally, if participants did not show-up at intervention sessions, they were contacted by telephone as well.

\section{Measurements}

Outcome measures

We assessed diet session attendance by dividing the number of times participants actually attended diet sessions or responded (telephone contact), by the number of sessions participants were asked to attend, or number of times participants were asked to respond, multiplied by $100 \%$. Exercise session attendance was measured by dividing the number of exercise sessions participants actually attended or exercised at home (exercise log) by the number of sessions participants were asked to attend or exercise at home, multiplied by $100 \%$. As we used a different time frame in our analyses and included a different number of participants in our sample than the main study outcome paper did, intervention session attendance percentages may differ across studies [24].

Since determinants of session attendance early in the intervention may differ from those later on in the intervention [20], we distinguished between initiation phase and maintenance phase in the analyses. Preliminary analyses indicated that both diet session attendance and exercise session attendance were not distributed normally. Therefore, we created four dichotomous outcome variables in which both initiation phase and maintenance phase session attendance were divided at median value into two approximately equally large categories, labeled low and high diet and exercise session attendance, respectively.

\section{Determinants}

Age, gender, marital status, years of education, and ethnicity were selfreported at baseline. Participants' self-reported medical histories at baseline assessed presence of arthritis in other sites of their bodies (yes/no), and 
presence of the following chronic diseases (yes/no): cardiovascular disease (CVD), cancer, diabetes, and lung disease. Study staff recorded participants' weight in kilograms and height in meters at the facility, with which baseline $B M I$ was calculated. Baseline self-reported physical function was measured with the Western Ontario and McMaster Universities Osteoarthritis Index (WOMAC) [27] and consisted of three sub scales: a) Function: difficulty performing activities of daily living, b) Pain: pain experienced due to arthritis, and c) Stiffness: severity of experienced stiffness. Three separate scale scores were used in the analyses, with high scores indicating, respectively, more difficulty, more pain, and more stiffness. The MMSE, administered by study staff, was used to assess cognitive function at baseline [26]. Since we used a MMSE score $\leq 23$ as an exclusion criterion, MMSE scores ranged from 24 to 30 (mildly impaired to good cognitive function, respectively). At baseline, participants were encouraged to complete a 6-minute walk test as quickly as possible without wearing a watch [28], from which walking speed in meters per second was derived. Participants were asked about their baseline smoking status (yes/no) and alcohol consumption (yes/no). We used the baseline Mental Health (5 items) and Social Functioning ( 2 items) scales of the Short Form 36 Quality of Life Health Survey (SF-36), which assess, respectively, participants' perceptions of their mental health and social functioning [29]. Baseline social support was assessed by the Medical Outcomes Study Social Support Survey [30]. Scores on these three scales ranged from 0 to 100 . As a measure of social participation we used participants' baseline responses to 4 questions whether they were a member of any religious community (yes/no), any organized club (yes/no), social organization (yes/no), and the frequency of attendance to these (never or almost never/once or twice a year/once a month/once a week/more than once a week). The sum score ranged from 2 to 12 , with high scores indicating higher social participation.

As attendance of intervention sessions is not stable over time, we considered percentage session attendance in the initiation phase to be a potential determinant of attendance to intervention sessions in the maintenance phase. Intervention randomization - i.e. being allocated to a single versus a combined intervention - was considered to be a potential determinant of attendance to intervention sessions. Finally, since participants in the EX and WL+EX 
intervention could choose their location of exercise after the initiation phase (at least partly at home versus at the facility), it was considered a potential determinant of exercise session attendance.

\section{Statistical analyses}

After descriptive analyses at baseline, we conducted chi-square and t-tests, and multivariate logistic regression analyses, with determinants of attendance as independent variable and dichotomous categories of session attendance as dependent variables, with odds ratios (OR's) and 95\% confidence intervals (95\%CI). Chi-square and t-tests identified relevant determinants. Statistical significance of $p \leq .15$ in univariate analyses was used as criterion for inclusion in additional multivariate analyses, which identified unique contributions of those determinants.

\subsection{Results}

Follow-up data on intervention outcome measurements of 32 of the participants $(N=238)$ were unavailable due to illness incidence, refusal, or moving out of the region. A chi-square test showed that non-respondents were divided evenly over intervention groups $(p=.67)$. We included 73 out of 82 $(89.0 \%)$ participants who were randomized into the WL intervention, 69 out of $80(86.3 \%)$ who were randomized into the EX intervention, and 64 out of 76 $(84.2 \%)$ who were randomized into the WL+EX intervention $(N=206)$. Chisquare and t-tests showed that intervention groups did not differ significantly on any of the baseline variables. Participants' mean age was 68.3 years (SD = 6.1 ), $25.7 \%$ were male, $59.3 \%$ were married, $27.7 \%$ had an education of 12 years or less, and the $26.6 \%$ non-white ethnicity consisted of $26.1 \%$ AfricanAmerican and $0.5 \%$ Hispanic participants. Mean percentage attendance to diet sessions over the 18 -month duration was $60.7 \%( \pm 28.5)$. The initiation phase of the diet sessions was inclined to be attended better by the WL intervention group than by the WL+EX intervention group ( $72.8 \%$ vs. $63.9 \% ; p=.07)$, whereas there was no significant difference in attendance in the maintenance phase of the diet sessions ( $55.2 \%$ vs. $48.9 \% ; p=.26)$. Overall attendance to diet sessions $(N=137)$ decreased over time from $68.6 \%( \pm 28.5)$ in the first four months of the study to $52.3 \%( \pm 31.9)$ in the last 14 months of the study. 
Mean percentage attendance to exercise sessions was 53.2\% ( \pm 29.0$)$. The percentage exercise session attendance did not differ significantly between the EX intervention group and the WL+EX intervention group for either the initiation phase $(67.8 \%$ vs. $69.9 \% ; p=.64)$, or the maintenance phase ( $51.2 \%$ vs. $48.5 \% ; p=.63)$. Overall exercise session attendance $(N=133)$ decreased over time from $68.8 \%( \pm 26.2)$ in the first four months of the study to $49.9 \%$ ( \pm 32.2 ) in the last 14 months of the study (not tabulated).

Since the percentages attendance to intervention sessions are rather comparable across groups, we merged data from weight loss groups (WL and $\mathrm{WL}+\mathrm{EX} ; N=137$ ) and exercise groups (EX and WL+EX; $N=133$ ) for further analyses on determinants of either diet session or exercise session attendance. In order to do so, we had to verify that intervention assignment (single or double intervention) did not interact with other determinants of attendance. Consequently, we examined the significance of interaction terms between determinants $\mathrm{x}$ intervention assignment on high or low session attendance in multivariate analyses. We found 3 interaction effects out of 91 possible, which can be attributed to chance. These analyses show that determinants of attendance were overall not different for participants who were assigned to a single versus a double intervention. We therefore merged data from participants with similar interventions for the purpose of subsequent analyses, resulting in one weight loss group who attended diet sessions and one exercise group who attended exercise sessions.

Median cut-off value for categories of attendance to diet sessions in the initiation phase was 75\%: 70 respondents attended less than or $75 \%$ of all diet sessions in the first four months and were assigned to the low attendance category; 67 respondents attended more than $75 \%$ of all diet sessions and were assigned to the high attendance category. Similarly, median cut-off value for categories of attendance to diet sessions in the maintenance phase was $60 \%$ : 70 respondents attended less than or $60 \%$ of all diet sessions and were assigned to the low attendance category; 67 respondents attended more than $60 \%$ of all diet sessions in months 5 to 18 and were assigned to the high attendance category. Median cut-off value for categories of attendance to exercise sessions in the initiation phase was 75\%: 66 respondents attended less than or $75 \%$ of all exercise sessions in the first four months and were 


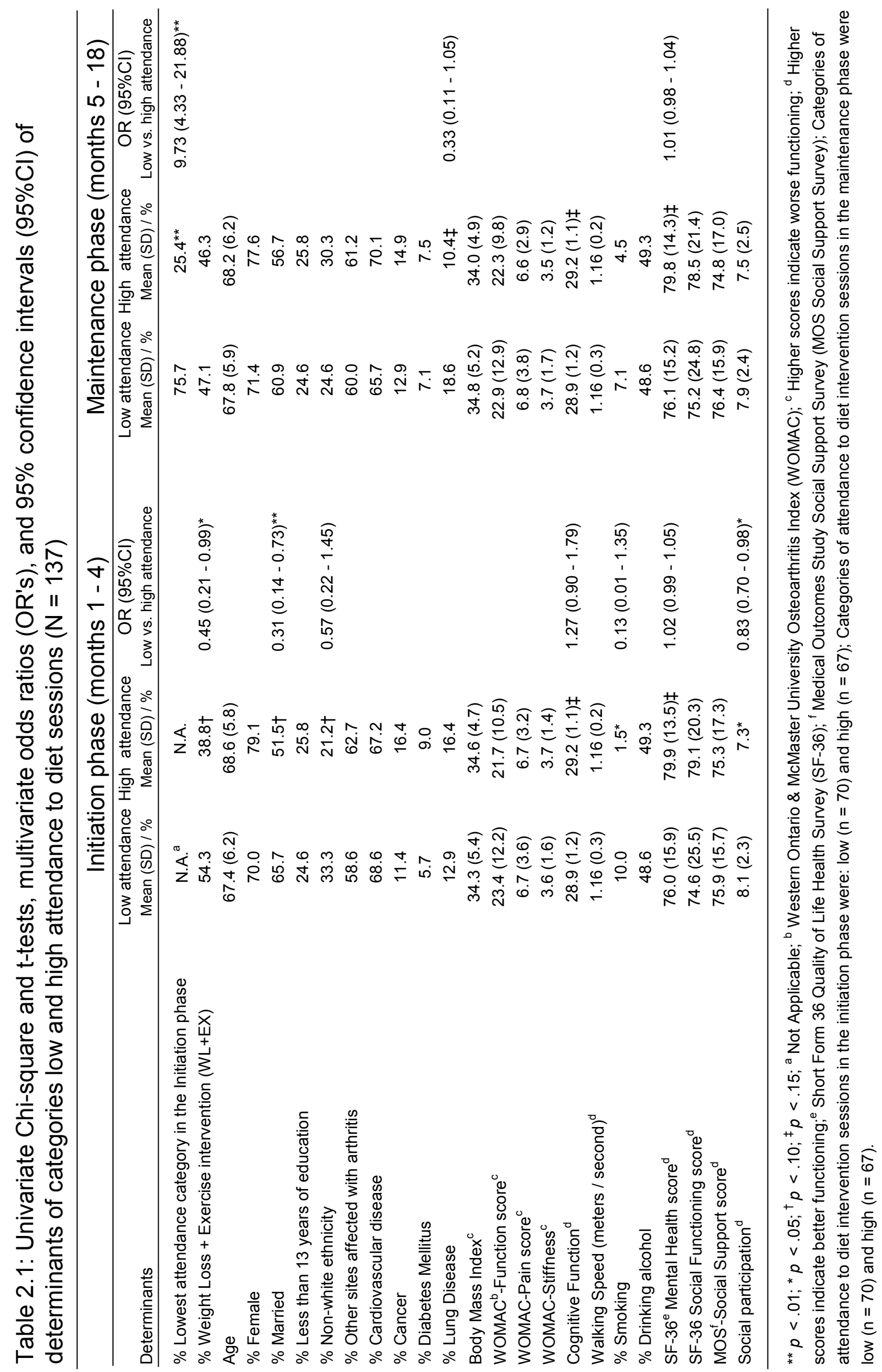


$75 \%$ of all exercise sessions and were assigned to the high attendance category. Alike, median cut-off value for categories of attendance to exercise sessions in the maintenance phase was 60\%: 73 respondents attended less than or $60 \%$ of all exercise sessions and were assigned to the low attendance category; 60 respondents attended more than $60 \%$ of all exercise sessions in months 5 to 18 and were assigned to the high attendance category.

Non-smoking status and low social participation were significant univariate determinants of high attendance to diet sessions in the initiation phase, as shown in Table $2.1(p<.05)$. Single intervention randomization versus the double intervention (WL vs. WL+EX), marital status, ethnicity, cognitive function and mental health status were included in the multivariate model as well, because of statistical significance below $p=.15$. In multivariate logistic regression analyses, marital status $(p<.01)$, social participation ( $p<$ $.05)$, and single intervention randomization $(p<.05)$ were significant determinants of attendance to diet sessions in the first 4 months: respondents who were married were less likely to attend the diet intervention sessions in the first four months than respondents who were not married (OR 0.31,95\%CI $0.14,0.74)$. Respondents who scored high on social participation were less likely to attend diet sessions in the first four months, compared to respondents who scored low on social participation (OR $0.83,95 \%$ CI $0.70,0.98$ ). Finally, respondents who were randomized into the WL+EX intervention were less likely to attend diet sessions in the first four months, compared to respondents who were in the WL intervention (OR $0.45,95 \%$ CI $0.21,0.99$ ).

High attendance to diet sessions in the initiation phase was the only significant univariate determinant of high attendance to diet sessions in the maintenance phase, as shown in Table $2.1(p<.01)$. Lung disease and mental health were included in the multivariate model as well, because of statistical significance below $p=.15$. In multivariate regression analyses, high attendance to diet sessions in the first 4 months was the only significant determinant of high attendance to diet sessions in the last 14 months ( $p<$ $.01)$ : respondents who were in the highest category of the variable diet session attendance in months 1 to 4 , were almost 10 times as likely to be in the highest category of the variable diet session attendance in months 5 to 18 , 
compared to respondents who were in the lowest category of the variable diet session attendance in months 1 to 4 (OR 9.73, 95\%CI 4.33, 21.88).

Not having cardiovascular disease and being of advanced age were significant univariate determinants of high attendance to exercise sessions in the first 4 months, as shown in Table $2.2(p<.05)$. Ethnicity, smoking status, and the WOMAC-Function subscale were included in the multivariate model as well, because of statistical significance below $p=.15$. In multivariate regression analysis, no determinant significantly predicted attendance to exercise sessions in the initiation phase.

After the initiation phase, 37 (27.8\%) participants chose to continue their intervention exercises (at least partly) at home, while 96 (72.2\%) participants continued doing their exercises at the facility (not tabulated). High attendance to exercise sessions in the initiation phase, having lung disease, male gender (all $p<.01$ ), exercising (partly) at home, Caucasian ethnicity, low BMI, and high walking speed (all $p<.05$ ) were significant univariate determinants of high attendance to exercise sessions in months 5 to 18 , as shown in Table 2.2. In the multivariate model we also included marital status, diabetes mellitus, the WOMAC-Stiffness subscale, and single intervention randomization, because of statistical significance below $p=.15$. In multivariate regression analysis, high attendance to exercise sessions in the initiation phase $(p<.01)$, EX intervention randomization (vs. WL+EX), exercising (partly) at home, and not having lung disease (all $p<.05$ ) significantly predicted high attendance to exercise sessions in months 5 through 18. Respondents who were in the highest category of the variable exercise session attendance in months 1 to 4 , were almost 7 times as likely to be in the highest category of the variable exercise session attendance in months 5 to 18 , compared to respondents who were in the lowest category of the variable exercise session attendance in months 1 to 4 (OR 6.86,95\%CI 2.62, 17.96). Respondents who continued doing their exercises at the facility were less likely to adhere to the exercise program than their counterparts who opted for doing their exercises at least partly at home (OR $0.26,95 \%$ CI $0.09,0.76)$. Also, respondents who were randomized into the $\mathrm{WL}+\mathrm{EX}$ intervention were less likely to attend exercise sessions in the final 14 months, compared to respondents who were in the EX intervention (OR $0.35,95 \%$ CI $0.14,0.86$ ). Finally, respondents with 


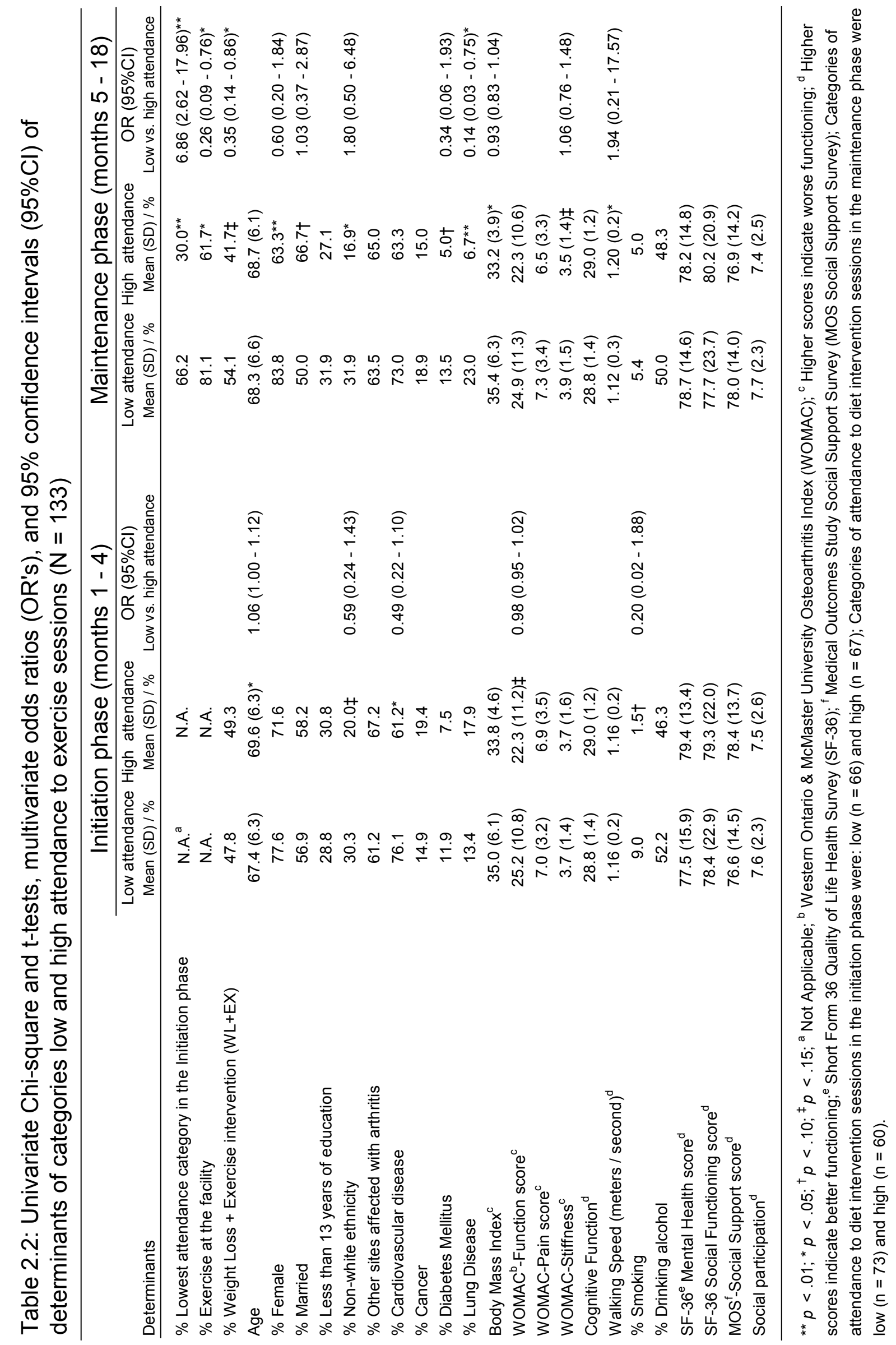


lung disease were less likely to attend exercise sessions in months 5 to 18 compared to respondents not reporting lung disease (OR $0.14,95 \% \mathrm{CI} 0.03$, $0.75)$.

\subsection{Discussion}

Our study found an overall diet session attendance of $60.7 \%$ among older persons with knee $\mathrm{OA}$, and varied from $68.6 \%$ in the first four months of the study to $52.3 \%$ in the last 14 months of the intervention. Overall exercise session attendance was $53.2 \%$, and varied from $68.8 \%$ in the first four months of the study to $49.9 \%$ in the last 14 months of the intervention. In multivariate analyses we found that not being married, low social participation, and single intervention randomization were predictive of high diet session attendance in the initiation phase of the study. In multivariate analyses, high diet session attendance in months 1 to 4 was the only significant predictor of high diet session attendance in the maintenance phase. Multivariate analyses on determinants of initiation phase exercise session attendance yielded no significant results. High exercise session attendance in the initiation phase, and exercising (at least partly) at home, single intervention randomization, and not having cardiovascular disease were predictors of high exercise session attendance in the maintenance phase.

Attendance to dietary interventions has shown to decrease with intervention duration, e.g. from $90 \%$ during a 10 -week dietary intervention among overweight and obese, post-menopausal women to $70 \%$ during a 2 year dietary intervention which was similar in intensity to our diet intervention [31,32]. Diet session attendance diminished in our study as well; from $68.6 \%$ in the first four months of the study to $52.3 \%$ in the last 14 months of the study. Our average diet intervention attendance (61\%) seems poor, compared to the aforementioned $70 \%$. However, this percentage was achieved in a study among women aged 45 to 69 without any apparent health problems [31], whereas our study was conducted among older respondents with pain, mobility problems and knee OA.

Exercise session attendance tends to decrease with intervention duration [32]. We found this in our study as well: from $68.8 \%$ in the first four months of the study, to $49.9 \%$ in months 5 to 18 . Our overall exercise session 
attendance of $53.2 \%$ seems to be in line with the described attendance range of $36 \%-68 \%$ in long-term home-based exercise interventions or compared to the attendance range of $36 \%-80 \%$ in long-term group-based exercise interventions [33].

Married respondents were less likely to attend diet sessions than their divorced, widowed, or never married counterparts. Perhaps married respondents were less likely to find the time and dedication to attend diet sessions in the first 4 months due to all kinds of social or familial involvements. On the other hand, the greater attendance to diet sessions among respondents who are divorced, widowed, or never married, could reflect the strong desire to keep up their health and remain independent, despite their knee OA. Alike, low social participation was associated with high diet session attendance. This may indicate that participants, who were less socially involved in all kinds of community or religious activities, were more likely to find the time and dedication to attend diet sessions in the first 4 months. It is also possible that these participants were more susceptible to the social aspect that goes out from group interventions, and were more likely to attend diet sessions.

In the maintenance phase of the exercise sessions, we found that participants who were doing their exercises at least partly at home to be likely to adhere better to the exercise program than their counterparts who remained exercising at the facility. Participants who exercised at home were asked to keep their own exercise logs. Whether these logs reflect true exercise effort of participants, or rather social desirability remains unclear. However, Castro and colleagues [34] found that exercise logs are valid and reliable reflections of true energy expenditure. Although exercising at home requires a strong selfdiscipline of a participant, it still is easier to implement in a person's daily life than fixed exercise classes. It may also be that participants acquire a sense of control when they are given the choice where to do their exercises, which may boost their motivation. In addition, perceived barriers, such as climate factors and mobility problems, may have lessened participant's enthusiasm to continue session attendance at the facility.

Being randomized into the double intervention versus a single intervention demonstrated to be detrimental for session attendance in the initiation phase of the diet sessions and in the maintenance phase of the 
exercise sessions. It should be kept in mind that randomization into a double intervention may interfere too strongly with participant's daily life than single intervention randomization does.

We found that for both the dietary and the exercise intervention, session attendance in the initiation phase is a very strong predictor of session attendance in a later stage of the intervention. This may indicate that if participants are convinced of intervention benefits and willing to come in for the first months of interventions, they are more likely to remain engaged. This could be due to the fact that repetition of behavior tends to make the behavior habitual $[20-22,35]$, or due to the fact that participants are simply interested in the topic of study. This finding may suggest that efforts to stimulate attendance to intervention sessions should be done from the very early phase of the intervention on. Moreover, a study on the effects of exercise session attendance in this same sample demonstrated that the respondents in the highest tertile regarding intervention session attendance improved significantly more in physical performance and self-reported disability than respondents who were in the lowest tertile regarding intervention session attendance [12].

A shortcoming of our study was that we only included sociodemographic, health-related, and social variables, and did not consider psychological variables, such as self-efficacy expectancies, and health-related attitudes. These should be subject of future studies regarding interventions prone to noncompliance. Although we acknowledge to the fact that attendance to intervention sessions does not equal intervention compliance, we believe that measures of intervention attendance reflect a certain precursory value of the extent to which a participant really is physically active, or really is changing eating habits.

In sum, various determinants - some of which modifiable - were predictive of high and low diet and exercise session attendance in our study. Overall, in the initiation phase, determinants of diet session attendance were not the same determinants that predicted exercise session attendance. Since session attendance in the maintenance phase of our study was mainly determined by session attendance in the initiation phase, this shows that efforts to motivate people and increase session attendance should be done in the very early stage of interventions. It is remarkable that among our older 
respondents with pain, mobility problems and knee OA, determinants of diet and exercise session attendance were mainly non-medical. This suggests that interventions such as ours are conductible and appropriate for older persons who are hindered in their mobility. 


\subsection{References}

1. Messier SP, Loeser RF, Hoover JL, Semble EL, Wise CM. Osteoarthritis of the knee: effects on gait, strength, and flexibility. Arch Phys Med Rehabil 1992;73(1):29-36.

2. Ettinger WH, Jr., Fried LP, Harris T, Shemanski L, Schulz R, Robbins J. Self-reported causes of physical disability in older people: the Cardiovascular Health Study. CHS Collaborative Research Group. J Am Geriatr Soc 1994;42(10):1035-1044.

3. Schultz AB. Mobility impairment in the elderly: challenges for biomechanics research. $J$ Biomech 1992;25(5):519-528.

4. Recommendations for the medical management of osteoarthritis of the hip and knee: 2000 update. American College of Rheumatology Subcommittee on Osteoarthritis Guidelines. Arthritis Rheum 2000;43(9):1905-15.

5. Davis MA, Ettinger WH, Neuhaus JM. Obesity and osteoarthritis of the knee: evidence from the National Health and Nutrition Examination Survey (NHANES I). Semin Arthritis Rheum 1990;20(3 Suppl 1):34-41.

6. Felson DT. The epidemiology of knee osteoarthritis: results from the Framingham Osteoarthritis Study. Semin Arthritis Rheum 1990;20(3 Suppl 1):42-50.

7. Hartz AJ, Fischer ME, Bril G, Kelber S, Rupley D, Jr., Oken B, et al. The association of obesity with joint pain and osteoarthritis in the HANES data. J Chronic Dis 1986;39(4): 311-319.

8. Felson DT, Zhang Y, Anthony JM, Naimark A, Anderson JJ. Weight loss reduces the risk for symptomatic knee osteoarthritis in women. The Framingham Study. Ann Intern Med 1992;116(7):535-539.

9. Ettinger WH, Jr., Burns R, Messier SP, Applegate W, Rejeski WJ, Morgan T, et al. A randomized trial comparing aerobic exercise and resistance exercise with a health education program in older adults with knee osteoarthritis. The Fitness Arthritis and Seniors Trial (FAST). JAMA 1997;277(1):25-31.

10. Minor MA, Hewett JE, Webel RR, Anderson SK, Kay DR. Efficacy of physical conditioning exercise in patients with rheumatoid arthritis and osteoarthritis. Arthritis Rheum 1989;32(11):1396-1405.

11. Fisher NM, Pendergast DR, Gresham GE, Calkins E. Muscle rehabilitation: its effect on muscular and functional performance of patients with knee osteoarthritis. Arch Phys Med Rehabil 1991;72(6):367-374.

12. Van Gool CH, Penninx BW, Kempen GI, Rejeski WJ, Miller GD, van Eijk JTh, Pahor M, Messier SP. Effects of exercise adherence on physical function among overweight older adults with knee osteoarthritis. Arthritis Rheum; 53(1):24-32.

13. Wilbur J, Chandler $P$, Miller AM. Measuring adherence to a women's walking program. West J Nurs Res 2001;23(1):8-24.

14. King AC, Rejeski WJ, Buchner DM. Physical activity interventions targeting older adults. A critical review and recommendations. Am J Prev Med 1998;15(4):316-333. 
15. Rhodes RE, Martin AD, Taunton JE, Rhodes EC, Donnelly M, Elliot J. Factors associated with exercise adherence among older adults. An individual perspective. Sports Med $1999 ; 28(6): 397-411$.

16. Courneya KS, Blanchard CM, Laing DM. Exercise adherence in breast cancer survivors training for a dragon boat race competition: a preliminary investigation. Psychooncology $2001 ; 10(5): 444-452$.

17. Kyngas $\mathrm{H}$, Lahdenpera $\mathrm{T}$. Compliance of patients with hypertension and associated factors. J Adv Nurs 1999;29(4):832-839.

18. Sherman AM, Bowen DJ, Vitolins M, Perri MG, Rosal MC, Sevick MA, et al. Dietary adherence: characteristics and interventions. Control Clin Trials 2000;21(5Suppl): 206S211S.

19. Urban N, White E, Anderson GL, Curry S, Kristal AR. Correlates of maintenance of a lowfat diet among women in the Women's Health Trial. Prev Med 1992;21(3):279-291.

20. Maddux JE, Brawley LR, Boykin A. Self-efficacy and health behavior: protection, promotion, and detection. In: J.E.Maddux, editor. Self-efficacy, Adaptation, and Adjustment: Theory, Research, and Application. New York: Plenum; 1995. p. 173-202.

21. Rejeski WJ, Brawley LR, Ettinger W, Morgan T, Thompson C. Compliance to exercise therapy in older participants with knee osteoarthritis: implications for treating disability. Med Sci Sports Exerc 1997;29(8):977-985.

22. Ronis DL, Yates JF, Kirscht JP. Attitudes, decisions, and habits as determinants of behavior. In: A.R.Pratkanis, S.J.Breckler, A.G.Greenwald, editors. Attitude structure and function. New York: Erlbaum; 2002. p. 213-239.

23. Rejeski WJ, Focht BC, Messier SP, Morgan T, Pahor M, Penninx B. Obese, older adults with knee osteoarthritis: weight loss, exercise, and quality of life. Health Psychol 2002; 21(5):419-26.

24. Messier SP, Loeser RF, Miller GD, Morgan TM, Rejeski WJ, Sevick MA, Ettinger WH Jr, Pahor M, Williamson JD. Exercise and dietary weight loss in overweight and obese older adults with knee osteoarthritis: the Arthritis, Diet, and Activity Promotion Trial. Arthritis Rheum 2004 May;50(5):1501-10.

25. Miller GD, Rejeski WJ, Williamson JD, Morgan T, Sevick MA, Loeser RF, Ettinger WH Jr, Messier SP. The Arthritis, Diet and Activity Promotion Trial (ADAPT): design, rationale, and baseline results. Control Clin Trials 2003; 24: 462-80.

26. Folstein MF, Folstein SE, McHugh PR. "Mini-mental state". A practical method for grading the cognitive state of patients for the clinician. J Psychiatr Res 1975; 12(3): 189-198.

27. Bellamy N, Buchanan WW, Goldsmith CH, Campbell J, Stitt LW. Validation study of WOMAC: a health status instrument for measuring clinically important patient relevant outcomes to antirheumatic drug therapy in patients with osteoarthritis of the hip or knee. J Rheumatol 1988;15(12):1833-1840.

28. Rejeski WJ, Ettinger WH, Jr., Shumaker S, Heuser MD, James P, Monu J, et al. The evaluation of pain in patients with knee osteoarthritis: the knee pain scale. J Rheumatol $1995 ; 22(6): 1124-1129$. 
29. Ware JE, Jr., Sherbourne CD. The MOS 36-item short-form health survey (SF-36). I. Conceptual framework and item selection. Med Care 1992;30(6):473-483.

30. Sherbourne CD, Stewart AL. The MOS social support survey. Soc Sci Med 1991;32(6): 705-714.

31. Bunyard LB, Dennis KE, Nicklas BJ. Dietary intake and changes in lipoprotein lipids in obese, postmenopausal women placed on an American Heart Association Step 1 diet. J Am Diet Assoc 2002;102(1):52-57.

32. Insull W, Jr., Henderson MM, Prentice RL, Thompson DJ, Clifford C, Goldman S, et al. Results of a randomized feasibility study of a low-fat diet. Arch Intern Med 1990;150(2): 421-427.

33. Van der Bij AK, Laurant MG, Wensing M. Effectiveness of physical activity interventions for older adults: a review. Am J Prev Med 2002;22(2):120-133.

34. Castro CM, Wilcox S, O'Sullivan P, Baumann K, King AC. An exercise program for women who are caring for relatives with dementia. Psychosom Med 2002; 64 (3): 45868.

35. Oliver $\mathrm{K}$, Cronan T. Predictors of exercise behaviors among fibromyalgia patients. Prev Med 2002; 35: 383-9.

\subsection{Acknowledgement}

Support for this study was provided by the Claude D. Pepper Older Americans Independence Center of Wake Forest University through grants from the National Institutes of Health 5P60-AG-10484-07, and a General Clinical Research Grant M01-RR00211. 
CHAPTER $3^{*}$

\title{
Effects of exercise adherence on physical function among overweight older adults with knee osteoarthritis
}

Coen H. van Gool, Brenda W.J.H. Penninx, Gertrudis I.J.M. Kempen, W. Jack

Rejeski, Gary D. Miller, Jacques Th.M. van Eijk, Marco Pahor, Stephen Messier

\begin{abstract}
Objective: For patients with knee osteoarthritis $(O A)$, adherence to prescribed exercise regimen is important in preserving physical function. We explored whether high exercise adherence improved physical function among older adults with $\mathrm{OA}$ who were overweight and obese. Methods: Associations between exercise adherence, changes in 6-minute walking distance in meters, and self-reported disability (Western Ontario and McMaster Universities Osteoarthritis Index [WOMAC] - Function subscale) after 6 and 18 months were examined among a 'Arthritis, Diet, and Activity Promotion Trial' subsample $(\mathrm{N}=134)$, using multiple linear regression models. Results: Higher exercise adherence was associated with greater improvements in 6-minute walking distance after 6 and 18 months and in disability after 6 months. Pain and body mass index (BMI) contributed - to some extent - in explaining the link between exercise adherence and changes in physical performance and self-reported disability. Conclusions: Higher exercise adherence is associated with improved physical function. This indicates that promoting adherence is clinically relevant when prescribing exercise regimen which also focus on decrease in pain and BMI to overweight and obese older adults with knee OA.
\end{abstract}

Key words: Intervention adherence, physical function, disability.

\footnotetext{
* As published in Arthritis \& Rheumatism (Arthritis Care \& Research) 2005; 53 (1): 24-32.
} 


\subsection{Introduction}

nee osteoarthritis (OA) is a leading cause of decreasing physical function among older adults, and may limit a person's independence of living and affect health-related quality of life $(1,2)$. In knee OA disease management, treatment options include adopting healthy lifestyles and physical exercise (3). These treatment options may also have beneficial effects on mental health (4). Compliance to treatment is important in attaining treatment goals. Specifically, when a physical exercise regimen is prescribed, adherence to this regimen is crucial in preserving physical performance and function, in terms of observed walking distance and self-reported disability, respectively, and in reducing pain for patients with knee OA (5).

Generally, exercise adherence tends to decrease with intervention duration, and usually results in an increase in concurrent and subsequent physical activity levels, although changes are small and generally short-lived (6-9). Several studies in healthy and diseased older adults showed favorable effects of exercise on muscle strength, aerobic capacity, reduction of fracture risk, and general well-being $(7,10,11)$. Studies among older adults with (knee) OA examining effects of exercise adherence have described greater improvements in physical performance, disability, pain, quality of life, and depressive symptoms for participants who adhered more to the exercise intervention regimen $(4,12,13)$. However, poor exercise adherence may partly have caused studies examining effects of exercise adherence in older adults who were overweight and obese to be inconclusive regarding weight maintenance and physical fitness $(8,9)$.

Studies examining effects of exercise intervention adherence on health outcomes in overweight and obese older adults with knee OA may offer insight into the effectiveness of exercise interventions in the growing group of overweight and obese older adults suffering from knee OA. The present study examined 1) whether higher exercise adherence to an 18-month intervention program was associated with more improvements in physical performance and self-reported disability, and 2) whether changes in modifiable, potentially explanatory variables, i.e. pain, mental health, social functioning, body mass index (BMI), location of exercise, could explain the association between exercise adherence and changes in physical performance and self-reported 
disability, by performing secondary analyses using data of the 'Arthritis, Diet, and Activity Promotion Trial' (ADAPT).

\subsection{Materials \& Methods \\ Design \& Study sample}

ADAPT was a randomized controlled trial conducted among overweight and obese, 60-year old and older adults with knee OA to compare effectiveness of three different 18-month interventions - a dietary weight loss, an exercise, and a combined dietary weight loss plus exercise intervention - with a healthy lifestyle control group on physical function, knee pain, stiffness, weight loss, and physical performance. Data collection visits took place at baseline, 6 and 18 months post-randomization. The study was approved of by Wake Forest University's institutional review board. Sampling, data-collection procedures, information on the interventions, and main study findings have been reported in detail elsewhere (14-16).

Inclusion criteria for participation in ADAPT were: 1) aged 60 years and over; 2 ) body mass index (BMI $=$ weight in kilograms $/$ height in meters ${ }^{2}$ ) $\geq$ 28 ; 3 ) knee pain on most of the days; 4) sedentary activity pattern for the past 6 months with less than 20 minutes of formal exercise once a week; 5) self-reported difficulty ascribed to knee pain in at least one (Instrumental) Activity of Daily Living ((I)ADL); and 6) radiographic evidence of tibia-femoral OA. Potential participants were excluded if they: 1) had a serious medical condition that prevented safe participation in the exercise intervention program; 2) had a mini-mental state examination (MMSE; 17) score $\leq 23 ; 3$ ) could not finish the 18 month trial due to severe psychiatric morbidity or endstage terminal illness; or 4) were unable to walk without a cane or other assistive device. Written informed consent was obtained from 316 eligible community-dwelling older adults. Subsequently they were randomly assigned to one of four study groups: 80 in the exercise group; 76 in the exercise plus dietary weight loss group - hereafter respectively called exercise only and exercise plus diet; 82 in the diet only group; and 78 in the healthy lifestyle control group. Since these last two groups did not contain exercise information we only included the two exercise groups $(N=156)$ in our secondary data analyses. 


\section{Intervention}

The exercise intervention was intended to expand aerobic and resistancetraining capacities for participants in the exercise only and exercise plus diet intervention group. The three days per week exercise program and consisted of two 15 minutes aerobics phases, during which participants walked within $50-85 \%$ of their heart rate reserve, and were separated by a resistancetraining phase (20 minutes), which consisted of two sets of 12 repetitions of the following exercises: leg extension, leg curl, heel raise, and step up. Ankle cuff weights and weighted vests were used to provide resistance. Five minutes of warming up and cooling down started and ended each session, respectively. The initiation phase (months 1 to 4 ) was held at the facility. After the transition phase (months 5 and 6 ) participants could either choose to exercise at home, exercise in a facility-based program, or to combine both options in the maintenance phase (months 7 to 18). Those who had opted for the (combined) home-based program were expected to exercise as much as the facility-based participants - 60 minutes, three days a week - and had to keep daily exercise logs, in which they were asked to carefully report on exercise frequency, duration, and achieved heart rate. During the first two months of home-based exercise study staff contacted these participants by telephone biweekly, tri-weekly during the following two months, and monthly thereafter, to exert supervision. If participants did not show-up at intervention sessions, they were contacted by telephone as well.

\section{Measurements}

\section{-Evaluation of exercise adherence}

Percentage exercise regimen adherence was measured by dividing the number of exercise sessions the participant actually attended or exercised at home (exercise log) by the number of prescribed sessions, multiplied by 100 (15). We calculated percentage exercise adherence for the first 6 months (called initiation phase), and overall percentage exercise adherence (months 1 to 18). Scores range from 0 to 100 on both variables with higher scores indicating more exercise adherence. 
-Physical performance

The performance based 6-minute walk test was used at each study assessment to study physical performance (18). Change in walking distance in meters was defined as follow-up minus baseline walking distance, and higher change scores indicate more improvement in walking distance. Two week test-retest reliability of walking distance has been reported to be 0.87 for patients with knee OA (19). Participants were encouraged to complete the test with their best effort without wearing a watch (20).

-Osteoarthritis-related Disability

At each study assessment we used the 17-item Function subscale of the Western Ontario and McMaster Universities Osteoarthritis Index (WOMAC; 21) to assess self-reported osteoarthritis-related disability in (instrumental) activities of daily living ((I)ADL). Scores range from 0 to 68 with higher scores indicating more disability in (I)ADL. Change in disability was defined as followup minus baseline score, and lower change scores indicate more improvement in disability in (I)ADL. The WOMAC has been extensively validated, used in comparative studies to other health status measures, and applied in clinical research and clinical practice settings (22). Cronbach's alpha of the WOMAC Function subscale at baseline was 0.94 .

\section{-Confounding Variables}

Non-modifiable, demographic information (age, gender, and ethnicity) was collected by self-report. Analyses were adjusted for whether or not participants in the exercise groups also received a diet intervention. Furthermore, because change in walking distance and disability are outcome measures, we adjusted analyses for baseline levels of these outcome measures.

\section{-Potentially Explanatory Variables}

We used the Pain subscale of the WOMAC (21) and changes in this subscale over time to assess self-reported osteoarthritis-related pain at each assessment. Scores range from 0 to 20 with higher scores indicating more pain. We used the Social Functioning and Mental Health subscales of the 36item Short Form-36 Quality of Life Health Survey (SF-36) and changes in these subscales to assess these domains of health-related quality of life at each assessment (23). This widely used generic health status instrument has been reported to be a psychometrically sound tool to assess health status of 
participants with osteoarthritis (24). Scores range from 0 to 100 with higher scores indicating greater quality of life. BMI and changes in BMI over time were calculated using weight in kilograms divided by the square of height in meters. Also, participant's choice of location of exercise was considered to be an explanatory variable (9). All change scores in potentially explanatory variables were defined as follow-up minus baseline score. Hence, lower change scores in pain and BMI indicate more improvement in pain and BMI, whereas higher change scores in mental health and social functioning indicate more improvement in mental health and social functioning.

\section{Statistical analyses}

Since overall exercise adherence did not differ between the two exercise intervention groups ( $54.5 \%$ exercise only versus $52.9 \%$ exercise plus diet, $p=$ 0.74 ), we merged exercise groups together for further analyses on the impact of exercise adherence on change in walking distance and disability. In order to do so, we had to verify that intervention assignment (exercise only or exercise plus diet) did not modify the association between exercise adherence and physical outcomes. Consequently, we compared means of walking distance and disability at baseline using t-tests and examined the significance of interaction terms between intervention assignment $x$ exercise adherence on changes in walking distance and disability in multiple linear regression analyses. Baseline means of walking distance (423.9 \pm 75.3 exercise only versus $411.0 \pm 88.2$ exercise plus diet; $p=0.389)$ and disability ( $23.8 \pm 10.3$ exercise only versus $23.6 \pm 11.9$ exercise plus diet; $p=0.923$ ) did not differ between intervention groups. We found no significant interaction effects, showing that the link between exercise adherence and change in physical outcomes was not different for participants who were assigned to exercise only versus exercise plus diet intervention.

In order to examine associations between percentage exercise adherence and change in walking distance and disability, we conducted multiple linear regression analyses, adjusted for confounding variables. These analyses were conducted for exercise adherence during months 1 to 6 and changes in outcomes after 6 months, as well as for overall exercise adherence (months 1 to 18 ) and changes in outcomes after 18 months. Outliers in the distribution of 
the variable change in walking distance after 6 months - scores below and over the $2.5^{\text {th }}$ percentiles - were transformed into the value of the lower and upper $2.5^{\text {th }}$ percentiles, -84.1 and 169.9 meters, respectively, to ensure that all outcome variables were distributed normally. Hereafter, tertile scores of percentage exercise adherence were created by dividing participants in three equally large categories: (1) low adherence, (2) intermediate adherence, and (3) high adherence to the exercise regimen for both the initiation phase ( $\leq$ $62 \%, n=46 ; 63 \%$ to $82 \%, n=43$; and $\geq 83 \%, n=45$, respectively) and overall study duration ( $\leq 40 \%, n=45 ; 41 \%$ to $70 \%, n=44$; and $\geq 71 \%, n=$ 45 , respectively). Univariate analyses of covariance (ANCOVA) were used to examine differences in estimated means in changes in walking distance and disability after 6 and 18 months between adherence categories with low adherence as reference category, adjusted for confounding variables. As a potentially mediating or explanatory variable in an association has to correlate with both the independent, and with the dependent variable, correlations between potentially explanatory variables and percentage exercise adherence, and correlations between potentially explanatory variables and change in walking distance and change in disability were examined. Finally, multiple linear regression models were computed in which each potentially explanatory variable was entered as covariate, after adjustment for confounding variables, to explore their contribution in explaining the associations between exercise adherence and change in physical performance and disability. A priori level of significance used in all analyses was 0.05 .

\subsection{Results}

Of the 156 participants, $69(86.3 \%)$ of the exercise only and $65(85.5 \%)$ of the exercise plus diet intervention were still exercising after the 18 months of the study. Analyses of variance and chi-square tests indicated that respondents lost to follow-up $(N=22)$ did not differ from participants $(N=134)$ on any of the baseline variables (all $p$ 's $>0.05$ ), or on intervention assignment ( $p=$ $0.90)$. Participants' mean age was $68.5 \pm 6.3$ years $(N=134), 72.2 \%$ were women, $76.1 \%$ were Caucasian, $57.6 \%$ were married, and $68.7 \%$ were educated more than 12 years. 
Mean percentage exercise adherence was $65.6 \% \pm 27.1$ in the initiation phase and $53.7 \% \pm 29.4$ overall $(N=134)$. Mean walking distance at baseline was $417.4 \pm 81.9$ meters, and ranged from 141 to 650 meters. After 6 and 18 months, significant mean improvements in walking distance were observed compared to baseline: $50.1 \pm 54.9$ meters and $46.4 \pm 65.4$ meters, respectively ( $p$ 's $<0.01$ ). Mean disability score at baseline was $23.7 \pm 11.1$, and ranged from 2 to 68 . After 6 and 18 months, significant mean improvements in disability were observed compared to baseline: $-3.6 \pm 9.2$ and $-3.5 \pm 9.9$, respectively ( $p$ 's $<0.01$ ). After the initiation phase, 37 (27.6\%) participants chose to continue their intervention exercises (at least partly) at home, while 97 (72.4\%) participants continued doing their exercises solely at the facility.

Table 3.1 shows the standardized linear regression coefficients $(\beta)$ of both initiation phase and overall exercise adherence on 6 - and 18-month change in walking distance and disability, adjusted for age, gender, ethnicity, intervention assignment, and baseline levels of outcome variables. Exercise adherence in the initiation phase and during overall study follow-up were associated with, respectively, 6 -month improvement in walking distance $(p=$ $0.002)$ and 18 -month improvement in walking distance $(p<0.001)$. Exercise

Table 3.1: Adjusted $^{\mathrm{a}}$ standardized linear regression coefficients $(\beta)$, adjusted estimated means (est. $M$ ) from

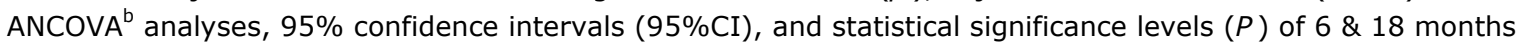
exercise adherence on change in walking distance and IADL disability after $6 \& 18$ months $(\mathrm{N}=134)$.

\begin{tabular}{|c|c|c|c|c|c|c|}
\hline \multirow[b]{2}{*}{ Exercise adherence in initiation phase } & \multicolumn{3}{|c|}{$\begin{array}{l}\text { Change in walking distance } \\
\text { in meters after } 6 \text { months }\end{array}$} & \multicolumn{3}{|c|}{$\begin{array}{l}\text { Change in disability } \\
\text { score after } 6 \text { months }\end{array}$} \\
\hline & $\beta$ & $95 \% \mathrm{CI}$ & $P$ & $\beta$ & $95 \%$ CI & $P$ \\
\hline \% Exercise adherence (continuous) & 0.28 & $0.25,1.07$ & 0.002 & -0.23 & $-0.14,-0.03$ & 0.001 \\
\hline \multirow[b]{2}{*}{$\begin{array}{l}\% \text { Exercise adherence (tertiles) } \\
\text { Low }(\leq 62 \% ; n=46) \\
\text { Intermediate }(\geq 63 \%-\leq 82 \% ; n=43) \\
\text { High }(\geq 83 \% ; n=45)\end{array}$} & est.M & $95 \% \mathrm{CI}$ & $P$ & est.M & $95 \% \mathrm{CI}$ & $P$ \\
\hline & $\begin{array}{l}35.2 \\
50.4 \\
63.5\end{array}$ & $\begin{array}{l}17.4,53.0 \\
33.0,67.9 \\
47.4,79.7\end{array}$ & $\begin{array}{l}\text { Ref. }^{c} \\
0.233 \\
0.024\end{array}$ & $\begin{array}{l}-0.3 \\
-6.4 \\
-3.6\end{array}$ & $\begin{array}{l}-2.6,2.0 \\
-8.7,-4.1 \\
-5.8,-1.4\end{array}$ & $\begin{array}{r}\text { Ref. } \\
<0.001 \\
0.049\end{array}$ \\
\hline & \multicolumn{3}{|c|}{$\begin{array}{l}\text { Change in walking distance } \\
\text { in meters after } 18 \text { months }\end{array}$} & \multicolumn{3}{|c|}{$\begin{array}{l}\text { Change in disability } \\
\text { score after } 18 \text { months }\end{array}$} \\
\hline Overall exercise adherence & $\beta$ & $95 \% \mathrm{CI}$ & $P$ & $\beta$ & $95 \% \mathrm{CI}$ & $P$ \\
\hline \% Exercise adherence (continuous) & 0.39 & $0.48,1.30$ & $<0.001$ & -0.18 & $-0.12,0.00$ & 0.052 \\
\hline & est.M & $95 \%$ CI & $P$ & est.M & $95 \% \mathrm{CI}$ & $P$ \\
\hline $\begin{array}{l}\text { Low }(\leq 40 \% ; n=45) \\
\text { Intermediate }(\geq 41 \%-\leq 70 \% ; n=44) \\
\text { High }(\geq 71 \% ; n=45)\end{array}$ & $\begin{array}{l}21.2 \\
45.0 \\
68.3\end{array}$ & $\begin{array}{l}-2.3,44.8 \\
24.9,65.1 \\
50.0,86.6\end{array}$ & $\begin{array}{c}\text { Ref. } \\
0.135 \\
0.002\end{array}$ & $\begin{array}{l}-1.3 \\
-4.9 \\
-5.9\end{array}$ & $\begin{array}{l}-4.7,2.1 \\
-7.9,-1.8 \\
-8.9,-2.9\end{array}$ & $\begin{array}{l}\text { Ref. } \\
0.121 \\
0.047\end{array}$ \\
\hline
\end{tabular}

Note: negative change scores in disability indicate improvement; a Adjusted for age, gender, ethnicity, intervention assignment, and baseline levels of physical outcome measures; ${ }^{\mathrm{b}}$ Analyses of covariance; ${ }^{\mathrm{C}}$ Reference group. 
adherence in the initiation phase was associated with 6-month improvement in disability $(p=0.001)$.

Results from ANCOVA analyses show that participants in the intermediate and highest adherence tertile improved 15.2 and 28.3 meters more, respectively, in walking distance after 6 months, compared to those in the lowest adherence tertile ( $p^{\prime}$ s 0.233 and 0.024, respectively; Table 3.1). Participants in the intermediate and highest tertile improved 23.8 and 47.1 meters more, respectively, in walking distance after 18 months, compared to those in the lowest adherence tertile ( $p^{\prime}$ s 0.135 and 0.002 , respectively; Table 3.1). For walking distance, the tertile analyses confirmed a dose-response association, since the highest adherence tertile had the greatest improvement after 6 and 18 months.

Participants in the intermediate and highest adherence tertile improved 6.1 and 3.3 units more, respectively, in disability after 6 months, compared to those in the lowest adherence tertile ( $p$ 's $<0.001$ and 0.049 , respectively; Table 3.1). Participants in the intermediate and highest adherence tertile improved 3.6 and 4.6 units more, respectively, in disability after 18 months, compared to those in the lowest adherence tertile ( $p$ 's 0.121 and 0.047, respectively; Table 3.1).

As shown in the Pearson correlation Table 3.2, most of the potentially explanatory variables - except for social functioning and location of exercise -

Table 3.2: Pearson correlations between percentage exercise adherence, changes in walking distance, disability, and potentially explanatory variables among exercise intervention participants $(\mathrm{N}=134)$.

\begin{tabular}{|c|c|c|c|c|c|c|}
\hline $\begin{array}{r}\text { Exerci } \\
\text { mo }\end{array}$ & $\begin{array}{l}\text { cise adherence } \\
\text { onths } 1 \text { to } 6\end{array}$ & $\begin{array}{l}\text { Exercise adherence } \\
\text { months } 1 \text { to } 18\end{array}$ & $\begin{array}{l}\text { Change in walking } \\
\text { distance in meters } \\
\text { after } 6 \text { months }\end{array}$ & $\begin{array}{l}\text { Change in walking } \\
\text { distance in meters } \\
\text { after } 18 \text { months }\end{array}$ & $\begin{array}{l}\text { Change in } \\
\text { disability score } \\
\text { after } 6 \text { months }\end{array}$ & $\begin{array}{l}\text { Change in } \\
\text { disability score } \\
\text { after } 18 \text { months }\end{array}$ \\
\hline \multicolumn{7}{|l|}{ Potential explanatory variables: } \\
\hline Baseline pain & -0.01 & -0.09 & 0.07 & -0.04 & $-0.31 * *$ & $-0.21 *$ \\
\hline 6-Month change in pain & $-0.20 *$ & & $-0.21 *$ & & $0.64 * *$ & \\
\hline 18-Month change in pain & & -0.17 & & $-0.27 * *$ & & $0.68 * *$ \\
\hline Baseline mental health & 0.07 & 0.05 & -0.05 & -0.11 & -0.04 & 0.06 \\
\hline 6-Month change in mental health & $0.26 * *$ & & 0.15 & & $-0.23 * *$ & \\
\hline 18-Month change in mental health & & 0.14 & & 0.19 & & $-0.31 * *$ \\
\hline Baseline social functioning & 0.12 & 0.15 & -0.06 & -0.01 & -0.08 & 0.03 \\
\hline 6-Month change in social functioning & 0.04 & & 0.19 & & $-0.29 * *$ & \\
\hline 18-Month change in social functioning & & 0.05 & & 0.17 & & $-0.21 *$ \\
\hline Baseline BMI a & $-0.26 * *$ & $-0.29 * *$ & 0.01 & -0.06 & 0.03 & -0.06 \\
\hline 6-Month change in BMI & $-0.20 *$ & & $-0.24 *$ & & 0.14 & \\
\hline 18-Month change in BMI & & $-0.27 * *$ & & $-0.21 *$ & & 0.08 \\
\hline $\begin{array}{l}\text { Location of exercise; } \\
\text { (partly) at home (0) vs. solely at facilit) }\end{array}$ & -0.12 & $-0.26 * *$ & -0.03 & -0.15 & $0.23 * *$ & 0.16 \\
\hline
\end{tabular}

Note: all change scores are defined as follow-up scores minus baseline scores; hence negative change scores in pain, BMI, disability indicate improvement and positive change scores in mental health, social functioning, and walking distance indicate improvement; ${ }^{* *} \mathrm{p}<0.01 ; *<0.05 ;$ a Body mass index. 
were either significantly correlated with both exercise adherence and change in walking distance, or were significantly correlated with both exercise adherence and change in disability. Prominent results of correlation analyses were that both improvements in pain, as well as improvements in mental health, were correlated significantly with improvements in disability. Also, improvements in pain, as well as decreased BMI, were correlated significantly with increased walking distance (Table 3.2).

Table 3.3 shows multiple linear regression models examining the associations between exercise adherence and change in walking distance after 6 months and after the entire duration of the study. In these analyses, we explored the influence of each potentially explanatory variable separately by entering it into a model, which is already adjusted for potentially confounding variables. After adjustment for confounding variables, high 6-month exercise adherence was significantly associated with greater 6-month improvements in walking distance $(\beta 0.28 ; p=0.002)$. When we entered the potentially explanatory variable baseline BMI and 6-month change in BMI in the multiple linear regression model with 6-month exercise adherence as independent variable and 6-month change in walking distance as dependent variable - after initial adjustment for confounding variables - the standardized regression coefficient dropped substantially to $0.24(p=0.013$; Table 3.3$)$. To a lesser

Table 3.3: Multiple linear regression models and standardized regression coefficients $(\beta)$ of percentage exercise adherence over 6 and 18 months on 6 - and 18-months changes in walking distance in meters, after adjustment for potentially confounding and explanatory variables $(\mathrm{N}=134)$.

\begin{tabular}{|c|c|c|c|c|c|c|c|}
\hline & & \multicolumn{3}{|c|}{$\begin{array}{l}\text { 6-month change in } \\
\text { walking distance }\end{array}$} & \multicolumn{3}{|c|}{$\begin{array}{l}\text { 18-month change in } \\
\text { walking distance }\end{array}$} \\
\hline & & $\beta$ & $95 \% \mathrm{CI}^{\mathrm{a}}$ & $P$ & $\beta$ & $(95 \% \mathrm{CI})$ & $P$ \\
\hline Model 1 & Potentially confounding variables ${ }^{b}$ & 0.28 & $0.25,1.07$ & 0.002 & 0.39 & $0.48,1.30$ & $<0.001$ \\
\hline Model 2 & $\begin{array}{l}\text { Potentially confounding variables } \\
\text { +Baseline } \& \text { change in pain }\end{array}$ & 0.26 & $0.25,1.01$ & 0.004 & 0.37 & $0.44,1.28$ & $<0.001$ \\
\hline Model 3 & $\begin{array}{l}\text { Potentially confounding variables } \\
\text { +Baseline \& change in mental health }\end{array}$ & 0.26 & $0.17,1.04$ & 0.007 & 0.38 & $0.47,1.31$ & $<0.001$ \\
\hline Model 4 & $\begin{array}{l}\text { Potentially confounding variables } \\
\text { +Baseline } \& \text { change in social functionin! }\end{array}$ & 0.26 & $0.17,1.01$ & 0.007 & 0.36 & $0.40,1.26$ & $<0.001$ \\
\hline Model 5 & $\begin{array}{l}\text { Potentially confounding variables } \\
\text { +Baseline \& change in } \mathrm{BMI}^{\mathrm{C}}\end{array}$ & 0.24 & $0.12,0.98$ & 0.013 & 0.28 & $0.21,1.11$ & 0.004 \\
\hline Model 6 & $\begin{array}{l}\text { Potentially confounding variables } \\
\text { + Location of exercise }\end{array}$ & 0.28 & $0.25,1.08$ & 0.002 & 0.38 & $0.47,1.30$ & $<0.001$ \\
\hline
\end{tabular}

a $95 \%$ confidence interval; ${ }^{b}$ potentially confounding variables include age, gender, ethnicity, intervention assignment, and baseline levels of walking distance; ${ }^{c}$ Body mass index. 
extent, this also goes when the potentially explanatory variables baseline and 6 -month change in pain $(\beta 0.26 ; p=0.004)$, baseline and 6 -month change in mental health $(\beta 0.26 ; p=0.007)$, and baseline and 6 -month change in social functioning ( $\beta 0.26 ; p=0.007$ ), were entered (Table 3.3).

After adjustment for confounding variables, high overall exercise adherence was significantly associated with greater 18 -month improvements in walking distance $(\beta 0.39 ; p<0.001)$. When we entered the potentially explanatory variable baseline BMI and 18-month change in BMI in the multiple linear regression model with overall exercise adherence as independent variable and 18-month change in walking distance as dependent variable after initial adjustment for confounding variables - the standardized regression coefficient dropped substantially to $0.28(p=0.004)$. The other potentially explanatory variables did not have that kind of effect on the original association (Table 3.3).

Table 3.4 shows multiple linear regression models examining the associations between exercise adherence and change in disability after 6 months and after the entire duration of the study. As before, we explored the influence of each potentially explanatory variable separately by entering it into a model, which is already adjusted for potentially confounding variables. After adjustment for confounding variables, high 6-month exercise adherence was

Table 3.4: Multiple linear regression models and standardized regression coefficients $(\beta)$ of percentage exercise adherence over 6 and 18 months on 6 - and 18-months changes in disability, after adjustment for potentially confounding and explanatory variables $(\mathrm{N}=134)$.

\begin{tabular}{|c|c|c|c|c|c|c|c|}
\hline & & \multicolumn{3}{|c|}{$\begin{array}{l}\text { 6-month change } \\
\text { in disability }\end{array}$} & \multicolumn{3}{|c|}{$\begin{array}{l}\text { 18-month change } \\
\text { in disability }\end{array}$} \\
\hline & & $\beta$ & $95 \% \mathrm{CI}^{\mathrm{a}}$ & $P$ & $\beta$ & $95 \% \mathrm{CI}$ & $P$ \\
\hline Model 1 & Potentially confounding variables ${ }^{b}$ & -0.26 & $-0.14,-0.03$ & 0.001 & -0.18 & $-0.12,0.00$ & 0.052 \\
\hline Model 2 & $\begin{array}{l}\text { Potentially confounding variables } \\
\text { +Baseline } \& \text { change in pain }\end{array}$ & -0.15 & $-0.09,-0.01$ & 0.019 & -0.06 & $-0.07,0.02$ & 0.355 \\
\hline Model 3 & $\begin{array}{l}\text { Potentially confounding variables } \\
\text { +Baseline \& change in mental health }\end{array}$ & -0.17 & $-0.11,0.00$ & 0.036 & -0.14 & $-0.11,0.01$ & 0.091 \\
\hline Model 4 & $\begin{array}{l}\text { Potentially confounding variables } \\
\text { +Baseline \& change in social functionin! }\end{array}$ & -0.16 & $-0.10,0.00$ & 0.035 & -0.14 & $-0.11,0.02$ & 0.140 \\
\hline Model 5 & $\begin{array}{l}\text { Potentially confounding variables } \\
\text { +Baseline \& change in } \mathrm{BMI}^{\mathrm{C}}\end{array}$ & -0.20 & $-0.14,-0.01$ & 0.022 & -0.11 & $-0.11,0.03$ & 0.276 \\
\hline Model 6 & $\begin{array}{l}\text { Potentially confounding variables } \\
\text { + Location of exercise }\end{array}$ & -0.24 & $-0.13,-0.03$ & 0.002 & -0.16 & $-0.12,0.01$ & 0.088 \\
\hline
\end{tabular}

${ }^{\text {a }} 95 \%$ confidence interval; ${ }^{b}$ Potentially confounding variables include age, gender, ethnicity, intervention assignment, and baseline levels of disability; ${ }^{\mathrm{C}}$ Body mass index. 
significantly associated with greater 6-month improvements in disability ( $\beta$ $0.26 ; p=0.001$ ). When we entered the potentially explanatory variable baseline pain and 6 -month change in pain in the multiple linear regression model with 6-month exercise adherence as independent variable and 6-month change in disability as dependent variable - after initial adjustment for confounding variables - the standardized regression coefficient dropped to 0.15 ( $p=0.019$; Table 3.4$)$. This also goes when the potentially explanatory variables baseline and 6 -month change in social functioning $(\beta-0.16 ; p=$ $0.035)$, baseline and 6 -month change in mental health $(\beta-0.17 ; p=0.036)$, and baseline and 6 -month change in BMI $(\beta-0.20 ; p=0.022)$ were entered. The other potentially explanatory variables did not have that kind of effect on the original association (Table 3.4).

After adjustment for confounding variables, high overall exercise adherence was not significantly associated with greater 18 -month improvements in disability $(\beta 0.18 ; p=0.052)$. When we entered the potentially explanatory variable baseline pain and 18 -month change in pain in the multiple linear regression model with overall exercise adherence as independent variable and 18-month change in disability as dependent variable - after initial adjustment for confounding variables - the standardized regression coefficient dropped to $-0.06(p=0.355$; Table 3.4$)$. This also goes when the potentially explanatory variable baseline and 6 -month change in BMI $(\beta-0.11 ; p=0.276)$ was entered. The other potentially explanatory variables did not have that kind of effect on the original association (Table 3.4).

\subsection{Discussion}

Our study provides evidence that exercise adherence is associated with improvements in (observed) physical performance and self-reported disability. We found that, after adjustment for confounding variables, higher exercise adherence goes together with greater improvements in walking distance after 6 and 18 months, and with greater improvements in disability after 6 months. Pain, mental health, and BMI correlated both with exercise adherence and with changes in walking distance or disability. Because of these associations, these variables were able to contribute - to some extent - in explaining the link 
between exercise adherence and changes in physical performance and selfreported disability.

In our 18-month study, percentage exercise adherence in the initiation phase $(65.6 \%)$ was higher than overall exercise adherence $(53.7 \%)$. Considering the fact that our sample consisted of overweight and obese older adults suffering from knee $O A$, we conclude that both percentages are in line with current literature regarding adherence rates (25).

Exercise adherence was a significant predictor of greater improvements in walking distance, even when potentially explanatory variables were taken into account. Moreover, ANCOVA analyses revealed that the tertiles with the participants who had the best adherence improved significantly more in walking distance between baseline and, respectively, 6- and 18-month followup compared to the tertile with the participants who had the poorest adherence. So, in line with a dose-response association, our study showed that the more participants adhere to the exercise regimen, the more they improve on walking distance.

We also found a significant association in the short-term period between high exercise adherence and improvement in disability. Possible explanations for the association between exercise adherence and disability not being sustained after 6 six months could be that the first six months of the intervention were very intensive, with exercise sessions at the facility, for at least four months. Hereafter, exercise adherence decreased and participants' improvement in disability could have stagnated. Secondly, knee OA is an aggravating condition; hence it is possible that participants' condition declined, and self-reported disability worsened. Both short- and long-term ANCOVA analyses revealed that the tertile with participants who had highest adherence rates - improved significantly more in disability compared to the tertile with participants who had the poorest adherence.

A potentially mediating or explanatory variable in an association has to correlate with both the independent, and with the dependent variable. We found significant correlations with independent and dependent variables for most, but not all, potentially explanatory variables. Overall, the choice of our potentially explanatory variables seems justified. 
From our multiple linear regression analyses it seemed that especially BMI during the intervention period was a contributing variable in explaining the association between high exercise adherence and improvement in physical performance. Pain during the intervention period was the most contributing variable in explaining the association between exercise adherence and improvement in self-reported disability.

Our results of a positive link between exercise adherence and improvements in physical performance and self-reported disability are in line with Ettinger and colleagues (12), who also found significant associations between high exercise adherence and improvements in physical performance and disability in a sample which consisted of obese older adults with knee OA for more than $46 \%$. Conform other studies, we found significant correlations between high exercise adherence and improvements in pain $(5,12)$. Rejeski, Ettinger, Martin, \& Morgan suggested that changes in knee pain may mediate effects of exercise interventions on disability (26). From our analyses it also seemed that decrease in pain during the intervention period was a contributing variable in explaining the association between high exercise adherence and improvement in disability. Although it is plausible that exercise does improve pain levels, a reciprocal association might also be present: participants in great pain being less likely to exercise and thus not adhere to prescribed exercise regimen. Participants who do not adhere to exercise regimen are not exercising (enough), perhaps due to their physical complaints, and will therefore not experience beneficial effects of exercise on pain. Either way, not exercising enough could trap persons into a downward spiral, where inactivity stimulates pain levels and pain results in more inactivity, which eventually could end in loss of independence.

Empowering patients with knee OA through self-management courses could break the abovementioned downward spiral. If patients learn to attribute their symptoms in a cognitive way, beliefs of control over the disease may increase, levels of fear may decrease, and through the decrease of perceived barriers, patients might no longer be hesitant about physical activity. Subsequent perceived benefits of (adherence to) exercise on pain and disability may eventually result in better disease control. Rejeski and colleagues (26) already concluded that beliefs of control mediated the effects 
that (adherence to) exercise programs had on disability and health perceptions in a study among patients with knee OA.

Decrease in BMI was an important mediating variable in the associations of exercise adherence with physical performance and self-reported disability. Although decrease in BMI can be associated closely with decrease in pain and improved stamina, and thus have an effect on physical performance and selfreported disability, decrease in BMI can also be associated with improvements in physical impediments, such as decreased skinfold thickness, and increased dynamic balance and result consequently in improvements in physical performance and self-reported disability.

In our study, adherence was measured in terms of attendance to exercise sessions, and not actual level of participation. To some extent, this obscures the actual effect of the intervention on physical function. However, attendance to intervention sessions is crucial for participants to acquire knowledge and skills regarding the core elements of an intervention. Therefore, we believe that measures of intervention attendance reflect a certain precursory value of the extent to which a participant is really physically active. It would serve comparison of results, if more exercise studies would use attendance measures in their design.

We believe the strength of our study is that we explored the association between exercise adherence and concurrent change in physical function, over a short-term, and a long-term period, and tried to explain this association with modifiable, potentially explanatory variables. Our findings show that higher exercise adherence goes together with greater physical improvements in a dose-response fashion, and with improvements in self-reported disability. Consequently, promoting exercise adherence appears to be clinically relevant when prescribing exercise regimen, which also focus on improvements in knee pain and in BMI, to overweight older adults with knee OA. 


\subsection{References}

1. Brown JH, Kazis LE, Spitz PW, Gertman PJ, Fries F, Meenan RF. The dimensions of health outcomes: a cross-validated examination of health status measurement. Am J Public Health 1984; 74(2): 159-61.

2. Ettinger WH Jr, Fried LP, Harris T, Shemanski L, Schulz R, Robbins J. Self-reported causes of physical disability in older people: the Cardiovascular Health Study. CHS Collaborative Research Group. J Am Geriatr Soc 1994; 42(10): 1035-44.

3. American College of Rheumatology Subcommittee on Osteoarthritis Guidelines. Recommendations for the medical management of osteoarthritis of the hip and knee: 2000 update. Arthritis Rheum 2000; 43(9): 1905-15.

4. Penninx BW, Rejeski WJ, Pandya J, Miller ME, Di Bari M, Applegate WB, Pahor M. Exercise and depressive symptoms: a comparison of aerobic and resistance exercise effects on emotional and physical function in older persons with high and low depressive symptomatology. J Gerontol B Psychol Sci Soc Sci 2002; 57(2): P124-32.

5. Thomas KS, Muir KR, Doherty M, Jones AC, O'Reilly SC, Bassey EJ. Home based exercise programme for knee pain and knee osteoarthritis: randomised controlled trial. BMJ 2002; 325(7367): 752-6.

6. Van der Bij AK, Laurant MG, Wensing M. Effectiveness of physical activity interventions for older adults: a review. Am J Prev Med 2002; 22(2): 120-33.

7. Dorn J, Naughton J, Imamura D, Trevisan M. Correlates of compliance in a randomized exercise trial in myocardial infarction patients. Med Sci Sports Exerc 2001; 33(7): 1081-9.

8. Fogelholm M, Kukkonen-Harjula K. Does physical activity prevent weight gain - a systematic review. Obes Rev 2000; 1(2): 95-111.

9. Borg P, Kukkonen-Harjula K, Fogelholm M, Pasanen M. Effects of walking or resistance training on weight loss maintenance in obese, middle-aged men: a randomized trial. Int J Obes Relat Metab Disord 2002; 26(5): 676-83.

10. King AC, Rejeski J, Buchner DM. Physical activity interventions targeting older adults. A critical review and recommendations. Am J Prev Med 1998; 15: 316-33.

11. Rejeski WJ, Mihalko SL. Physical activity and quality of life in older adults. J Gerontol A Biol Sci Med Sci 2001; 56 Spec No 2(2): 23-35.

12. Ettinger WH Jr, Burns R, Messier SP, Applegate W, Rejeski WJ, Morgan T, Shumaker S, Berry MJ, O'Toole M, Monu J, Craven T. A randomized trial comparing aerobic exercise and resistance exercise with a health education program in older adults with knee osteoarthritis. The Fitness Arthritis and Seniors Trial (FAST). JAMA 1997; 277(1): 25-31.

13. Belza B, Topolski T, Kinne S, Patrick DL, Ramsey SD. Does adherence make a difference? Results from a community-based aquatic exercise program. Nurs Res 2002; 51: 285-91.

14. Rejeski WJ, Focht BC, Messier SP, Morgan T, Pahor M, Penninx B. Obese, older adults with knee osteoarthritis: weight loss, exercise, and quality of life. Health Psychol 2002; 21(5): 419-26.

15. Messier SP, Loeser RF, Miller GD, Morgan TM, Rejeski WJ, Sevick MA, Ettinger WH Jr, Pahor M, Williamson JD. Exercise and dietary weight loss in overweight and obese older 
adults with knee osteoarthritis: the Arthritis, Diet, and Activity Promotion Trial. Arthritis Rheum 2004; 50: 1501-10.

16. Miller GD, Rejeski WJ, Williamson JD, Morgan T, Sevick MA, Loeser RF, Ettinger WH Jr, Messier SP. The Arthritis, Diet and Activity Promotion Trial (ADAPT): design, rationale, and baseline results. Control Clin Trials 2003; 24: 462-80.

17. Folstein MF, Folstein SE, McHugh PR. "Mini-mental state". A practical method for grading the cognitive state of patients for the clinician. J Psychiatr Res 1975; 12(3): 189-98.

18. Butland RJ, Pang J, Gross ER, Woodcock AA, Geddes DM. Two-, six-, and 12-minute walk tests in respiratory disease. BMJ 1982; 284: 1607-8.

19. Rejeski WJ, Ettinger WH Jr, Shumaker S, James P, Burns R, Elam JT. Assessing performance-related disability in patients with knee osteoarthritis. Osteoarthritis Cartilage 1995; 3(3): 157-67.

20. Rejeski WJ, Ettinger WH Jr, Shumaker S, Heuser MD, James P, Monu J, Burns R. The evaluation of pain in patients with knee osteoarthritis: the knee pain scale. J Rheumatol 1995; 22(6): 1124-9.

21. Bellamy N, Buchanan WW, Goldsmith $\mathrm{CH}$, Campbell J, Stitt LW. Validation study of WOMAC: a health status instrument for measuring clinically important patient relevant outcomes to antirheumatic drug therapy in patients with osteoarthritis of the hip or knee. J Rheumatol 1988; 15(12): 1833-40.

22. Bellamy N. WOMAC: A 20-Year Experiential Review of a Patient-Centered Self-reported Health Status Questionnaire. J Rheumatol 2002; 29(12): 2473-6.

23. Ware JE Jr, Sherbourne CD. The MOS 36-item short-form health survey (SF-36). I. Conceptual framework and item selection. Med Care 1992; 30(6): 473-83.

24. Kosinski M, Keller SD, Hatoum HT, Kong SX, Ware JE Jr. The SF-36 Health Survey as a generic outcome measure in clinical trials of patients with osteoarthritis and rheumatoid arthritis: tests of data quality, scaling assumptions and score reliability. Med Care 1999; 37(5 Suppl): MS10-22.

25. King AC, Pruitt LA, Phillips W, Oka R, Rodenburg A, Haskell WL. Comparative effects of two physical activity programs on measured and perceived physical functioning and other health-related quality of life outcomes in older adults. J Gerontol A Biol Sci Med Sci 2000; 55(2): M74-83.

26. Rejeski WJ, Ettinger WH Jr, Martin K, Morgan T. Treating disability in knee osteoarthritis with exercise therapy: a central role for self-efficacy and pain. Arthritis Care Res 1998; 11(2): 94-101.

\subsection{Acknowledgement}

Support for this study was provided by the Claude D. Pepper Older Americans Independence Center of Wake Forest University through grants from the National Institutes of Health 5P60-AG-10484-07, and a General Clinical Research Grant M01-RR00211. 
CHAPTER 4 *

\title{
Chronic disease and lifestyle changes
}

\author{
Results from the Longitudinal Aging Study Amsterdam \\ Coen H. van Gool, Gertrudis I.J.M. Kempen, Brenda W.J.H. Penninx, \\ Dorly J.H. Deeg, Jacques Th.M. van Eijk
}

\section{Abstract}

This paper addresses the association between course of chronic disease and lifestyle. We examined differences in unhealthy lifestyles - smoking, excessive alcohol use, being sedentary - and lifestyle changes after six years in prevalent and incident chronic disease categories - lung and cardiovascular disease, diabetes, and osteo- and/or rheumatic arthritis - among 2184 late middle- and older aged respondents from the Netherlands. Lastly, we examined whether changes in lifestyle were related to changes in diseaserelated symptomatology. Overall, proportions of respondents who smoked decreased over time, while proportions of respondents who were sedentary increased. Respondents with incident cardiovascular disease changed their lifestyles more than those from other disease categories. Respondents demonstrating healthy lifestyle changes did not differ in change in diseaserelated symptoms from those persisting in unhealthy lifestyles. If our findings are replicated in future studies, health promotion strategies might be targeted differently, to reach patient groups for intervention who do not initiate more healthy lifestyles.

Key words: chronic disease, lifestyle, symptomatology, longitudinal studies

\footnotetext{
As submitted to the International Journal of Behavioral Medicine.
} 


\subsection{Introduction}

$\Delta \mathrm{n}$ abundance of studies showed that certain unhealthy lifestyles, such as smoking, excessive alcohol use, and lack of physical activity, can provoke or worsen different chronic diseases (e.g., lung disease [Viegi et al., 2001], cardiovascular disease [CVD; Yusuf et al., 2001; Gohlke, 2004], diabetes [Eliasson et al., 2004], osteo- and/or rheumatic arthritis [OA/RA; Saag et al., 1997]). Conversely, healthy lifestyles, such as not smoking, moderate alcohol use, and daily physical activity, may help preserve physical function and reduce the risk of disease worsening in patients with chronic diseases (e.g., Aldana et al., 2003; Penninx et al., 2001; Baumann, 2004).

Healthy lifestyle changes - from unhealthy behavior to healthy - are hypothesized to be associated with a more favorable course of chronic diseases, as compared to persistence in unhealthy lifestyles, and are often encouraged in self-management programs that aim to enhance coping with chronic diseases (Clark \& Hampson, 2001; Lorig \& Holman, 2003; Song et al., 2003; Eagan et al., 2004). Healthy lifestyle changes can be the result of patients' adherence to healthy lifestyle regimens, advised to them by health professionals (Ellingsen et al., 2003), or may follow from patients' awareness of their responsibility for their own health. For some patients their chronic disease status alone can be a reason to alter their health behavior (Blanchard et al., 2003). Healthy lifestyle changes can also be the result of patients behaving according to what society expects from them. This latter phenomenon - also called 'behaving according to the social label of disease' has been described before and is known to have changed (health) behavior (Lemert, 1951; Twaddle \& Hessler, 1977); Lastly, healthy lifestyle changes may follow from personal necessity. Patients may experience serious diseaserelated symptoms, for example intense chest pains, and realize that they cannot go on like before.

This paper addresses the association between course of chronic disease and lifestyle and examines if our data can support one or more of the reasons for healthy lifestyle changes desribed in the paragraph above. We studied prevalences of unhealthy lifestyles - smoking, excessive alcohol use, being sedentary - and changes in these over a six-year period across prevalent and incident chronic disease categories in a population-based sample of late 
middle- and older aged respondents in the Netherlands. Subsequently, we examined if changes in lifestyle were related to changes in disease-related symptomatology, within disease categories.

\subsection{Methods}

\section{Design and Study population}

The Longitudinal Aging Study Amsterdam (LASA) is a population-based cohortstudy on predictors and consequences of changes in well-being and autonomy in the late middle- and older aged population. Sampling, data collection procedures, and non-response were reported in detail elsewhere (Penninx et al., 2000; Van den Heuvel et al., 1996). Briefly, a random sample, stratified by age and gender, was drawn from the population registers of 11 municipalities, divided over three geographic regions in the Netherlands. Initially, 3107 respondents, aged 55-85 years, were enrolled in the study. The baseline cycle was in 1992 and 1993 and consisted of two interview sessions, termed the main and medical interview. A group of 352 respondents, all born after 1930, did not receive the medical interview after participation in the baseline main interview and had incomplete data on lifestyle variables by default. Finally, a group of $571(20.7 \%)$ respondents chose not to participate after the main interview $(n=519)$ or had incomplete data at baseline $(n=52)$, leaving our baseline sample with $2184(79.3 \%)$ respondents. After six years, respondents were approached for follow-up (Broese van Groenou, Deeg, \& Penninx, 2003). Between baseline and follow-up medical interview, 549 (25.1\%) respondents died, $132(6.1 \%)$ refused participation, $138(6.3 \%)$ were interviewed by telephone and had no data on lifestyle variables, 74 (3.4\%) respondents were unable to participate due to cognitive or physical impairments, $57(2.6 \%)$ could not be contacted, and $67(3.1 \%)$ respondents had incomplete data on the follow-up medical interview, leaving 1167 (53.4\%) respondents at followup.

\section{Measurements}

Chronic Disease Status

Self-reported chronic disease status was assessed at both baseline and followup, using an adapted form of the Dutch Health Interview Questionnaire 
(Statistics Netherlands, 1989). Respondents were asked whether or not they had a specific disease. The list of diseases was summed and included lung disease (including chronic obstructive pulmonary disease [COPD], emphysema, bronchitis, asthma), CVD (including coronary heart disease [CHD], cerebrovascular accident [CVA], peripheral arterial disease [PAD]), diabetes, and osteo- and/or rheumatic arthritis [OA/RA]. Respondents could indicate if they had other chronic diseases that were not summed. Because of the heterogeneous character of the physical complaints that go with cancer, we categorized this ailment into the 'other diseases' category. Due to heterogeneity in this 'other diseases' category, the chronic disease categories of interest for this study were limited to four: lung disease, CVD, diabetes, and OA/RA. Reported diseases at baseline were 'prevalent'. Reported diseases at follow-up that were not reported at baseline, were 'incident'. Cohen's Kappa's for concordance between patient and general practitioner compared to nonpatient and general practitioner in our study ranged from 0.31 for OA/RA, and 0.59 for lung disease, to 0.69 for heart disease, and 0.85 for diabetes (Kriegsman et al., 1996).

\section{Disease-related symptomatology}

Disease-related symptomatology was assessed using self-reported symptom inventories of the chronic diseases at both data collection cycles (Kriegsman et al., 1997). The symptom inventory of lung disease included eight questions about the frequency of coughing, coughing up phlegm, wheezing, shortness of breath, and the quality of the respondents' night rest. Scores ranged from 0 to 11 , with higher scores indicating more lung disease-related symptoms. The symptom inventory of CHD included five questions about the frequency of chest pains, and how fast these pains disappear, swollen feet at getting up and going to bed, and the use of extra pillows at night. Scores ranged from 0 to 6 , with higher scores indicating more CHD-related symptoms. The symptom inventory of PAD included three questions about pain experienced when walking, and whether this pain disappears when stopping walking. Scores ranged from 0 to 4 , with higher scores indicating more PAD-related symptoms. The symptom inventory of CVA included four questions about problems with the use of arms, hands, or legs ever since the occurrence of the CVA (yes/no), 
problems with vision since the CVA (yes/no), problems with speech since the CVA (yes/no), and problems with understanding written text (yes/no). Scores range from 0 to 4 , with higher scores indicating more CVA-related symptoms. The composite variable for symptoms regarding cardiovascular disease (CVD) included the sum of the abovementioned symptom inventories of CHD, PAD, and CVA, and ranged from 0 to 14 with higher scores indicating more CVDrelated symptoms. The symptom inventory of diabetes included six questions about the frequency of chest pains, pain experienced when walking, and whether this pain disappears when stopping walking. Scores ranged from 0 to 8 , with higher scores indicating more diabetes-related symptoms. The combined symptom inventory of OA/RA included 12 questions about the frequency of pain, stiffness, and swelling of joints, and the prevalence of arthritic symptoms in a list of joints. Scores ranged from 0 to 12 , with higher scores indicating more arthritis-related symptoms. For patients with prevalent disease, we computed a disease-specific symptomatology change score (follow-up minus baseline), with higher scores indicating greater increase in disease-related symptoms. For patients with incident disease only follow-up disease-related symptoms were taken into consideration.

\section{Lifestyle variables}

Respondents' self-reported smoking behavior was assessed at baseline and follow-up, and was initially dichotomized into 'not smoking' versus 'smoking ([self-rolled] cigarettes, cigars, pipe)'. Also, we measured the average number of cigarettes smoked per week among persons who smoked cigarettes. We also used a smoking behavior change score over a period of six years to indicate whether or not respondents had ceased smoking. When respondents reported smoking cigarettes either at baseline or at follow-up, average number of cigarettes smoked per week was used to compute a continuous follow-up minus baseline change score, with negative change scores indicating decrease in average number of cigarettes smoked per week over a six-year period.

Respondents' self-reported alcohol intake was assessed at baseline and follow-up, and was categorized into 'no alcohol use at all', 'light or moderate alcohol use (i.e. drinking up to two alcoholic consumptions on average per day)', or 'excessive alcohol use (i.e. drinking more than two alcoholic 
consumptions on average per day)'. We also used an alcohol intake change score over a period of six years to indicate whether or not respondents had ceased excessive alcohol use. Also, we used baseline and follow-up average number of alcoholic consumptions per week to compute a continuous follow-up minus baseline change score, with negative change scores indicating decrease in average number of alcoholic consumptions per week over six years.

At baseline and follow-up, averaged daily minutes of physical activity was computed by multiplying self-reported frequency and duration of walking, cycling, sports, and light (e.g., doing the dishes, or ironing) and heavy (e.g., cleaning windows, or vacuum cleaning) household chores (Stel et al., 2004). If either frequency of the activity was missing, or time spent on the activity in minutes, these were imputed by gender- and activity-specific series means. Averaged daily minutes of physical activity was then dichotomized into the lowest quartile on the one hand, representing 'sedentary lifestyle', versus the upper three quartiles on the other, representing 'active lifestyle'. The cut-off score to determine sedentary lifestyle was $<86$ minutes of averaged daily physical activity, both at baseline and follow-up. A six-year period change score was computed to indicate whether or not respondents had become active. Also, we used baseline and follow-up average number of minutes of physical activity per day, to compute a change score (follow-up minus baseline), with positive change scores indicating increase in minutes of physical activity per day over a of six-year period.

\section{Covariates}

Potentially confounding covariates were age, gender, and educational level. The latter ranged from 1 (not finished elementary school) to 9 (finished university). Since respondents could report more than one chronic disease, multimorbidity - number of self-reported diseases, including those in the 'other diseases' category - was used as a covariate, ranged from 0 to 10, and was assessed at both data collection cycles. Also, a follow-up minus baseline multimorbidity change score was used in longitudinal analyses, with higher scores indicating greater increase in number of chronic diseases over a sixyear period. 


\section{Statistical Analyses}

Following descriptive sample analyses at baseline, we compared lifestyle and covariate means, as well as proportional differences in lifestyle and covariates, for each prevalent chronic disease category at baseline, using Chi-square and one-sample t-tests, and (multinomial) logistic regression analyses adjusted for covariates. Lifestyle changes between baseline and follow-up were examined separately for prevalent versus incident categories of the four chronic disease categories, using McNemar tests for one-sample dependent observations. Kruskall-Wallis non-parametric tests were used to explore continuous lifestyle change variables among respondents who smoked, used alcohol excessively, or had a sedentary lifestyle at baseline, for each chronic disease category. Finally, we examined if change in disease-related symptoms differed between respondents who showed a healthy lifestyle change and respondents who persisted in unhealthy lifestyles, within each chronic disease category, using multivariate analyses of variance. These analyses were performed both unadjusted, and adjusted for age, gender, education, and change in multimorbidity. Data were analyzed using SPSS 11.5. Level of significance in all analyses was $p<0.05$.

\subsection{Results}

Baseline

Compared to respondents in the study sample with complete data on all key variables at baseline $(n=2184)$, respondents who chose not to participate after the main interview or had incomplete data at baseline $(n=571)$, were older (74.6 \pm 7.9 versus [vs.] $71.7 \pm 8.0 ; p<.001)$, were more likely to be in the category of elementary through lower vocational education ( $73.0 \%$ vs. $63.0 \%$; $p<.001)$, were more likely to have CVD $(34.7 \%$ vs. $29.2 \% ; p<.05)$, were more likely to have diabetes $(11.0 \%$ vs. $7.8 \%, p<.05)$, were more likely to smoke ( $32.7 \%$ vs. $23.9 \% ; p<.05)$, and drank fewer alcoholic drinks per week on average ( $4.2 \pm 8.6$ vs. $7.1 \pm 10.0 ; p<.001$; not tabulated).

Table 4.1 shows chronic disease prevalence figures across categories of background variables at baseline. Respondents in all chronic disease categories were older compared to respondents in the rest of the sample not reporting that specific chronic disease. Also, all four chronic diseases became more 


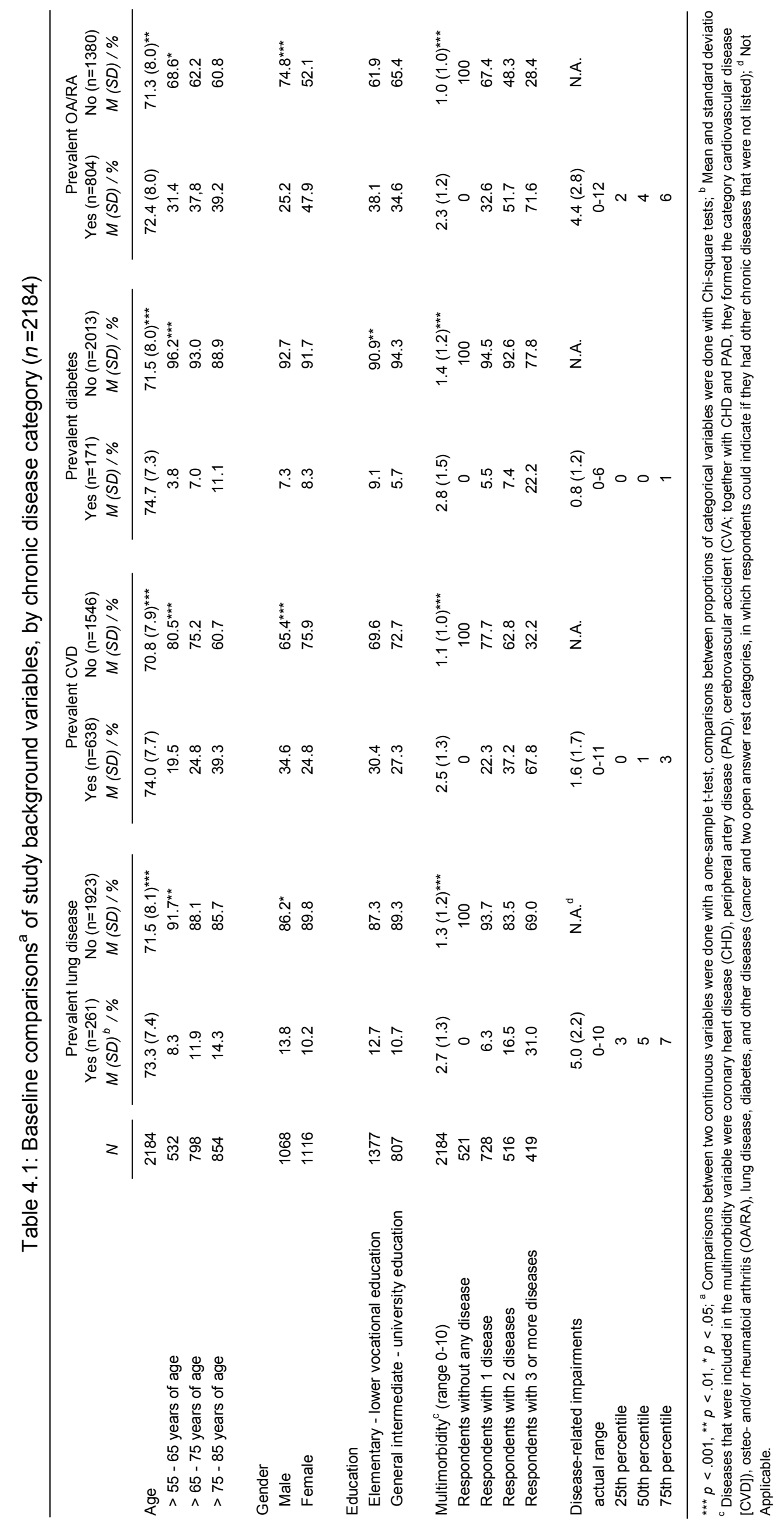


prevalent across increasing age-categories. Proportionally more men than women reported lung disease and/or CVD (13.8\% vs. $10.7 \%$ and $34.6 \%$ vs. $24.8 \%$, respectively), while proportionally more women than men reported OA/RA (47.9\% vs. $25.2 \%$ ). Also, proportionally more respondents with elementary through lower vocational education than respondents with general intermediate through university education reported diabetes ( $9.1 \%$ vs. $5.7 \%)$. Regarding multimorbidity, respondents in the chronic disease categories reported an average of $2.7( \pm 1.3), 2.5( \pm 1.3), 2.8( \pm 1.5)$, and $2.3( \pm 1.2)$ chronic conditions, respectively. Exactly one-third of our baseline sample reported having one chronic disease $(n=728)$. Among respondents reporting two diseases $(n=516)$, prevalence figures of lung disease and diabetes are lower than those of CVD and OA/RA. Finally, two out of three respondents reporting three or more diseases $(n=419)$ were likely to have CVD, and almost three out of four respondents reporting three or more diseases were likely to have OA/RA.

Respondents with lung disease reported a mean of $5.0( \pm 2.2)$ symptoms at baseline, on a theoretical score range from 0 to 11 with an actual score range from 0 to 10, with higher scores indicating more disease-related symptoms. Respondents with CVD reported a mean of 1.6 ( \pm 1.7$)$ diseaserelated symptoms at baseline, with an actual score range from 0 to 11 on a theoretical score range from 0 to 14 . Respondents with diabetes reported a mean of $0.8( \pm 1.2)$ symptoms at baseline, with an actual score range from 0 to 6 on a theoretical score range from 0 to 8. The distributions of CVD- and diabetes-related symptoms appeared to be non-normal, as these were skewed positively. Respondents with OA/RA reported a mean of $4.4( \pm 2.8)$ diseaserelated symptoms at baseline, with an actual score range from 0 to 12 on a theoretical score range from 0 to 12 (Table 4.1).

At baseline, $23.9 \%$ of the respondents were current smokers, $19.2 \%$ reported excessive alcohol use, and $25.0 \%$ were sedentary. As shown in Table 4.2, the proportion of smokers was lower among respondents with OA/RA, compared to the rest of the study sample $(20.4 \%$ vs. $25.9 \%)$. However, this association became non-significant in logistic regression analyses, adjusting for the covariates age, gender, educational level, and multimorbidity. Respondents with CVD at baseline smoked significantly fewer cigarettes on average per 
Table 4.2: Baseline comparisons ${ }^{a}$ of lifestyle variables, by chronic disease category

\begin{tabular}{|c|c|c|c|c|c|c|}
\hline & & \multirow{2}{*}{\multicolumn{2}{|c|}{$N$}} & \multicolumn{2}{|c|}{ Smoking } & \multirow{2}{*}{$\begin{array}{c}\text { Mean }(\mathrm{SD})^{\mathrm{b}} \text { number of } \\
\text { cigarettes smoked per week }\end{array}$} \\
\hline & & & & \multicolumn{2}{|c|}{$\%$ Yes $\quad \%$ No } & \\
\hline \multicolumn{2}{|c|}{ Entire baseline study sample } & 2184 & & 23.9 & 76.1 & $80.7(62.5)$ \\
\hline \multirow[t]{2}{*}{ Prevalent lung disease } & Yes & 261 & & 23.8 & 76.2 & $98.8(62.2)$ \\
\hline & No & 1923 & & 23.9 & 76.1 & $78.3(62.5)$ \\
\hline \multirow[t]{2}{*}{ Prevalent $C V D^{d}$} & Yes & 638 & & 23.8 & 76.2 & $68.4(58.4)^{\star 9}$ \\
\hline & No & 1546 & & 23.9 & 76.1 & $85.4(63.5)$ \\
\hline \multirow[t]{2}{*}{ Prevalent diabetes } & Yes & 171 & & 18.1 & 81.9 & $100.1(73.4)$ \\
\hline & No & 2013 & & 24.3 & 75.7 & $79.7(61.8)$ \\
\hline \multirow[t]{4}{*}{ Prevalent OA/RA ${ }^{\mathrm{e}}$} & Yes & 804 & & 20.4 & $79.6^{* *^{f}}$ & $78.4(54.4)$ \\
\hline & No & 1380 & & 25.9 & 74.1 & $81.9(66.2)$ \\
\hline & & & & Alcohol use $^{h}$ & & Mean (SD) number of \\
\hline & & $N$ & $\%$ Abstaining & \% Moderate (Ref.') & $\%$ Excessive & alcoholic drinks per week \\
\hline \multicolumn{2}{|c|}{ Entire baseline study sample } & 2184 & 22.3 & 58.5 & 19.2 & $7.1(10.0)$ \\
\hline \multirow[t]{2}{*}{ Prevalent lung disease } & Yes & 261 & 27.6 & 47.1 & $25.3^{* * 9}$ & $8.5(11.3)^{\star 9}$ \\
\hline & No & 1923 & 21.5 & 60.1 & 18.4 & $6.9(9.8)$ \\
\hline \multirow[t]{2}{*}{ Prevalent CVD } & Yes & 638 & 28.1 & 55.6 & $16.3^{* * * 9}$ & $6.0(8.9)^{\star * * g}$ \\
\hline & No & 1546 & 19.9 & 59.7 & 20.4 & $7.6(10.4)$ \\
\hline \multirow[t]{2}{*}{ Prevalent diabetes } & Yes & 171 & 37.4 & 46.2 & $16.4^{* * * f}$ & $5.4(8.9)^{\star f}$ \\
\hline & No & 2013 & 21.0 & 59.6 & 19.4 & $7.3(10.1)$ \\
\hline \multirow[t]{4}{*}{ Prevalent OA/RA } & Yes & 804 & 26.9 & 55.2 & $17.9^{* * * g}$ & $6.4(9.9)^{* 9}$ \\
\hline & No & 1380 & 19.7 & 60.4 & 19.9 & $7.6(10.1)$ \\
\hline & & & & \multicolumn{2}{|c|}{ Physical activity ${ }^{j}$} & Mean (SD) number of minutes \\
\hline & & $N$ & & $\%$ Sedentary & $\%$ Active & of physical activity per day \\
\hline \multicolumn{2}{|c|}{ Entire baseline study sample } & 2184 & & 25.0 & 75.0 & $168.6(121.1)$ \\
\hline \multirow[t]{2}{*}{ Prevalent lung disease } & Yes & 261 & & 32.6 & $67.4^{* *^{f}}$ & $145.3(112.5)^{\star * f}$ \\
\hline & No & 1923 & & 23.9 & 76.1 & $171.8(121.9)$ \\
\hline \multirow[t]{2}{*}{ Prevalent CVD } & Yes & 638 & & 32.0 & $68.0^{* * * f}$ & $146.3(110.7)^{\star * \star f}$ \\
\hline & No & 1546 & & 22.1 & 77.9 & $177.8(124.0)$ \\
\hline \multirow[t]{2}{*}{ Prevalent diabetes } & Yes & 171 & & 38.6 & $61.4^{* * * g}$ & $138.4(108.3)^{* * * f}$ \\
\hline & No & 2013 & & 23.8 & 76.2 & $171.2(121.8)$ \\
\hline \multirow[t]{2}{*}{ Prevalent OA/RA } & Yes & 804 & & 26.2 & 73.8 & $169.8(127.0)$ \\
\hline & No & 1380 & & 24.2 & 75.8 & 167.9 (116.9) \\
\hline
\end{tabular}

${ }^{* * *} p<.001,{ }^{* *} p<.01,{ }^{*} p<.05 ;{ }^{\text {a }}$ Comparisons between two continuous variables were done with a one-sample t-test, comparisons between proportions of categorical variables were done with Chi-square tests, multivariate testing was done with (multinomial) logistic regression for categorical variables and with multivariate analyses of variance for continuous variables; ${ }^{b}$ Mean and standard deviation (SD); ${ }^{\mathrm{c}}$ Among cigarette smokers $(\mathrm{n}=291)$ at baseline; ${ }^{\mathrm{d}} \mathrm{Cardiovascular}$ diseases; ${ }^{\mathrm{e}}$ Osteo- and/or rheumatoid arthritis; ${ }^{\mathrm{f}}$ Became non-significant, or ${ }^{9}$ remained significant, in multivariate analyses, adjusting for age, gender, educational level, and multimorbidity; ${ }^{\mathrm{h}}$ Drinking up to 2 alcoholic drinks per day on average was termed 'Moderate', drinking more than 2 alcoholic drinks per day on average was termed 'Excessive'; ' Reference category in multivariate testing; ${ }^{j}$ Being sedentary was defined as being physically active for less than 86 minutes on average per day, being physically active for more than 85 minutes on average per day was termed active. 
week than the rest of the study sample. This association remained significant in multivariate analyses. Respondents with lung disease reported more than the rest of the study sample either to abstain from alcohol use, or to use alcohol excessively ( $27.6 \%$ vs. $21.5 \%$, and $25.3 \%$ vs. $18.4 \%$, respectively; Table 4.2). In contrast, respondents with CVD, diabetes, and/or OA/RA reported less excessive alcohol intake than the rest of the study sample ( $16.3 \%$ vs. $20.4 \%, 16.4 \%$ vs. $19.4 \%$, and 17.9 vs. $19.9 \%$, respectively). In multivariate multinomial logistic regression analyses, only the association between having diabetes and alcohol use became non-significant. Respondents with lung disease reported to drink more glasses of alcohol on average per week than their counterparts in the rest of the study sample $(8.5 \pm 11.3 \mathrm{vs}$. $6.9 \pm 9.8$ ), whereas respondents with CVD, diabetes, and/or OA/RA reported to drink fewer glasses of alcohol than their counterparts in the rest of the study sample $(6.1 \pm 8.9$ vs. $7.6 \pm 10.4,5.4 \pm 8.9$ vs. $7.3 \pm 10.1$, and $6.4 \pm$ 10.1 vs. $7.5 \pm 10.0$, respectively; Table 4.2 ). When tested in multivariate analyses, adjusted for covariates, the association between having diabetes and baseline average number of alcoholic drinks per week became non-significant.

In all chronic disease categories but the OA/RA category, proportions of respondents who reported sedentary lifestyles were significantly larger compared to the rest of the sample. Except for the OA/RA category, respondents in chronic disease categories reported less average minutes of physical activity per day than their counterparts in the rest of the sample without that chronic disease (Table 4.2). However, when tested in multivariate analyses, adjusted for covariates, only the association between having diabetes and being sedentary remained significant.

\section{Follow-up}

Compared to respondents in the study sample with complete data on all key variables at baseline and follow-up $(n=1167)$, at baseline, respondents in the attrition group ( $n=1017)$ were older $(74.1 \pm 8.2$ vs. $69.6 \pm 7.3 ; p<.001)$, were more likely to be male $(51.6 \%$ vs. $46.5 \% ; p<.05)$, were more likely to be in the category of elementary through lower vocational education $(68.5 \%$ vs. $58.3 \% ; p<.001)$, had higher multimorbidity scores ( $1.6 \pm 1.3$ vs. $1.3 \pm$ $1.2 ; p<.001)$, were more likely to have lung disease $(14.1 \%$ vs. $10.1 \% ; p<$ 
Table 4.3: Proportional changes ${ }^{\mathrm{a}}$ in lifestyles, stratified by prevalent and incident chronic disease categories between baseline and follow-up

\begin{tabular}{|c|c|c|c|c|c|}
\hline & \multicolumn{5}{|c|}{ \% Smoking } \\
\hline & $N$ & $1992 / 3$ & $\%$ initiated & $\%$ ceased & 1998/9 \\
\hline Entire Sample (valid at baseline \& follow-up) & 1167 & 20.9 & 1.5 & 5.4 & $17.0^{* * *}$ \\
\hline Prevalent lung disease 1992/3 & 118 & 16.1 & 0.8 & 8.4 & $8.5^{*}$ \\
\hline Incident lung disease between $1992 / 3$ and $1998 / 9$ & 81 & 33.3 & 2.5 & 4.9 & 30.9 \\
\hline Prevalent CVD ${ }^{\mathrm{b}} 1992 / 3$ & 277 & 18.8 & 2.2 & 4.8 & 16.2 \\
\hline Incident CVD between 1992/3 and 1998/9 & 186 & 23.1 & 2.2 & 8.6 & $16.7^{*}$ \\
\hline Prevalent diabetes 1992/3 & 64 & 15.6 & 3.1 & 1.5 & 17.2 \\
\hline Incident diabetes between $1992 / 3$ and $1998 / 9$ & 44 & 15.9 & 4.5 & 4.5 & 15.9 \\
\hline Prevalent OA/RAc $1992 / 3$ & 434 & 18.4 & 0.9 & 4.6 & $14.7^{* *}$ \\
\hline \multirow[t]{3}{*}{ Incident OA/RA between 1992/3 and 1998/9 } & 226 & 22.6 & 0.9 & 6.2 & $17.3^{* *}$ \\
\hline & \multicolumn{5}{|c|}{$\%$ Excessive alcohol use ${ }^{d}$} \\
\hline & $N$ & $1992 / 3$ & $\%$ initiated & $\%$ ceased & 1998/9 \\
\hline Entire Sample (valid at baseline \& follow-up) & 1167 & 20.7 & 5.1 & 5.7 & 20.1 \\
\hline Prevalent lung disease 1992/3 & 118 & 29.7 & 5.9 & 11.0 & 24.6 \\
\hline Incident lung disease between $1992 / 3$ and $1998 / 9$ & 81 & 21.0 & 7.4 & 4.9 & 23.5 \\
\hline Prevalent CVD 1992/3 & 277 & 17.0 & 4.0 & 5.1 & 15.9 \\
\hline Incident CVD between 1992/3 and 1998/9 & 186 & 23.7 & 1.6 & 8.1 & $17.2^{\star *}$ \\
\hline Prevalent diabetes $1992 / 3$ & 64 & 18.8 & 6.3 & 9.5 & 15.6 \\
\hline Incident diabetes between $1992 / 3$ and $1998 / 9$ & 44 & 15.9 & 4.5 & 6.8 & 13.6 \\
\hline Prevalent OA/RA 1992/3 & 434 & 19.1 & 4.8 & 5.9 & 18.0 \\
\hline \multirow[t]{3}{*}{ Incident OA/RAbetween $1992 / 3$ and 1998/9 } & 226 & 21.2 & 4.4 & 6.1 & 19.5 \\
\hline & \multicolumn{5}{|c|}{$\%$ Sedentary lifestyle $e^{e}$} \\
\hline & $N$ & $1992 / 3$ & $\%$ initiated & $\%$ ceased & 1998/9 \\
\hline Entire Sample (valid at baseline \& follow-up) & 1167 & 20.6 & 17.6 & 8.7 & $29.5^{\star * *}$ \\
\hline Prevalent lung disease 1992/3 & 118 & 25.4 & 17.8 & 9.3 & 33.9 \\
\hline Incident lung disease between $1992 / 3$ and $1998 / 9$ & 81 & 27.2 & 25.9 & 11.1 & $42.0^{*}$ \\
\hline Prevalent CVD 1992/3 & 277 & 23.1 & 22.0 & 10.5 & $34.7^{* *}$ \\
\hline Incident CVD between 1992/3 and 1998/9 & 186 & 24.2 & 21.5 & 8.6 & $37.1^{* *}$ \\
\hline Prevalent diabetes 1992/3 & 64 & 28.1 & 21.9 & 3.1 & $46.9^{* *}$ \\
\hline Incident diabetes between $1992 / 3$ and 1998/9 & 44 & 15.9 & 20.5 & 11.4 & 25.0 \\
\hline Prevalent OA/RA 1992/3 & 434 & 21.7 & 18.4 & 9.9 & $30.2^{\star *}$ \\
\hline Incident OA/RA between 1992/3 and 1998/9 & 226 & 17.7 & 16.8 & 5.7 & $28.8^{\star *}$ \\
\hline
\end{tabular}

${ }^{* * *} \mathrm{p}<.001 ;{ }^{* *} \mathrm{p}<.01 ;{ }^{*} \mathrm{p}<.05 ;{ }^{\text {a }}$ Proportions were compared with McNemar's test for one-sample, dependent observations; ${ }^{\mathrm{b}}$ Cardiovascular disease(s); ${ }^{\mathrm{c}}$ Osteo- and/or rheumatoid arthritis; ${ }^{\mathrm{d}}$ Excessive alcohol use was defined as drinking more than 2 alcoholic drinks per day on average; ${ }^{\mathrm{e}}$ Having a sedentary lifestyle was defined as being physically active for less than 86 minutes per day on average. 
$.01)$, were more likely to have CVD $(35.5 \%$ vs. $23.7 \% ; p<.001)$, were more likely to have diabetes $(10.5 \%$ vs. $5.5 \%, p<.001)$, were more likely to smoke ( $27.2 \%$ vs. $20.9 \% ; p<.01)$, were more likely to report alcohol abstinence $(26.2 \%$ vs. $18.9 \% ; p<.001)$, and were more likely to report a sedentary lifestyle (30.0\% vs. $20.6 \% ; p<.001$ [not tabulated]).

Table 4.3 shows the proportional changes in lifestyles between baseline and follow-up in the entire sample and stratified by prevalent and incident chronic disease categories. In the entire sample, there was a significant decrease in proportion of respondents who smoked (from $20.9 \%$ to $17.0 \%$ ). Similar significant decreases in smoking between baseline and follow-up were seen in respondents with prevalent lung disease (from $16.1 \%$ to $8.5 \%$ ), in respondents with incident CVD (from $23.1 \%$ to $16.7 \%$ ), and in respondents from both the prevalent and incident OA/RA category (respectively, from $18.4 \%$ to $14.7 \%$, and from $22.6 \%$ to $17.3 \%$ ). In the entire study sample the proportion of respondents reporting excessive alcohol use did not change much between baseline and follow-up (from $20.7 \%$ to $20.1 \%$ ). However, within the different chronic disease categories, proportions of respondents reporting excessive alcohol use tended to decrease between baseline and follow-up, except for respondents with incident lung disease (from $21.0 \%$ to $23.5 \%$ ). The only significant decrease in proportion of respondents reporting excessive alcohol use was found among respondents with incident CVD between baseline and follow-up (from $23.7 \%$ to $17.2 \%$; Table 4.3 ). In the entire sample, we found a significant increase in proportion of respondents who were sedentary between baseline and follow-up (from $20.6 \%$ to $29.5 \%$ ). After stratification, significant increases in proportion of respondents who were sedentary between baseline and follow-up were found in respondents with incident lung disease (from $27.2 \%$ to $42.0 \%$ ), prevalent and incident CVD (from $23.1 \%$ to $34.7 \%$, and $24.2 \%$ to $37.1 \%$, respectively), prevalent diabetes (from $28.1 \%$ to $46.9 \%$ ), and prevalent and incident OA/RA (from $21.7 \%$ to $30.2 \%$, and from $17.7 \%$ to $28.8 \%$, respectively; Table 4.3 ).

Due to non-normality of the continuous lifestyle change variables, we used non-parametric Kruskal-Wallis tests to see if categories within each chronic disease differed in continuous lifestyle change scores, among respondents who smoked, used alcohol excessively, and/or were sedentary at 


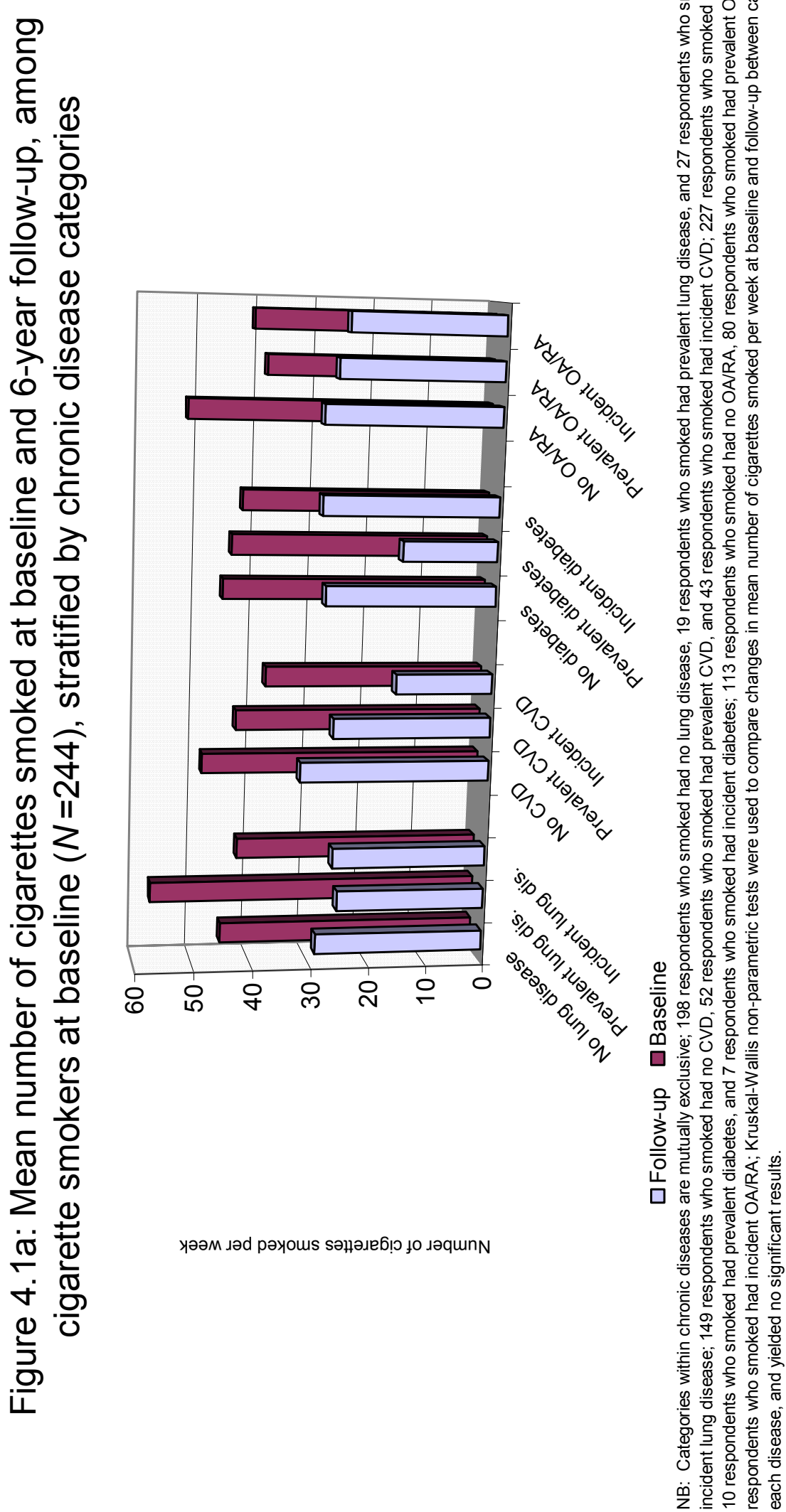


baseline. In the figures we depicted grouped means of both baseline and follow-up continuous lifestyle scores. Among smokers at baseline (Figure 4.1a), respondents with prevalent lung disease and/or prevalent diabetes appeared to cut down relatively more on number of cigarettes smoked per week compared to respondents with incident lung disease and/or incident diabetes. In the CVD and OA/RA categories this pattern could not be established. Among excessive alcohol users at baseline (Figure 4.1b), respondents with prevalent diabetes appeared to cut down relatively more on number of alcoholic drinks per week than respondents in other prevalent or incident chronic disease categories, followed by respondents with incident CVD (Figure 4.1b). Improvement in minutes of physical activity per day among respondents who were sedentary at baseline and had no diabetes, prevalent diabetes, or incident diabetes differed significantly: respondents with prevalent diabetes appeared to improve less in minutes of physical activity per day compared to the other two categories (Figure 4.1c).

Consequently, we compared adjusted means of changes in diseaserelated symptomatology in prevalent and incident disease categories between respondents who showed a healthy lifestyle change, i.e. ceased smoking, ceased using alcohol excessively, and/or initiated an active lifestyle, on the one hand and those who persisted in their unhealthy lifestyle, i.e. continued smoking, using alcohol excessively, and/or being sedentary, on the other. These analyses were performed only for the 11 disease categories in which lifestyles changed significantly, as shown in Table 4.3, and were performed both unadjusted and adjusted for covariates. The analyses yielded no statistically significant differences in disease-related symptoms between respondents who showed a healthy lifestyle change and those who persisted in their unhealthy lifestyle (not tabulated).

\subsection{Discussion}

This study addressed the associations between chronic disease and lifestyle domains. We described and examined the prevalence of lifestyles - smoking, excessive alcohol use, being physically active - and proportional changes in these lifestyles over a six-year period across chronic disease categories in a population-based sample of late middle- and older aged respondents in the 


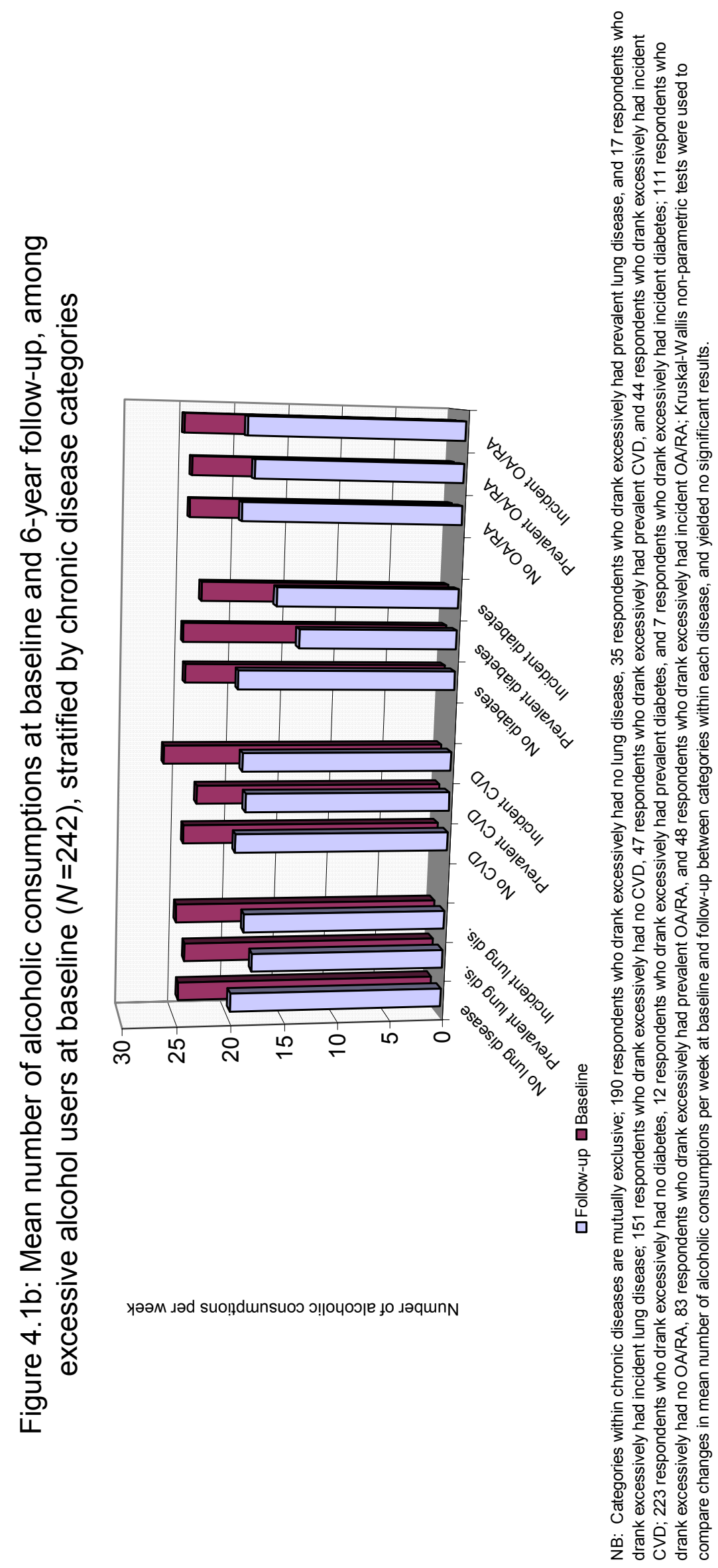


Netherlands. At baseline, associations between chronic diseases and lifestyle domains appeared to vary. In our sample, the percentage of respondents who reported to smoke at baseline with prevalent CVD was about similar to the percentage of respondents who reported to smoke at baseline without CVD. However, this latter group smoked significantly more cigarettes per week on average than the former group. The percentage of respondents who reported excessive alcohol use at baseline with prevalent lung disease was significantly higher than the percentage of respondents who reported excessive alcohol use at baseline without prevalent lung disease, while the associations between baseline excessive alcohol use and CVD, diabetes, and OA/RA tended to be reversed. The percentage of sedentary respondents at baseline with prevalent diabetes was significantly higher than the percentage of sedentary respondents at baseline without prevalent diabetes.

In the entire sample, proportions of respondents who reported to smoke decreased over a six-year period, while the proportion of respondents who reported sedentary lifestyles increased. Respondents with incident CVD reacted strongly to their newly diagnosed disease: they were more likely than respondents in other chronic disease categories to quit smoking, to cease excessive alcohol use, and less likely to initiate a physically active lifestyle between baseline and follow-up. Respondents with prevalent or incident OA/RA were more likely to quit smoking and less likely to initiate a physically active lifestyle between baseline and follow-up, compared to respondents without those conditions.

Adjusted analyses examining the continuous measures of lifestyle change within each disease category among the respondents who smoked or drank excessively at baseline yielded no statistically significant results (Figure 4.1ab). However, among the respondents who were sedentary at baseline, respondents with prevalent diabetes improved less in averaged daily minutes of physical activity compared to those without diabetes or incident diabetes (Figure 4.1c).

Finally, adjusted analyses comparing change in disease-related symptomatology between respondents who showed a healthy lifestyle change and those who persisted in their unhealthy lifestyle across chronic disease 


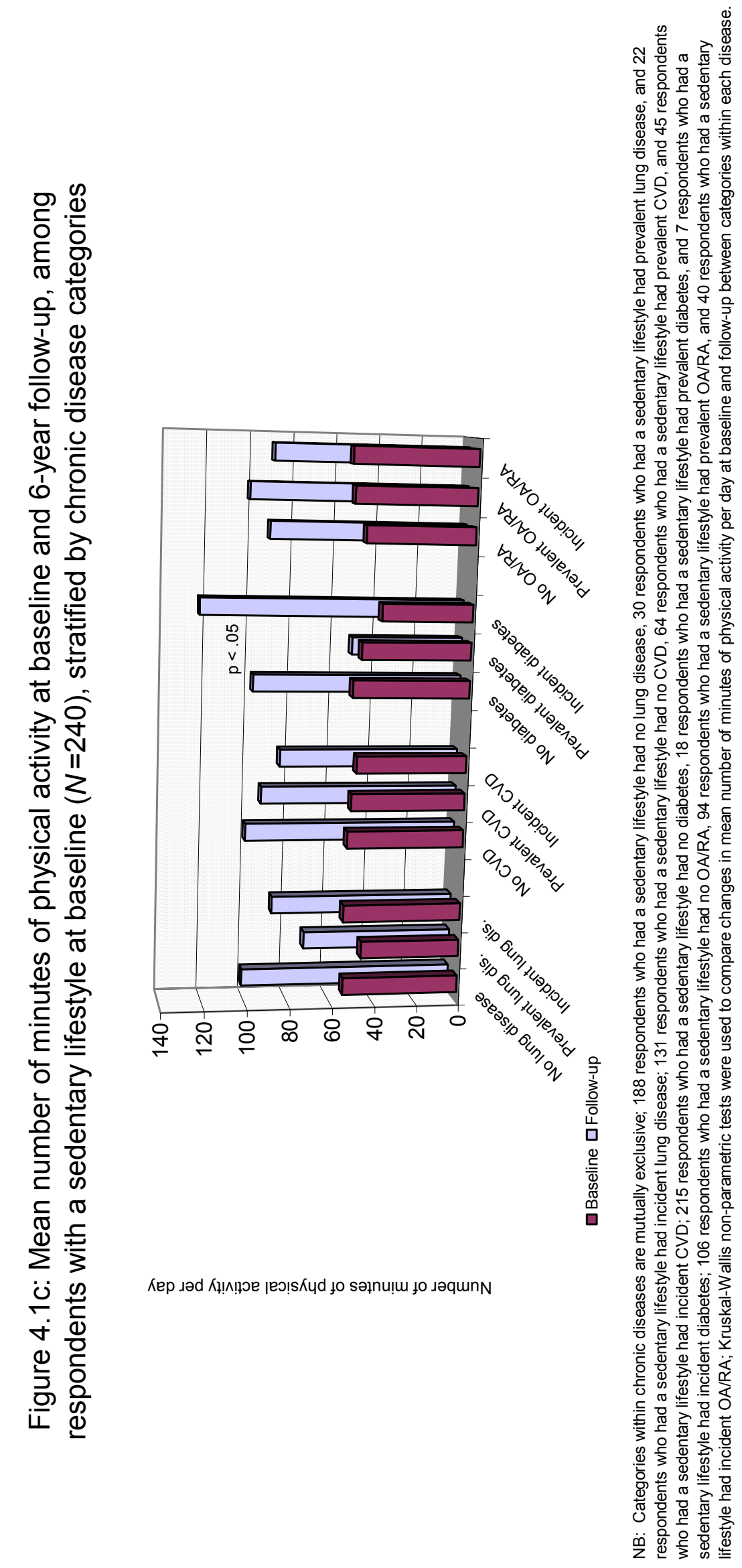


categories in which a significant proportional lifestyle change took place - as presented in Table 4.3 - yielded no significant results.

Our findings regarding lifestyle changes are concordant with studies that conclude that lifestyles are variable over time (Mulder et al., 1998; Johansson \& Sundquist, 1999). We found that current smoking behavior and excessive alcohol use are less susceptible to change than physical activity. The extent to which these health behaviors fluctuate differs across chronic disease categories.

Healthy lifestyle changes have been reported to be associated with a remission of disease-related symptoms (Eagan et al., 2004), with improved self-reported health status (Johansson \& Sundquist, 1999), and with decreased mortality (Paffenbarger et al., 1993). Despite the above, our study results defy the hypothesis that healthy lifestyle changes may follow from personal necessity, that patients may experience such serious disease-related symptoms, for example intense chest pains, and realize that they cannot go on like before. It appears that change in disease severity, as indicated by diseaserelated symptomatology, does not play a role in healthy lifestyle changes, because, among respondents reporting the same prevalent or incident chronic disease, changes in disease-related symptoms did not differ between those who showed healthy lifestyle changes and those who persisted in their unhealthy behavior.

Furthermore, our findings cannot disprove the other notions that were hypothesized in the introduction; that, within our sample, respondents with chronic diseases make healthy lifestyle changes as a result of their adherence to healthy lifestyle regimens, advised to them by health professionals (Ellingsen et al., 2003); as a result of their awareness that they are responsible for their own health, as for some respondents their chronic disease status alone may be a reason to alter their health behavior (Blanchard et al., 2003); or as a result of respondents with chronic diseases behaving according to what is expected from them by society. Because sample sizes in several analyses were small, resulting in suboptimal statistical power, it was not feasible to examine other potential correlates of lifestyle change, like personality, and social network size. 
In the literature, many studies can be found regarding lifestyle variables. A small part of these studies use the same definitions of lifestyle variables. Additionally, only a fraction of those studies followed up on and quantified categories of lifestyle change, e.g. percentage quit smoking or percentage incident excessive alcohol use. Thus, our study contributes to the existing literature by explicitly quantifying these lifestyle changes.

In sum, in this sample of community-dwelling late middle-aged and older persons from the Netherlands associations between chronic diseases and lifestyle domains appeared to be variable over time and across chronic disease categories. Changes in continuous lifestyle measures among respondents with unhealthy lifestyles at baseline appeared not to differ across chronic disease categories, nor were changes in disease-related symptoms different for respondents who showed a healthy lifestyle change and those who persisted in their unhealthy behavior. To our knowledge this is the first study that described the prevalences of lifestyles and lifestyle changes across different chronic diseases, and the effect of healthy lifestyle changes on change in disease-related symptomatology among late middle-aged and older respondents. Knowing whether a certain group of patients is inclined more than others to make healthy lifestyle changes might be important information which can be used to target health promotion strategies more effectively and to enhance the effectiveness of self-management programs that aim at coping with chronic diseases. If our findings are replicated in future studies, health promotion strategies may be targeted more effectively, and patient groups who do not initiate more healthy lifestyles might be reached for intervention. 


\subsection{References}

Aldana, S.G., Whitmer, W.R., Greenlaw, R., Avins, A.L., Salberg, A., Barnhurst, M., Fellingham, G., \& Lipsenthal, L. (2003). Cardiovascular risk reductions associated with aggressive lifestyle modification and cardiac rehabilitation. Heart Lung. 32: 374-82.

Baumann, A.E. (2004). Updating the evidence that physical activity is good for health: an epidemiological review 2000-2003. J. Sci. Med. Sport. 7 (1 Suppl): 6-19.

Blanchard, C.M., Denniston, M.M., Baker, F., Ainsworth, S.R., Courneya, K.S., Hann, D.M., Gesme, D.H., Reding, D., Flynn, T., \& Kennedy, J.S. (2003). Do adults change their lifestyle behaviors after a cancer diagnosis? Am. J. Health Behav 27: 246-56.

Broese van Groenou, M.I., Deeg, D.J., \& Penninx, B.W. (2003). Income differentials in functional disability in old age: relative risks of onset, recovery, decline, attrition and mortality. Aging Clin. Exp. Res. 15: 174-83.

Clark, M., \& Hampson, S.E. (2001). Implementing a psychological intervention to improve lifestyle self-management in patients with Type 2 diabetes. Patient Educ. Couns. 42: 247256.

Eagan, T.M., Gulsvik, A., Eide, G.E., \& Bakke, P.S. (2004). Remission of respiratory symptoms by smoking and occupational exposure in a cohort study. Eur. Respir. J. 23: 589-94.

Eliasson, M., Asplund, K., Nasic, S., \& Rodu, B. (2004). Influence of smoking and snus on the prevalence and incidence of type 2 diabetes amongst men: the northern Sweden MONICA study. J. Intern. Med. 256: 101-10.

Ellingsen, I., Hjermann, I., Abdelnoor, M., Hjerkinn, E.M., \& Tonstad S. (2003). Dietary and antismoking advice and ischemic heart disease mortality in men with normal or high fasting triacylglycerol concentrations: a 23-y follow-up study. Am. J. Clin. Nutr. 78: 935-40.

Gohlke H. (2004). Prävention durch Lebensstiländerung: Was ist gesichert? [Lifestyle modification - is it worth it?] Herz. 29: 139-44.

Johansson, S.E., \& Sundquist, J. (1999). Change in lifestyle factors and their influence on health status and all-cause mortality. Int. J. Epidemiol. 28: 1073-80.

Kriegsman, D.M., Deeg, D.J., van Eijk, J.T., Penninx, B.W., \& Boeke, A.J. (1997). Do disease specific characteristics add to the explanation of mobility limitations in patients with different chronic diseases? A study in The Netherlands. J. Epidemiol. Community Health 51: 676-85.

Kriegsman, D.M., Penninx, B.W., Van Eijk, J.Th., Boeke, A.J., \& Deeg, D.J. (1996). Self-reports and general practitioners information on the presence of chronic diseases in communitydwelling elderly. A study of accuracy of patients' self-reports and on determinants of accuracy. J. Clin. Epidemiol. 49: 1407-17.

Lemert, E. (1951). Social pathology. McGraw-Hill book Co., New York.

Lorig, K.R., \& Holman, H.R. (2003). Self-management education: History, definition, outcomes, and mechanisms. Ann. Behav. Med. 26: 1-7.

Mulder, M., Ranchor, A.V., Sanderman, R., Bouma, J., \& van den Heuvel, W.J. (1998). The stability of lifestyle behaviour. Int. J. Epidemiol. 27: 199-207. 
Paffenbarger, R.S. Jr, Hyde, R.T., Wing, A.L., Lee, I.M., Jung, D.L., \& Kampert, J.B. (1993). The association of changes in physical-activity level and other lifestyle characteristics with mortality among men. N. Engl. J. Med. 328: 538-45.

Penninx, B.W., Deeg, D.J., Van Eijk, J.Th., Beekman, A.T., \& Guralnik, J.M. (2000). Changes in depression and physical decline in older adults: a longitudinal perspective. J. Affect. Disord. 61: 1-12.

Penninx, B.W., Messier, S.P., Rejeski, W.J., Williamson, J.D., DiBari, M., Cavazzini, C., Applegate, W.B., \& Pahor, M. (2001). Physical exercise and the prevention of disability in activities of daily living in older persons with osteoarthritis. Arch. Intern. Med. 161: 230916.

Saag, K.G., Cerhan, J.R., Kolluri, S., Ohashi, K., Hunninghake, G.W., \& Schwartz, D.A. (1997). Cigarette smoking and rheumatoid arthritis severity. Ann. Rheum. Dis. 56: 463-9.

Song, R., Lee, E.O., Lam, P., \& Bae, S.C. (2003). Effects of tai chi exercise on pain, balance, muscle strength, and perceived difficulties in physical functioning in older women with osteoarthritis: a randomized clinical trial. J. Rheumatol. 30: 2039-44.

Statistics Netherlands. (1989). Health Interview Questionnaire. Statistics Netherlands, Heerlen, The Netherlands.

Stel, V.S., Smit, J.H., Pluijm, S.M., Visser, M., Deeg, D.J., \& Lips, P. (2004). Comparison of the LASA Physical Activity Questionnaire with a 7-day diary and pedometer. J. Clin. Epidemiol. 57: 252-8.

Twaddle, A.C., \& Hessler, R.M. (1977). A sociology of health. Mosby, Saint Louis.

Van den Heuvel, N., Smits, C.H., Deeg, D.J., \& Beekman, A.T. (1996). Personality: A moderator of the relation between cognitive functioning and depression in adults aged 5585? J. Affect. Disord. 41: 229-240.

Viegi, G., Scognamiglio, A., Baldacci, S., Pistelli, F., \& Carrozzi, L. (2001). Epidemiology of chronic obstructive pulmonary disease (COPD). Respiration 68: 4-19.

Yusuf, S., Reddy, S., Ounpuu, S., \& Anand, S. (2001). Global burden of cardiovascular diseases: part I: general considerations, the epidemiologic transition, risk factors, and impact of urbanization. Circulation 104: 2746-53.

\subsection{Acknowledgement}

The Longitudinal Aging Study Amsterdam is largely funded by the Ministry of Health, Welfare, and Sports of the Netherlands. 
CHAPTER $5^{*}$

\title{
Associations between lifestyle and depressed mood
}

\author{
Longitudinal results from the Maastricht Aging Study
}

Coen H. van Gool, Gertrudis I.J.M. Kempen, Hans Bosma, Martin P.J. van Boxtel, Jelle Jolles, \& Jacques Th.M. van Eijk

\begin{abstract}
Objectives: Associations between lifestyles and the development of affective problems are not unequivocally clear. We examined if healthy lifestyles protect against the development of depressed mood. Methods: A six-year follow-up sample of 1186 participants of the Maastricht Aging Study (MAAS), aged 24 through 81 years, provided data on smoking, alcohol use, physical exercise, body mass index (BMI), and mood at baseline and follow-up. Associations between lifestyles and depressed mood were examined using cross-sectional and longitudinal techniques of analysis. Results: No cross-sectional associations between lifestyle and depressive symptomatology were found. Excessive alcohol use at baseline predicted depressed mood at follow-up (Relative Risk [RR] 2.53; 95\% Confidence Interval [95\%CI] 1.11 - 5.79), and $>30$ minutes of physical exercise per day at baseline predicted follow-up absence of depressed mood (RR $0.50 ; 95 \%$ CI 0.29 - 0.87). Not being overweight for six years (RR $0.49 ; 95 \%$ CI $0.25-0.95$ ) was associated with follow-up absence of depressed mood. Conclusions: In this relatively healthy population sample, certain lifestyles either predicted or protected against depressed mood. Adopting healthy lifestyles might be a starting point to prevent or deal with depressed mood over time.
\end{abstract}

Key words: Lifestyle, depressive symptomatology, longitudinal studies.

\footnotetext{
${ }^{*}$ As submitted to the American Journal of Public Health.
} 


\subsection{Introduction}

$T \mathrm{t}$ is assumed that depressed mood is caused by a complex of physical, 1 psychological, and socio-environmental factors [1]. For example, unhealthy lifestyles, such as smoking, excessive alcohol use, low levels of physical exercise, or being overweight or obese, may provoke chronic diseases $[2,3]$ or worsen health status over time [4]. Chronic diseases, in turn, go together with more symptoms of depression [5], and feelings of depression may provoke more unhealthy lifestyles [6]. Another potentially downward spiraling mechanism might be that unhealthy lifestyles elicit or exacerbate feelings of depression $[7,8]$, and that feelings of depression, subsequently, provoke or worsen (the consequences of) chronic diseases $[9,10]$. However, it is not unequivocally clear how unhealthy lifestyles and the development of depressed mood - referring to clinically relevant levels of depressive symptomatology along the depressive spectrum [11] - are associated over time.

Although the association between current smoking and depressed mood has been consistently established in various cross-sectional study samples [1214], little evidence is available regarding its longitudinal association: whether current smoking precedes or follows depressed mood. In general, heavy drinking is associated with depressed mood $[15,16]$. Moreover, depressed mood is more often secondary to alcoholism than primary [15]. Physical activity seems to help counteract prevalent depression and to protect against incident depression. Still, longitudinal studies are asked for to further unravel this association $[17,18]$. The association between being overweight or obese and depressed mood is controversial, as negative, positive, and no associations have been found [19-22].

If healthy lifestyles are associated with absence of, or protect against the development of depressed mood, this common, yet debilitating condition might be prevented or dealt with in the future by promoting healthy lifestyles. In this study we focus on the following question: Do healthy lifestyles protect against the development of depressed mood in the general population? 


\subsection{Methods}

\section{Design and Study population}

To date, the prospective Maastricht Aging Study (MAAS) on determinants of successful aging, has baseline and two three-year intermittent follow-up measurements. As first follow-up lifestyle variables were unavailable for respondents aged 49 or younger, we used baseline and second follow-up data. Between 1993 and 1995, participants were selected from a register of 15 family practices in the south of the Netherlands [23]. General practitioners invited 9919 persons, aged 24 to 81 years, to participate in the study by completing a questionnaire and undergoing medical and neuropsychological examination. Participants were stratified by age, sex, and level of general ability. Exclusion criteria were history of chronic neurological pathology, stroke, or mental retardation. Approximately 3449 respondents completed questionnaires. Of this group, 1877 respondents (54.4\%) participated in the medical and neuropsychological examination. Subsequently, 54 individuals were excluded due to unreliable test results, or MMSE scores below 24, indicating a cognitive disorder [24], leaving 1823 individuals at baseline. At follow-up, 1376 (75.5\%) of these 1823 individuals were invited for follow-up assessment. Beforehand, 274 (15.0\%) respondents refused further participation, $116(6.4 \%)$ had died, $42(2.3 \%)$ were lost to follow-up, and 15 $(0.8 \%)$ were medically unfit to participate. Ultimately, $1186(86.2 \%)$ of the 1376 respondents were included in the study sample, as $190(13.8 \%)$ respondents were lost to subsequent analyses due to incomplete data at baseline or follow-up on either lifestyle or depression. The local medical ethics committee approved of the study and participants gave their written informed consent. Sampling, data collection procedures, and non-response are described elsewhere $[25,26]$.

\section{Measurements}

Depressive symptomatology at baseline was measured with the Depression scale of the Symptom Checklist (SCL-90) $[27,28]$. The 16 items of the selfreport SCL-90 Depression scale range from 1 to 5 , with 1 indicating no complaint and 5 maximal complaint. Scores range from 16 to 80 , with higher scores indicating more symptoms of depression. At follow-up, we used the 
Center for Epidemiologic Studies Depression (CES-D) scale [29], as this 20item self-report scale was both designed for epidemiologic research purposes and has proven good psychometric qualities, for example in older populations [30]. The 20 items of the CES-D scale range from 0 to 3, with 0 indicating no complaint and 3 maximal complaint. Scores range from 0 to 60 , with higher scores indicating more symptoms of depression. In order to screen for people with depressed mood, we applied the commonly used cut-off score of $\geq 16$ regarding the CES-D [29]. Predictive validity of both depression instruments are reported elsewhere [31].

Habitual smoking behavior at baseline and follow-up was addressed to in the questionnaire with the questions: "Do you smoke currently? (no/yes); If you do not smoke currently, did you smoke in the past? (no/yes)". Baseline and follow-up habitual smoking behavior was categorized in: 1) Respondent currently smokes (reference category in analyses), 2) Respondent smoked formerly, and 3) Respondent never smoked. Change in smoking behavior over time was categorized in: 1) Respondent still does not smoke; 2) Respondent quit smoking; 3) Respondent started smoking; 4) Respondent still smokes (reference category in analyses).

Habitual alcohol intake at baseline and follow-up was addressed to in the questionnaire with the questions: "What kind of alcoholic beverage do you usually drink? (beer, wine/sherry/port/vermouth, liquor, varies, I absolutely never drink alcohol); If you drink alcohol, how many glasses of alcohol do you drink per day on average? ( $>10$ glasses, between 7 to 10 glasses, between 3 to 6 glasses, 1 or 2 glasses); If you drink alcohol, how many days of the week do you drink alcohol on average? (every day, 5 to 6,3 to 4,1 to 2, less than 1 day per week)". Based on these variables continuous baseline and follow-up averaged number of alcoholic consumptions per week was computed. Also, baseline and follow-up habitual alcohol intake measures were categorized in: 1) Respondent does not drink (reference category in analyses), 2) Respondent drinks up to 2 alcoholic consumptions per day on average, and 3) Respondent drinks 3 or more alcoholic consumptions per day on average (excessive alcohol use). Change in alcohol use over time was categorized in: 1) Respondent still drinks alcohol; 2) Respondent started drinking alcohol; 3) Respondent quit 
drinking alcohol; 4) Respondent still does not drink alcohol (reference category in analyses).

Habitual physical exercise at baseline and follow-up was addressed to in the questionnaire with the questions: "Can you indicate how many hours per week on average you spend on (light) sports, such as ball sports, aerobic exercise, walking, biking, etc. (If you do not sport at all, please fill out 0)?". Based on these variables continuous baseline and follow-up the average of minutes per day spent on physical exercise was computed. Furthermore, baseline and follow-up physical exercise measures were categorized in: 1) Respondent does not engage in physical exercise (reference category in analyses), 2) Respondent engages in physical exercise for up to 30 minutes per day on average, and 3) Respondent engages in physical exercise for more than 30 minutes per day on average. Change in physical exercise over time was categorized in: 1) Respondent still engages in physical exercise; 2) Respondent initiated physical exercise; 3) Respondent quit exercising; 4) Respondent still does not engage in physical exercise (reference category in analyses).

Body mass index (BMI) was calculated by dividing weight in kilograms by the square of height in meters. Study staff recorded body weight and height at baseline and follow-up. We used BMI cut-off scores of $\geq 27.8$ for men and $\geq$ 27.3 for women to distinguish between respondents who were (at least) overweight (reference category in analyses) and those who were not [32]. Change in overweight status over time was categorized in: 1) Respondent is still not overweight; 2) Respondent is no longer overweight; 3) Respondent became overweight; 4) Respondent is still overweight (reference category in analyses).

Previous research demonstrated that age, gender, education, and number of chronic diseases are associated with both lifestyle [33-35], and with depression $[10,36,37]$. Hence, these variables were included in our analyses as covariates. Educational level was obtained from the questionnaire, as were age and gender. We categorized educational level into low (respondents with primary education at most), intermediate (respondents with junior vocational training), and high (respondents with senior vocational or academic training). Lastly, respondents could indicate if a medical doctor ever made a diagnosis of 
one or more 37 chronic diseases that were screened for in a semi-structured interview by a trained research assistant.

\section{Statistical Analyses}

Following attrition analyses, description of baseline study sample, and comparisons of baseline and follow-up study variables, associations between baseline lifestyle and baseline and follow-up symptoms of depression were analyzed. Hereafter, we studied associations between changes in lifestyle between baseline and follow-up and depressive symptomatology at follow-up. Data were analyzed with SPSS 11.5 using cross-sectional and longitudinal techniques of analyses, specifically chi-square, McNemar, (paired samples) ttests, analyses of variance, and multivariate logistic regression models with the (changes in) lifestyle domains as independent and clinically relevant depressive symptomatology at follow-up as outcome variable, using the unhealthy lifestyles as reference categories and adjusted for covariates. Additionally, analyses regarding follow-up clinically relevant depressive symptomatology or lifestyle change variables were adjusted for baseline levels of the depression or lifestyle variables.

\subsection{Results}

As shown in Table 5.1, attrition analyses at baseline demonstrated that, compared to respondents, persons who were lost to follow-up ( $n=637$ ) or were non-respondents ( $n=1626$; together $n=2263$ ) were: significantly older (55.1 \pm 17.6 years lost to follow-up or non-respondents versus [vs.] $49.0 \pm$ 14.7 years respondents); more likely to be female (55.8\% vs. $47.7 \%$ ); more likely to report low educational level (51.6\% vs. $37.2 \%$ ); reported more chronic diseases $(1.9 \pm 1.8$ vs. $1.3 \pm 1.3)$; reported les minutes of physical activity per day (13.5 \pm 27.3 vs. $18.3 \pm 28.3$ ); were more likely to be overweight (39.9\% vs. 33.0\%); and had more symptoms of depression (20.0 \pm 7.9 vs. $20.5 \pm 6.1$; Table 5.1).

Also shown in Table 5.1 are the lifestyle domains at follow-up. Between baseline and follow-up, the proportion of respondents who reported smoking decreased from $26.6 \%$ to $21.9 \%$. Between baseline and follow-up, the proportions of respondents who either reported not drinking alcohol at all, or 
Table 5.1: Population characteristics at baseline and comparisons ${ }^{a}$ on key variables at baseline and follow-up

\begin{tabular}{|c|c|c|c|}
\hline & \multirow{2}{*}{$\begin{array}{l}\begin{array}{c}\text { Non-respondents } \\
\text { or lost to follow-up } \\
\left(n=2263^{\mathrm{b}}\right)\end{array} \\
\text { Mean (SD) / \% }\end{array}$} & \multicolumn{2}{|c|}{$\begin{array}{l}\text { Study Sample } \\
\qquad(n=1186)\end{array}$} \\
\hline & & $\begin{array}{c}\text { Baseline } \\
\text { Mean (SD) / \% }\end{array}$ & $\begin{array}{c}\text { Follow-up } \\
\text { Mean (SD) / \% }\end{array}$ \\
\hline \multicolumn{4}{|l|}{ Age } \\
\hline$\%$ 24-44 years & 32.3 & $41.6^{\mathrm{c} 1}$ & N.A. ${ }^{e}$ \\
\hline$\%$ 45-64 years & 32.3 & 40.7 & N.A. \\
\hline$\%$ 65-81 years & 35.4 & 17.7 & N.A. \\
\hline Age (continuous) & $55.1(17.6)$ & $49.0(14.7)^{c 1}$ & \\
\hline \multicolumn{4}{|l|}{ Gender } \\
\hline$\%$ Male & 44.2 & $52.3^{\mathrm{c} 1}$ & N.A. \\
\hline$\%$ Female & 55.8 & 47.7 & N.A. \\
\hline \multicolumn{4}{|l|}{ Education } \\
\hline \% High & 21.6 & $28.8^{\mathrm{c} 1}$ & N.A. \\
\hline$\%$ Intermediate & 26.8 & 34.0 & N.A. \\
\hline$\%$ Low & 51.6 & 37.2 & N.A. \\
\hline \multicolumn{4}{|l|}{ Chronic diseases } \\
\hline$\%$ No chronic disease & 23.3 & $33.4^{\mathrm{c} 1}$ & N.A. \\
\hline$\%$ One chronic disease & 27.2 & 33.8 & N.A. \\
\hline$\%$ Two or more chronic diseases & 49.4 & 32.8 & N.A. \\
\hline \# Chronic diseases & $1.9(1.8)$ & $1.3(1.3)^{\mathrm{c} 1}$ & N.A. \\
\hline \multicolumn{4}{|l|}{ Smoking behavior } \\
\hline \% Respondent currently smokes & 29.1 & 26.6 & $21.9^{\mathrm{d} 1}$ \\
\hline$\%$ Respondent used to smoke & 36.4 & 38.6 & 40.7 \\
\hline$\%$ Respondent never smoked & 34.5 & 34.8 & 37.4 \\
\hline \multicolumn{4}{|l|}{ Averaged daily alcohol intake } \\
\hline$\%$ Respondent does not drink alcohol & 20.3 & 13.9 & $15.5^{\mathrm{d} 1}$ \\
\hline$\%$ Up to 2 alcoholic drinks & 75.2 & 79.4 & 76.3 \\
\hline$\% 3$ or more alcoholic drinks & 4.5 & 6.7 & 8.2 \\
\hline \# Glasses of alcohol per week & $6.1(8.9)$ & $6.1(9.4)$ & $6.2(8.9)$ \\
\hline \multicolumn{4}{|l|}{ Averaged daily time spent on physical exercise } \\
\hline$\%$ Respondent does not engage in physical exercise & 61.2 & $49.4^{\mathrm{b} 1}$ & $62.7^{\mathrm{c} 1}$ \\
\hline$\%$ Up to 30 minutes & 23.3 & 28.3 & 25.2 \\
\hline$\%$ More than 30 minutes & 15.5 & 22.3 & 12.1 \\
\hline \# Minutes of physical exercise per day & $13.5(27.3)$ & $18.3(28.3)^{c 1}$ & $10.6(20.5)^{\mathrm{d} 1}$ \\
\hline \multicolumn{4}{|l|}{ Body mass index (BMI) } \\
\hline$\% \geq 27.3$ (women); $\geq 27.8$ (men) & 39.9 & $33.0^{\mathrm{c} 2}$ & $39.7^{\mathrm{d} 1}$ \\
\hline$\%<27.3$ (women); $<27.8$ (men) & 60.1 & 67.0 & 60.3 \\
\hline BMI (continuous) & $27.2(4.4)$ & $26.5(4.1)^{\mathrm{c} 1}$ & $27.0(4.2)^{\mathrm{d} 1}$ \\
\hline SCL-90 Depression scale & $22.0(7.9)$ & $20.5(6.1)^{\mathrm{c} 1}$ & N.A. \\
\hline CES-D Depression scale & N.A. & N.A. & $7.9(6.7)$ \\
\hline$\% \geq 16$ & N.A. & N.A. & 14.3 \\
\hline$\%<16$ & N.A. & N.A. & 85.7 \\
\hline
\end{tabular}

${ }^{a}$ Comparisons of continuous variables were tested with (paired samples) t-tests and univariate analyses of variance; comparisons of categories were tested using chi-square and McNemar tests; ${ }^{b}$ Numbers of nonresponse and loss to follow-up vary from 2263 for sociodemographics, smoking behavior, alcohol intake, physical exercise, and SCL-90 Depression scale to 637 for BMI and number of chronic diseases; ${ }^{c}$ differs significantly from non-respondents or persons lost to follow-up $\left({ }^{c 1} p<.001 ;{ }^{c 2} p<.01 ;{ }^{c 3} p<.05\right)$; ${ }^{d}$ differs significantly from baseline $\left({ }^{d 1} p<.001 ;{ }^{d 2} p<.01 ;{ }^{d 3} p<.05\right) ;{ }^{e}$ Not Applicable. 
reported to drink three or more alcoholic drinks per day on average, increased from $13.9 \%$ to $15.5 \%$ and from $6.7 \%$ to $8.2 \%$, respectively (Table 5.1 ). The proportion of respondents who did not engage in physical exercise increased from $45.4 \%$ at baseline to $62.7 \%$ at follow-up. In addition, the averaged number of minutes daily physical exercise decreased from $18.3 \pm 28.3$ at baseline to $10.6 \pm 20.5$ at follow-up. Not only did the average level of BMI in the study sample increase from $26.5 \pm 4.1$ to $27.0 \pm 4.2$ between baseline and follow-up, the proportion of overweight respondents increased from $33.0 \%$ at baseline to $39.7 \%$ at follow-up as well. Lastly, $14.3 \%$ of the respondents scored above the clinically relevant threshold of the CES-D scale at follow-up (Table 5.1).

Results from cross-sectional univariate analyses are shown in Table 5.2. Respondents aged 45 through 64 years reported higher mean depression scores at baseline compared to other age categories. Women had significantly higher mean depression scores than men. The proportion of respondents with low education reported significantly higher mean depression scores than respondents with intermediate or high education. Also at baseline, the proportion of respondents with two or more chronic diseases had higher mean depression scores compared to respondents without chronic disease or with no more than one chronic disease. Finally, respondents who reported excessive alcohol use at baseline had significantly lower mean SCL-90 depression scores at baseline than respondents who drank less alcohol or did not drink at all (Table 5.2). When the abovementioned covariates were taken into account in post hoc analyses, though, the association between baseline alcohol use and baseline depressive symptomatology became redundant (not tabulated).

Table 5.3 shows results from longitudinal analyses, presented as relative risks (RR's) and 95\% confidence intervals (95\%CI) from adjusted multivariate logistic regression models with baseline lifestyle domains as determinants of follow-up depressed mood. Compared to respondents who reported at baseline not to drink alcohol at all, respondents who reported to drink more than three alcoholic drinks per day on average at baseline were approximately 2.5 times as likely to be depressed at follow-up (RR 2.53; 95\%CI $1.11-5.79$ ). Also, every glass of alcohol consumed on average per week at baseline was 
Table 5.2: Baseline and follow-up depression scores and comparisons ${ }^{a}$ stratified by baseline sociodemographic information and baseline lifestyle domains $(n=1186)$

\begin{tabular}{|c|c|c|c|c|c|}
\hline & & \multirow{2}{*}{$\begin{array}{c}\text { SCL-90 Depression } \\
\text { score at baseline } \\
\text { Mean (SD) }\end{array}$} & \multicolumn{3}{|c|}{ CES-D Depression score at follow-up } \\
\hline & & & Mean (SD) & $\begin{array}{l}\text { Depressed }^{c} \text { vs. } \\
14.3 \% ; n=170 \text { vs. }\end{array}$ & $\begin{array}{l}\text { Non-depressed } \\
85.7 \% ; n=1016\end{array}$ \\
\hline \multicolumn{6}{|l|}{ Age } \\
\hline 24-44 years & $n=493$ & $20.3(6.2)^{\mathrm{b} 3}$ & $7.0(6.5)^{\mathrm{b} 1}$ & $12.6 \%$ & $83.4 \%$ \\
\hline $45-64$ years & $n=483$ & $21.1(6.7)$ & $8.5(6.9)$ & $14.9 \%$ & $85.1 \%$ \\
\hline $65-81$ years & $n=210$ & $19.8(4.2)$ & $9.1(6.2)$ & $17.1 \%$ & $82.9 \%$ \\
\hline Age; Mean (SD) & & & & $51.2(14.6)$ & $48.7(14.7)^{\mathrm{b} 3}$ \\
\hline \multicolumn{6}{|l|}{ Gender } \\
\hline Male & $n=620$ & $19.6(5.0)^{\mathrm{b} 1}$ & $7.1(5.8)^{\mathrm{b} 1}$ & $9.5 \%$ & $90.5 \%{ }^{\mathrm{b} 1}$ \\
\hline Female & $n=566$ & $21.5(7.1)$ & $8.9(7.4)$ & $19.6 \%$ & $80.4 \%$ \\
\hline \multicolumn{6}{|l|}{ Education } \\
\hline High & $n=342$ & $20.0(6.1)^{\mathrm{b} 2}$ & $6.9(6.3)^{b 1}$ & $12.0 \%$ & $88.0 \%^{\mathrm{b} 2}$ \\
\hline Intermediate & $n=403$ & $20.1(5.7)$ & $7.5(6.5)$ & $11.2 \%$ & $88.8 \%$ \\
\hline Low & $n=441$ & $21.3(6.4)$ & $9.1(7.0)$ & $19.0 \%$ & $81.0 \%$ \\
\hline \multicolumn{6}{|l|}{ Chronic diseases } \\
\hline No chronic disease & $n=396$ & $19.6(4.7)^{\mathrm{b} 1}$ & $7.0(6.7)^{\mathrm{b} 1}$ & $12.1 \%$ & $87.9 \%$ \\
\hline One chronic disease & $n=401$ & $20.4(6.0)$ & $7.8(6.4)$ & $13.2 \%$ & $86.8 \%$ \\
\hline Two or more chronic diseases & $n=389$ & $21.6(7.3)$ & $9.1(6.8)$ & $17.7 \%$ & $82.3 \%$ \\
\hline \# Chronic diseases; Mean (SD) & & & & $1.5(1.5)$ & $1.2(1.3)^{\mathrm{b} 3}$ \\
\hline \multicolumn{6}{|l|}{ Smoking behaviour } \\
\hline Respondent currently smokes & $n=315$ & $20.9(6.7)$ & $8.3(7.3)$ & $16.5 \%$ & $83.5 \%$ \\
\hline Respondent used to smoke & $n=458$ & $20.4(5.9)$ & $8.2(6.7)$ & $14.6 \%$ & $85.4 \%$ \\
\hline Respondent never smoked & $n=413$ & $20.3(5.9)$ & $7.4(6.1)$ & $12.3 \%$ & $87.7 \%$ \\
\hline \multicolumn{6}{|l|}{ Averaged daily alcohol intake } \\
\hline No, respondent does not drink alcohol & $n=164$ & $22.1(7.8)^{\mathrm{b} 1}$ & $8.7(7.7)$ & $17.1 \%$ & $82.9 \%$ \\
\hline Up to 2 alcoholic drinks & $n=942$ & $20.3(5.9)$ & $7.8(6.5)$ & $13.6 \%$ & $86.1 \%$ \\
\hline 3 or more alcoholic drinks & $n=80$ & $19.7(3.9)$ & $7.7(6.4)$ & $16.3 \%$ & $83.7 \%$ \\
\hline \# Glasses of alcohol per week; Mean (SD) & & & & $6.1(10.5)$ & $6.1(9.3)$ \\
\hline \multicolumn{6}{|l|}{ Averaged daily time spent on physical exercise } \\
\hline Respondent does not engage in physical exercise & $n=586$ & $20.8(6.4)$ & $8.6(7.2)^{b 1}$ & $17.1 \%$ & $84.1 \%{ }^{\mathrm{b} 2}$ \\
\hline Up to 30 minutes & $n=336$ & $20.6(5.7)$ & $7.9(6.3)$ & $14.3 \%$ & $85.7 \%$ \\
\hline More than 30 minutes & $n=264$ & $19.8(5.9)$ & $6.6(5.7)$ & $8.3 \%$ & $91.7 \%$ \\
\hline \# Minutes of physical exercise per day; Mean (SD) & & & & $12.8(24.2)$ & $19.2(28.9)^{\mathrm{b} 2}$ \\
\hline \multicolumn{6}{|l|}{ Body mass index (BMI) } \\
\hline$\geq 27.3$ (women); $\geq 27.8$ (men) & $n=391$ & $21.0(6.4)$ & $8.7(7.1)^{b 2}$ & $16.1 \%$ & $83.9 \%$ \\
\hline$<27.3$ (women); < 27.8 (men) & $n=795$ & $20.3(6.0)$ & $7.6(6.4)$ & $13.5 \%$ & $86.5 \%$ \\
\hline BMI; Mean (SD) & & & & $26.4(4.1)$ & $26.5(4.1)$ \\
\hline
\end{tabular}

associated with a $2 \%$ increased risk of being depressed at follow-up (RR 1.02; $95 \%$ CI $1.00-1.04$ ). Both analyses were adjusted for all covariates (Table $5.3)$.

Respondents who reported to be engaged in physical exercise for more than 30 minutes per day on average at baseline, decreased their risk of being depressed at follow-up by $50 \%$ compared to respondents who reported not to be engaged in physical exercise at all (RR $0.50 ; 95 \%$ CI $0.29-0.87$ ). Also, 
Table 5.3: Multivariate logistic regression models with baseline lifestyle domains as determinants of follow-up depression outcome $(n=1186)$

\begin{tabular}{|c|c|c|c|}
\hline \multirow[b]{2}{*}{ Baseline Lifestyle Domains } & & \multicolumn{2}{|c|}{ CES-D Depression at follow-up ( $\geq 16)$} \\
\hline & & $\begin{array}{c}\mathrm{RR}(95 \% \mathrm{Cl})^{\mathrm{a}} \\
\text { Adjusted }^{\mathrm{b}}\end{array}$ & $\begin{array}{c}\text { RR }(95 \% \mathrm{Cl}) \\
\text { Adjusted }^{\mathrm{c}}\end{array}$ \\
\hline \multicolumn{4}{|l|}{ Smoking behaviour } \\
\hline Respondent currently smokes & $n=315$ & Ref. $^{d}$ & Ref. \\
\hline Respondent used to smoke & $n=458$ & $0.91(0.59-1.41)$ & $0.88(0.56-1.37)$ \\
\hline Respondent never smoked & $n=413$ & $0.74(0.46-1.18)$ & $0.65(0.40-1.05)$ \\
\hline \multicolumn{4}{|l|}{ Averaged daily alcohol intake } \\
\hline No, respondent does not drink alcohol & $n=164$ & Ref. & Ref. \\
\hline Up to 2 alcoholic drinks & $n=942$ & $0.98(0.59-1.63)$ & $1.24(0.73-2.11)$ \\
\hline 3 or more alcoholic drinks & $n=80$ & $1.52(0.70-3.30)$ & $2.53(1.11-5.79)^{\mathrm{e} 3}$ \\
\hline \# Glasses of alcohol per week & $n=1186$ & $1.01(0.99-1.03)$ & $1.02(1.00-1.04)^{f 3}$ \\
\hline \multicolumn{4}{|l|}{ Averaged daily time spent on physical exercise } \\
\hline Respondent does not engage in physical exercise & $n=586$ & Ref. & Ref. \\
\hline Up to 30 minutes & $n=336$ & $0.81(0.54-1.22)$ & $0.77(0.50-1.16)$ \\
\hline More than 30 minutes & $n=264$ & $0.44(0.26-0.77)^{\mathrm{e} 2}$ & $0.50(0.29-0.87)^{\mathrm{e} 3}$ \\
\hline \# Minutes of physical exercise per day on average & $n=1186$ & $0.99(0.98-1.00)^{\mathrm{f} 2}$ & $0.99(0.98-1.00)^{f 3}$ \\
\hline \multicolumn{4}{|l|}{ Body mass index (BMI) } \\
\hline$\geq 27.3$ (women); $\geq 27.8$ (men) & $n=391$ & Ref. & Ref. \\
\hline < 27.3 (women); < 27.8 (men) & $n=795$ & $0.92(0.63-1.34)$ & $1.02(0.69-1.51)$ \\
\hline BMI score (continuous) & $n=1186$ & $0.99(0.95-1.04)$ & $0.98(0.94-1.03)$ \\
\hline
\end{tabular}

${ }^{a}$ Relative Risks and 95\% confidence intervals; ${ }^{b}$ Adjusted for baseline depression score; ${ }^{c}$ Adjusted additionally for age, sex, educational level, and number of chronic diseases; ${ }^{d}$ Reference category; ${ }^{e}$ Differs significantly from the reference category $\left({ }^{\mathrm{e} 1} \mathrm{p}<.001 ;{ }^{\mathrm{e} 2} \mathrm{p}<.01 ;{ }^{\mathrm{e} 3} \mathrm{p}<.05\right) ;{ }^{\mathrm{f}}$ statistically significant $\left({ }^{\mathrm{f} 1}<.001 ;{ }^{\mathrm{f} 2}<.01 ;{ }^{\mathrm{f} 3}<.05\right)$.

every minute of physical exercise per day at baseline was associated with a $1 \%$ decreased risk of being depressed at follow-up (RR 0.99; 95\%CI 0.98 1.00). Both analyses were adjusted for all covariates (Table 5.3).

Table 5.4 shows results from longitudinal analyses, presented as relative risks and 95\% confidence intervals from adjusted multivariate logistic regression models with changes in lifestyle domains as determinants of followup depressed mood. Analyses, adjusted for baseline levels of depression and alcohol intake, showed that respondents who drank both at baseline and follow-up, as well as respondents who initiated alcohol use between baseline and follow-up, had lower relative risks of being depressed at follow-up compared to respondents who reported to abstain from alcohol use at baseline and follow-up (RR's 0.55 and $0.21 ; 95 \% C I$ 's $0.32-0.92$ and $0.06-0.75$, 
Table 5.4: Multivariate logistic regression models with changes in lifestyle domains as determinants of follow-up depression outcome $(n=1186)$

\begin{tabular}{|c|c|c|c|}
\hline \multirow[b]{3}{*}{ Changes in Lifestyle Domains } & & \multicolumn{2}{|c|}{ CES-D Depression at follow-up ( $\geq 16$ ) } \\
\hline & & $\operatorname{RR}(95 \% \mathrm{Cl})^{a}$ & $\mathrm{RR}(95 \% \mathrm{Cl})$ \\
\hline & & Adjusted $^{b}$ & Adjusted $^{c}$ \\
\hline \multicolumn{4}{|l|}{ Smoking behaviour } \\
\hline Respondent still does not smoke & $n=840$ & $1.00(0.41-2.45)$ & $1.23(0.48-3.14)$ \\
\hline Respondent quit smoking & $n=86$ & $0.86(0.40-1.85)$ & $0.92(0.42-2.03)$ \\
\hline Respondent started smoking & $n=31$ & $1.74(0.54-5.57)$ & $2.55(0.76-8.57)$ \\
\hline Respondent still smokes & $n=229$ & Ref. $^{e}$ & Ref. \\
\hline \multicolumn{4}{|l|}{ Alcohol intake } \\
\hline Respondent still drinks & $n=955$ & $0.55(0.32-0.92)^{\mathrm{d} 3}$ & $0.74(0.73-1.28)$ \\
\hline Respondent started drinking & $n=47$ & $0.21(0.06-0.75)^{\mathrm{d} 3}$ & $0.22(0.06-0.82)^{d 3}$ \\
\hline Respondent quit drinking & $n=67$ & $1.11(0.52-2.37)$ & $1.13(0.52-2.46)$ \\
\hline Respondent still does not drink & $n=117$ & Ref. & Ref. \\
\hline \multicolumn{4}{|l|}{ Physical exercise } \\
\hline Respondent still engages in physical exercise & $n=334$ & $0.70(0.39-1.25)$ & $0.67(0.37-1.22)$ \\
\hline Respondent started to engage in physical exercise & $n=108$ & $0.60(0.30-1.19)$ & $0.62(0.31-1.24)$ \\
\hline Respondent quit engaging in physical exercise & $n=266$ & $1.02(0.39-1.77)$ & $0.91(0.52-1.59)$ \\
\hline Respondent still does not engage in physical exercise & $n=478$ & Ref. & Ref. \\
\hline \multicolumn{4}{|l|}{ Body mass index (BMI) } \\
\hline Respondent is still not overweight & $n=670$ & $0.42(0.22-0.81)^{\mathrm{d} 2}$ & $0.49(0.25-0.95)^{d 3}$ \\
\hline Respondent is no longer overweight & $n=45$ & $1.02(0.44-2.38)$ & $1.10(0.45-2.69)$ \\
\hline Respondent became overweight & $n=125$ & $0.68(0.34-1.34)$ & $0.78(0.39-1.56)$ \\
\hline Respondent is still overweight & $n=346$ & Ref. & Ref. \\
\hline
\end{tabular}

${ }^{a}$ Relative Risks and 95\% confidence intervals; ${ }^{b}$ Adjusted for baseline depression score and baseline level of lifestyle in question; ${ }^{c}$ Adjusted additionally for age, sex, educational level, and number of chronic diseases;

${ }^{d}$ Differs significantly from the reference category $\left({ }^{d 1} p<.001 ;{ }^{d 2} p<.01 ;{ }^{d 3} p<.05\right)$; ${ }^{\text {e }}$ Reference category.

respectively). However, when these analyses were adjusted additionally for covariates, only the association of alcohol use initiation between baseline and follow-up and absence of depressed mood at follow-up remained significant (RR 0.22; 95\%CI $0.06-0.82$; Table 5.4).

When adjusted for all covariates, analyses demonstrated that respondents who were not overweight at baseline, nor at follow-up, had a lower relative risk of being depressed at follow-up compared to respondents who were overweight at both moments of measurement (RR $0.49 ; 95 \%$ CI 0.25 - 0.95; Table 5.4).

\subsection{Discussion}

We studied cross-sectional and longitudinal associations between lifestyles and depressive symptomatology in a sample of relatively healthy participants of the 
MAAS study over a 6-year period. In cross-sectional baseline analyses, we found no associations between alcohol use and depressive symptomatology. In longitudinal analyses, we found that baseline excessive alcohol use, as compared to alcohol abstinence, predicted follow-up depressed mood, and that more than 30 minutes of physical exercise on average per day at baseline, as compared to not exercising at all, predicted follow-up absence of depressed mood. Finally, we found alcohol use initiation to be associated with absence of follow-up depressed mood compared to steady non-drinkers, and not being overweight at both moments of measurement to be associated with absence of follow-up depressed mood compared to respondents who are overweight at both moments of measurement.

Although our study found a decrease in proportion respondents who reported to smoke, we did not find any associations between (change in) smoking behavior and subsequent depressed mood. This is contradictory to a substantial part of the current literature $[6,12-14]$. Moreover, the increase in proportion respondents who never smoked indicates some inconsistency in completing the questionnaires over a six-year period. This may be detrimental to the reliability of data regarding smoking behavior and may have weakened associations between smoking behavior and depressive symptomatology.

Our finding of a significant longitudinal predictive effect of baseline excessive alcohol use on the development of depressed mood is in concordance to some extent with the finding of Aneshensel and colleagues [8]. They found contradictory cross-sectional and longitudinal effects of alcohol use on depression. From their study among 742 adults in the Los Angeles Metropolitan Area Sample, they inferred that high levels of alcohol use were associated with low levels of depressive symptomatology (cross-sectional), but that high initial levels of alcohol use were associated with increased depressive symptomatology (longitudinal).

Our finding of a significant longitudinal protective effect of high initial level of physical exercise on subsequent depressed mood, is partly in line with the results of Strawbridge and colleagues [17]. They found that high levels of physical activity were associated with absence of depression and were protective against incident depression among 1947 community-dwelling adults, aged 50 through 94 years, using a five-year follow-up. Their measure of 
physical activity was defined as usual frequency (never, sometimes, often; scoring was zero, one, or two, respectively) of physical exercise, taking part in active sports, taking long walks, and swimming.

Parallels can be drawn between our finding of a longitudinal association between successfully keeping BMI values below overweight cut-off levels and absence of depressed mood and the findings of Roberts and colleagues [20] and Ogden [38]. This last study reported a different psychological profile for individuals who proved successful in maintaining their BMI below obese cut-off levels: "they reported greater endorsement for psychological consequences, and indicated that they had been motivated to lose weight for psychological reasons". Lastly, the association between not being overweight for six years and the absence of follow-up depressed mood might be mediated by pain. Earlier work showed that high levels of BMI are associated with low levels of health-related quality of life (HRQoL) [39], and high levels of pain [40], and, moreover, that the association between BMI and HRQoL was being mediated by levels of pain [41]. Analogously, as compared to respondents who are unsuccessful in maintaining their BMI below overweight cut-off levels, respondents who are successful might experience lower levels of pain in joints that are crucial in mobility, for example, and potentially be at less risk for subsequent depressive symptomatology.

The authors are uncertain about the validity of the association between alcohol use initiation and absence of depressed mood at follow-up. Firstly, as this analysis was adjusted for baseline depression, we actually examined simultaneity of change in alcohol use and change in depression, which prohibits causal inferences. For all we know, a decrease in depressive symptomatology could be associated with an increase in alcohol use, also among those who initially reported to abstain from alcohol use. Secondly, we cannot rule out that this finding is a statistical artifact due to selection bias (as non-respondents reported more symptoms of depression), and relatively small sample size of the respondents who initiated alcohol use $(n=47)$.

Another limitation of our study pertains to the attrition due to nonresponse and loss to follow-up. Although our study used a six-year follow-up, the considerable proportion of attrition may have caused selection bias regarding our study sample. As we mentioned earlier, this could be an 
alternative explanation for the association we found between alcohol use initiation and absence of depressed mood. However, Kempen and van Sonderen take the view that the effect of attrition is more disturbing for descriptive results than for measures of (longitudinal) association, such as used in our study [42].

A last limitation of our study pertains to the use of our lifestyle change categories. As we categorized lifestyle changes simply as cross-product of baseline and follow-up smoking, drinking, exercising, or being overweight (no/yes), we may have augmented heterogeneity within categories, as compared to heterogeneity between categories, and diminished statistical power. Consequently, estimations of true effects of lifestyle changes on subsequent depressed mood may be conservative. These limitations should be kept in mind when interpreting our results and public health recommendations.

However, we believe that our study has strengths as well. To our knowledge, this is the first study that examined associations between four lifestyle domains and depressive symptomatology in the same sample, using both cross-sectional and longitudinal techniques of analyses. Pivotal in our study are the longitudinal findings that: 1 ) baseline excessive alcohol use predicted follow-up depressed mood; 2) more than 30 minutes of baseline physical exercise predicted absence of follow-up depressed mood; and 3) not being overweight over a longer period of time was associated with absence of follow-up depressed mood. Regarding the potentially downward spiral mentioned in the introduction - our results indicate that this downward motion might be stopped by adopting healthy lifestyles, in order to prevent incidence or worsening of depressive symptomatology over time. Consequently, chronic disease incidence or worsening might also be prevented.

Should the evidence of certain lifestyles being protective against the development of depressed mood accumulate after replication studies, then (more) controlled intervention studies should be called for. Preliminary results indicate favorable effects of, for example, exercise on mental health $[43,44]$. As good results were obtained in lowering symptoms of depression using psychoeducation $[45,46]$, future intervention studies might attempt to prevent incidence or worsening of depressed mood by encouraging healthy lifestyles as well as by using psychoeducation. 


\subsection{References}

1. Jorm AF. The epidemiology of depressive states in the elderly: implications for recognition, intervention and prevention. Soc Psychiatry Psychiatr Epidemiol 1995; 30: 53-9.

2. Gohlke H. Lifestyle modification - is it worth it? Herz 2004; 29: 139-44.

3. Meigs JB, Hu FB, Rifai N, et al. Biomarkers of endothelial dysfunction and risk of type 2 diabetes mellitus. JAMA 2004; 291: 1978-86.

4. Penninx BW, Leveille S, Ferrucci L, van Eijk JT, Guralnik JM. Exploring the effect of depression on physical disability: Iongitudinal evidence from the established populations for epidemiologic studies of the elderly. Am J Public Health 1999; 89: 1346-52.

5. Bisschop MI, Kriegsman DM, Deeg DJ, et al. The longitudinal relation between chronic diseases and depression in older persons in the community: the Longitudinal Aging Study Amsterdam. J Clin Epidemiol 2004; 57: 187-94.

6. Van Gool CH, Kempen GI, Penninx BW, et al. Relationship between changes in depressive symptoms and unhealthy lifestyles in late middle aged and older persons: results from the Longitudinal Aging Study Amsterdam. Age Ageing 2003; 32: 81-7.

7. National Academy on an Aging Society. Depression: A treatable disease. Challenges for the $21^{\text {st }}$ Century: Chronic \& Disabling Conditions 9. Retrieved May 31, 2004 from http://www.agingsociety.org/profiles.

8. Aneshensel CS, Huba GJ. Depression, alcohol use, and smoking over one year: a fourwave longitudinal causal model. J Abnorm Psychol 1983; 92: 134-50.

9. Depression Guideline Panel. Depression in primary care, Vol 1. Detection and diagnosis. Clinical Practice Guideline, Number 5. Rockville, MD: Department of Health and Human Services, Public Health Service, Agency for Health Care Policy and Research. AHCPR Publication No. 93-0550, 1993.

10. Van Gool CH, Kempen GI, Penninx BW, et al. Impact of depression on disablement in late middle aged and older persons: results from the Longitudinal Aging Study Amsterdam. Soc Sci Med; in press.

11. Haringsma R, Engels GI, Beekman AT, Spinhoven P. The criterion validity of the Center for Epidemiological Studies Depression Scale (CES-D) in a sample of self-referred elders with depressive symptomatology. Int J Geriatr Psychiatry 2004; 19: 558-63.

12. Anda RF, Williamson DF, Escobedo LG, et al. Depression and the dynamics of smoking. A national perspective. JAMA 1990; 264: 1541-5.

13. Carney RM, Rich MW, Tevelde A, et al. Major depressive disorder in coronary artery disease. Am J Cardiol 1987; 60: 1273-5.

14. Frederick T, Frerichs RR, Clark VA. Personal health habits and symptoms of depression at the community level. Prev Med 1988; 17: 173-82.

15. Freed EX. Alcohol and mood: an updated review. Int J Addict 1978; 13: 173-200.

16. Aneshensel, CS. An application of log-linear models: the stress-buffering function of alcohol use. J Drug Educ 1983; 13: 287-301. 
17. Strawbridge WJ, Deleger S, Roberts RE, et al. Physical activity reduces the risk of subsequent depression for older adults. Am J Epidemiol 2002; 156: 328-34.

18. Goodwin RD. Association between physical activity and mental disorders among adults in the United States. Prev Med 2003; 36: 698-703.

19. Bin Li Z, Yin Ho S, Man Chan W, et al. Obesity and depressive symptoms in Chinese elderly. Int J Geriatr Psychiatry 2004; 19: 68-74.

20. Roberts RE, Strawbridge WJ, Deleger S, et al. Are the fat more jolly? Ann Behav Med 2002; 24: 169-80.

21. Ross CE. Overweight and depression. J Health Social Beh 1994; 35: 63-79.

22. Carpenter KM, Hasin DS, Allison DB, et al. Relationships between obesity and DSM-IV major depressive disorder, suicide ideation, and suicide attempts: results from a general population study. Am J Public Health 2000; 90: 251-7.

23. Metsemakers JF, Höppener $P$, Knottnerus JA, et al. Computerized health information in the Netherlands: A registration network of family practices. British J Gen Practice 1992; 42: 102-6.

24. Folstein MF, Folstein SE, McHugh PR. "Mini-mental state". A practical method for grading the cognitive state of patients for the clinician. J Psychiatr Res 1975; 12: 189-198.

25. Jolles J, Houx PJ, van Boxtel MP, et al. (Eds). Maastricht Aging Study: Determinants of cognitive aging. Maastricht: Neuropsych Publishers, 1995.

26. Van Boxtel MP, Buntinx F, Houx PJ, et al. The relation between morbidity and cognitive performance in a normal aging population. Journal of Gerontology 1998; 53A: M146-54.

27. Derogatis LR, Lipman RS, Covi L. SCL-90: an outpatient psychiatric rating scale-preliminary report. Psychopharmacol Bull 1973; 9: 13-27

28. Arrindell WA, Ettema JHM. Dimensional structure, reliability and validity of the Dutch version of the Symptom Checklist (SCL-90). Ned Tijdschr Psychologie 1981; 43: 381-7.

29. Radloff LS. The CES-D scale: A self-report depressive mood scale for research in the general population. App Psychol Meas 1977; 1: 385-401.

30. Beekman AT, Deeg DJ, Van Limbeek J, et al. Criterion validity of the Center for Epidemiologic Studies Depression scale (CES-D): results from a community-based sample of older subjects in The Netherlands. Psychol Med 1997; 27: 231-5.

31. Dohrenwend BP. Mental illness in the United States: epidemiological estimates. New York: Praeger Publishers, 1980.

32. Williamson DF, Kahn HS, Remington PL, et al. The 10-year incidence of overweight and major weight gain in US adults. Arch Intern Med 1990; 150: 665-72.

33. Enright PL, McBurnie MA, Bittner $\mathrm{V}$, et al. The 6-min walk test: a quick measure of functional status in elderly adults. Chest 2003; 123: 387-98.

34. Ruchlin HS. Prevalence and correlates of alcohol use among older adults. Prev Med 1997; 26: 651-7.

35. Henderson PN, Rhoades D, Henderson JA, et al. Smoking cessation and its determinants among older American Indians: the Strong Heart Study. Ethn Dis 2004; 14: 274-9. 
36. Beekman AT, Penninx BW, Deeg DJ, et al. Depression and physical health in later life: results from the Longitudinal Aging Study Amsterdam (LASA). J Affect Disord 1997; 46: 219-31.

37. Dong C, Sanchez LE, Price RA. Relationship of obesity to depression: a family-based study. Int J Obes Relat Metab Disord 2004; 28: 790-5.

38. Ogden J.The correlates of long-term weight loss: a group comparison study of obesity. Int J Obes Relat Metab Disord 2000; 24: 1018-25.

39. Yancy WS Jr, Olsen MK, Westman EC, Bosworth HB, Edelman D. Relationship between obesity and health-related quality of life in men. Obes Res 2002; 10: 1057-64.

40. Barofsky I, Fontaine KR, Cheskin LJ. Pain in the obese: impact on health-related qualityof-life. Ann Behav Med 1997; 19: 408-10.

41. Heo M, Allison DB, Faith MS, Zhu S, Fontaine KR. Obesity and quality of life: mediating effects of pain and comorbidities. Obes Res 2003; 11: 209-16.

42. Kempen GI, Van Sonderen E. Psychological attributes and changes in disability among low-functioning, older persons: does attrition affect the outcomes? J Clin Epidemiol 2002, 55: 224-9.

43. Atlantis E, Chow CM, Kirby A, Fiatarone Singh M. An effective exercise-based intervention for improving mental health and quality of life measures: a randomized controlled trial. Prev Med 2004; 39: 424-34.

44. Blumenthal JA, Babyak MA, Moore KA, et al. Effects of exercise training on older patients with major depression. Arch Intern Med 1999; 159: 2349-56.

45. Commissaris K, Verhey FR, Jolles J. A controlled study into the effects of psychoeducation for patients with cognitive disturbances. J Neuropsychiatry Clin Neurosci 1996; 8: 42935.

46. Christensen $\mathrm{H}$, Griffiths KM, Jorm AF. Delivering interventions for depression by using the internet: randomised controlled trial. BMJ 2004; 328 (7434): 265.

\subsection{Acknowledgement}

This work was supported in part by a grant from the Dutch Ministries of Education and Health and Welfare, via the Steering Committee for Gerontological Research (NESTOR). It is part of the Maastricht Aging Study (MAAS). 


\author{
CHAPTER 6 *
}

\title{
Relationship between changes in depressive symptoms and unhealthy lifestyles in late middle aged and older persons
}

\author{
Results from the Longitudinal Aging Study Amsterdam \\ Coen H. van Gool, Gertrudis I.J.M. Kempen, Brenda W.J.H. Penninx, Dorly J.H. \\ Deeg, Aartjan T.F. Beekman, Jacques Th.M. van Eijk
}

\begin{abstract}
Background: Depressed mood is common in late life, more prevalent among the chronically diseased than in the general population, and has various health-related consequences. So far, the association between depression and unhealthy lifestyles among chronically diseased has not been examined longitudinally in older persons. Primary Objective: To determine if depressed mood is associated with unhealthy lifestyles in late middle aged and older people, with or without chronic somatic diseases. Methods: In a sample of 1280 community-dwelling people from the Netherlands, the associations between depressive symptoms and lifestyle domains were analysed crosssectionally and longitudinally - using logistic regression analyses and multivariate analyses of variance. Results: After controlling for confounders, depressed people ( $\mathrm{N}=176$ at baseline) were more likely to be smokers (OR $1.71 ; 95 \% \mathrm{CI} 1.17-2.52)$. A persistent depression was associated with an increase in cigarette consumption $(p=.036)$. Having an emerging depression $(\mathrm{N}=155)$ was most likely to co-occur with persons' change from being physically active to being sedentary (RR 1.62; 95\%CI 1.05-2.52), and was associated with the largest decrease in minutes of physical activity $(p=.038)$. This effect was not modified or confounded by chronic somatic disease. A persistent depression tended to be associated with incident excessive alcohol use (RR 4.04; 95\% CI 0.97-16.09; $\mathrm{p}=.056$ ). Conclusions: Depression is associated with smoking behavior, and with increase in cigarette consumption. An emerging depression is associated with becoming sedentary, irrespective of their disease status at baseline, and is associated with decrease in minutes of physical activity.
\end{abstract}

Key words: depression, lifestyle, chronic disease, longitudinal studies.

\footnotetext{
*As published in Age \& Ageing 2003; 32 (1): 81-7.
} 


\subsection{Introduction}

$D$

epression is common in late life [1]. On average, people with chronic diseases are 1.5 to 2 times more often depressed [2]. The most probable explanation is a reciprocal interaction between chronic somatic disease and late life depression [e.g., 3-6]. One mechanism is the adoption of unhealthy lifestyles by depressed people [7]. The deteriorating effects of unhealthy lifestyles on chronic somatic diseases have been described previously $[8,9]$. Lifestyle domains, such as alcohol use, smoking history, and physical activity were identified as confounders in the relation between depression and heart disease $[10,11]$. The importance of advanced insight in the mechanism through which depression may trigger or worsen chronic medical conditions is evident, with the increasing number of older people with chronic diseases in most western societies [12]. Also, the prevalence of depression may differ across specific disease groups [13], and different lifestyles may be relevant to different diseases. Improvement of mental health of chronically diseased is imperative. This improvement could change the attitudes towards healthy lifestyles, thus stopping a possible downward spiral of depression, unhealthy lifestyles, and deterioration of chronic disease.

There are a number of studies available regarding the effect of depression on unhealthy lifestyles, particularly in older people. While the relationship between depression and physical inactivity is well established [14], the association of depressive symptoms and smoking behavior remains unclear. In fact, some studies found major depression to increase the risk of smoking intensity significantly, but not of smoking initiation $[15,16]$. However, no causal inferences can be made, since most of these studies did not use longitudinal designs or yielded inconsistent results.

Little is known about the impact of depressed mood, or changes therein, on the adoption of unhealthy lifestyles in late middle aged and older persons, with or without chronic diseases. In this paper we focus on the following questions: Are depressive symptoms associated with unhealthy lifestyles, (i.e., alcohol use, smoking behavior, and physical activity)? Are there any differences in this respect among people with different chronic diseases (i.e. heart disease, chronic non-specific lung disease (CNSLD), diabetes, and osteoarthritis)? 


\subsection{Methods}

\section{Design}

For this study baseline and second follow-up measurements were used from the Longitudinal Aging Study Amsterdam (LASA). LASA is a longitudinal, prospective cohort-study on predictors and consequences of changes in wellbeing and autonomy in the late middle aged and older population with baseline and two three-year intermittent follow-up measurements. Because first followup lifestyle variables were not available for all respondents, only baseline and second follow-up data were used. Sampling, data collection procedures, and non-response have been reported in detail elsewhere $[10,17,18]$.

\section{Study sample}

A total of 3107 respondents, aged 55-85 years, were enrolled in the study. The first round of data collection took place in 1992 and 1993. The six-year followup data collection was in 1998 and 1999 [19]. Between baseline interview and follow-up, 766 (24.6\%) respondents had died, 217 (7.0\%) refused participation, $202(6.5 \%)$ were interviewed by telephone, which interview did not include data on lifestyle, $102(3.3 \%)$ respondents were unable to participate due to cognitive or physical impairments, and $86(2.8 \%)$ could not be contacted. After participation in the main baseline interview, another 352 (11.3\%) respondents, all born after 1930, were not followed up for practical reasons related to the study design. Ultimately, 102 (3.3\%) respondents were lost to subsequent analyses because of their incomplete data on depression and lifestyle, leaving a total of $1280(41.2 \%)$ respondents with complete data.

\section{Measurements}

Depressive symptoms were measured with the Center for Epidemiologic Studies Depression (CES-D) scale [20]. This 20-item self-report scale was designed for epidemiologic research purposes in older populations and has proven good psychometric qualities, for instance in the Netherlands [21]. In order to screen for people with clinically relevant levels of depressive symptoms, hereafter called depression, we applied the commonly used CES-D cut-off score of 16 (i.e. 16 or higher [20]). We used two measures of depression: the depression score at baseline (depressed vs. not depressed) 
and a measure for change in depression during follow-up. This change in depression was categorised into: 'no depression', 'emerging depression', 'remitted depression', and 'persistent depression'. Similar to Kennedy [22] and Penninx [19] a relevant change in depression was defined as an increase (emerging depression) or a decrease (remitted depression) of more than $0.5 \times$ standard deviation (SD) $(0.5 \times 8=4$ CES-D points $)$ between baseline and follow-up, thereby transcending the cut-off score. Persons not fulfilling the condition of relevant change were categorised as having either no depression or a persistent depression, depending on their baseline level of depressive symptoms.

Respondents' alcohol intake [23] at baseline and follow-up was dichotomised in: no to moderate alcohol intake (to an average of two drinks a day) vs. excessive alcohol intake (average of three or more drinks per day; [e.g., 19]). We used baseline alcohol intake as initial score and two dichotomised change scores (quit excessive alcohol use vs. remain drinking; emerging excessive alcohol use vs. no excessive alcohol use). Smoking behavior [23] at baseline and follow-up was dichotomised in: never smoked or stopped smoking, vs. currently smoking cigarettes, cigars, or pipe [e.g., 19]. We used baseline smoking behavior as initial score and two dichotomised change scores (quit smoking vs. continue smoking; smoking initiation vs. remain non-smoking). In addition, we examined number of cigarettes smoked per week. Physical activity was measured in minutes per day by adding up averaged, self-reported time spent on walking, cycling, sports, and light (e.g., doing the dishes, or ironing) and heavy (e.g., cleaning windows, or vacuum cleaning) household chores [24-26]. This variable was then dichotomised in the lowest quartile on the one hand, representing sedentary lifestyle at baseline, and the upper three quartiles on the other, representing more active lifestyles at baseline. The cut-off score to determine sedentary lifestyle was at 83.6 minutes of average daily physical activity, both at baseline and follow-up. Again, we used baseline physical activity as initial score and two dichotomised change scores (become sedentary vs. remain active; become physically active vs. remain inactive).

Potential confounders included baseline socio-demographics: sex, age, and years of education. In addition, physical disability was measured with a 3- 
item physical disability scale, previously validated in the Netherlands $[27,28]$; scores range from 3 to 12 , theoretically. Low scores on this scale indicate more physical disability. These confounders were selected because they relate to both lifestyle and depression [2, 14, 19, 29-31].

Chronic disease status, as a potential effect modifier, was assessed by self-report [23]. We selected CNSLD, heart disease, diabetes, and osteoarthritis. These four chronic diseases each represent one major disease category: CNSLD represents disorders of the respiratory system, heart disease represents disorders regarding the cardiovascular system, diabetes represents metabolic disorders, and osteoarthritis represents musculo-skeletal disorders. Data on psychometric qualities of the concordance between patient and general practitioner in our study sample have been reported in detail elsewhere [32] and appeared to be satisfactory.

\section{Statistical Analyses}

First, associations between depression at baseline and lifestyle at baseline were studied. In addition, associations between depression at baseline and changes in lifestyle were analysed. Third, associations between changes in depression and changes in lifestyle were examined. Finally, to determine moderating effects of chronic somatic disease, interaction terms of chronic disease status $\times$ depression were entered in all analyses.

Data were analysed with SPSS 10.0 using chi-square tests, $t$-tests, and logistic regression models with depression as independent and the separate (changes in) lifestyle domains as outcome variables, while controlling for age, sex, educational level attained, and physical disability. Odds-ratios (ORs), relative risk-ratios (RRs), and 95\% confidence intervals (CIs) are presented. In addition, multivariate analyses of variance (MANOVA's) were performed with depression change scores as independent and continuous lifestyle change scores as dependent variables, while controlling for age, sex, educational level attained, and physical disability.

\subsection{Results}

Analyses of attrition at baseline demonstrated that persons who were lost to follow-up $(N=1827)$ were significantly: older $(71.4$ years non-responders vs. 
69.9 years respondents), more likely to be men ( $50.6 \%$ vs. $45.4 \%$ ), and more physically disabled (9.3 vs. 10.3). In addition, significantly more nonresponders reported to have enjoyed only elementary through lower vocational education (66.2\% vs. 59.9\%), and to have chronic diseases (45.3\% vs. $40.3 \%)$. Furthermore, non-responders were more often likely to be smokers ( $28.7 \%$ vs. $21.4 \%$ ), to be less often excessive drinkers (2.7\% vs. $4.1 \%$ ), and to have more often sedentary lifestyles (38.2\% vs. $25.5 \%$ ) compared to respondents.

The percentage of respondents with clinically relevant levels of depressive symptoms, i.e. with CES-D scores $\geq 16$, increased significantly from $13.8 \%$ to $20.3 \%$ between baseline and follow-up ( $p \leq .001$ ), which may be due to age-related health changes or other life events. The proportion of respondents who smoked decreased significantly from $21.4 \%$ to $17.3 \%$ ( $p \leq$ $.001)$. The proportion of respondents who were excessive alcohol users decreased significantly from $4.1 \%$ to $3.4 \%(p \leq .001)$. The proportion of respondents with sedentary lifestyles increased significantly from $25.5 \%$ to $35.2 \%(p \leq .001)$. Study sample characteristics by depression status at baseline are presented in Table 6.1.

At baseline, a significant relation was found between depression and smoking behavior: persons with depressed mood were significantly more often smokers (see Table 6.1), with a corresponding OR of 1.71 (95\% CI; 1.17-2.52; adjusted for age, sex, years of education, and baseline physical disability). Other associations yielded no significance. None of the interaction terms of each chronic somatic disease status $\times$ depression reached the level of significance, after inclusion in the logistic regression analyses regarding smoking behavior. In addition, after implementing each chronic somatic disease status term as a confounder, the association between depression and smoking behavior remained similar (data not shown).

The logistic regression analyses of baseline depression and changes in lifestyle yielded no significant associations (data not shown).

Changes in depression could only significantly predict changes in physical activity in respondents who were originally physically active: respondents with an emerging depression between baseline and follow-up were at a $62 \%$ higher risk of becoming sedentary in physical activity between baseline and follow-up 
Table 6.1: Study sample characteristics at baseline $(N=1280)$.

\begin{tabular}{|c|c|c|c|c|}
\hline & \multicolumn{2}{|c|}{$1992 / 1993$} \\
\hline & & & $\begin{array}{c}\text { Depressed } \\
(13.8 \% ; N=176)\end{array}$ & $\begin{array}{c}\text { Non-depressed } \\
(86.2 \% ; N=1104)\end{array}$ \\
\hline$\%$ Age & \multicolumn{2}{|l|}{$-55-64$ yrs } & 28.8 & $38.1^{\dagger}$ \\
\hline$\%$ Gender & \multicolumn{2}{|l|}{ - Female } & 68.2 & $52.4 *$ \\
\hline$\%$ Education & \multicolumn{2}{|c|}{$\begin{array}{l}\text { - elementary through lower } \\
\text { vocational education }\end{array}$} & 70.5 & $58.2 *$ \\
\hline \multicolumn{3}{|l|}{$\% \operatorname{CNSLD}(N=127)$} & 13.6 & 9.3 \\
\hline \multicolumn{3}{|c|}{$\%$ Heart disease $(N=229)$} & 20.5 & 17.5 \\
\hline \multicolumn{3}{|c|}{$\%$ Diabetes $(N=68)$} & 6.8 & 5.1 \\
\hline \multicolumn{3}{|c|}{$\%$ Osteoarthritis $(N=457)$} & 45.5 & $34.1 *$ \\
\hline \multicolumn{3}{|c|}{$\%$ Excessive alcohol use (avg of $\geq 3$ glasses a day) } & 4.0 & 4.1 \\
\hline \multicolumn{3}{|c|}{$\%$ Smoking $(\mathrm{N}=157)$} & 28.4 & $20.3^{\dagger}$ \\
\hline \multicolumn{3}{|c|}{$\begin{array}{l}\% \text { Sedentary lifestyle (avg of } \leq 83.6 \text { minutes of } \\
\text { physical activity a day) }\end{array}$} & 30.7 & 24.7 \\
\hline \multicolumn{2}{|l|}{ Age } & $M(S D)$ & $69.3(8.6)$ & $69.9(7.1)$ \\
\hline Physical disability & $(N=1279)$ & $M(S D)$ & $8.8(3.7)$ & $10.6(2.5)^{*}$ \\
\hline \multicolumn{2}{|c|}{ Number of cigarettes a week $(N=157)$} & $M(S D)$ & $88.5(74.2)$ & $75.5(60.5)$ \\
\hline \multicolumn{2}{|c|}{ Minutes of daily physical activity } & $M(S D)$ & $154.5(111.7)$ & $171.4(125.6)$ \\
\hline
\end{tabular}

Note: ${ }^{*} p$ is significant at the $\leq .01$ level; ${ }^{\dagger} p$ is significant at the $\leq .05$ level. Proportional variables were tested using Chi-square tests; continuous variables were tested using Ttests.

(Table 6.2). Overall changes in excessive alcohol use were small. Note, however, that the four-fold likelihood of persistent depressed persons,compared to never depressed persons, of incident excessive alcohol use over a six-year period was borderline significant $(p=0.056)$.

None of the interaction terms of each chronic somatic disease status $x$ relevant change in depression reached the level of significance. In addition, after implementing each chronic somatic disease status term as a confounder, the associations between relevant change in depression and change in physical activity, and persistent depression and incident excessive alcohol use remained similar (data not shown). 


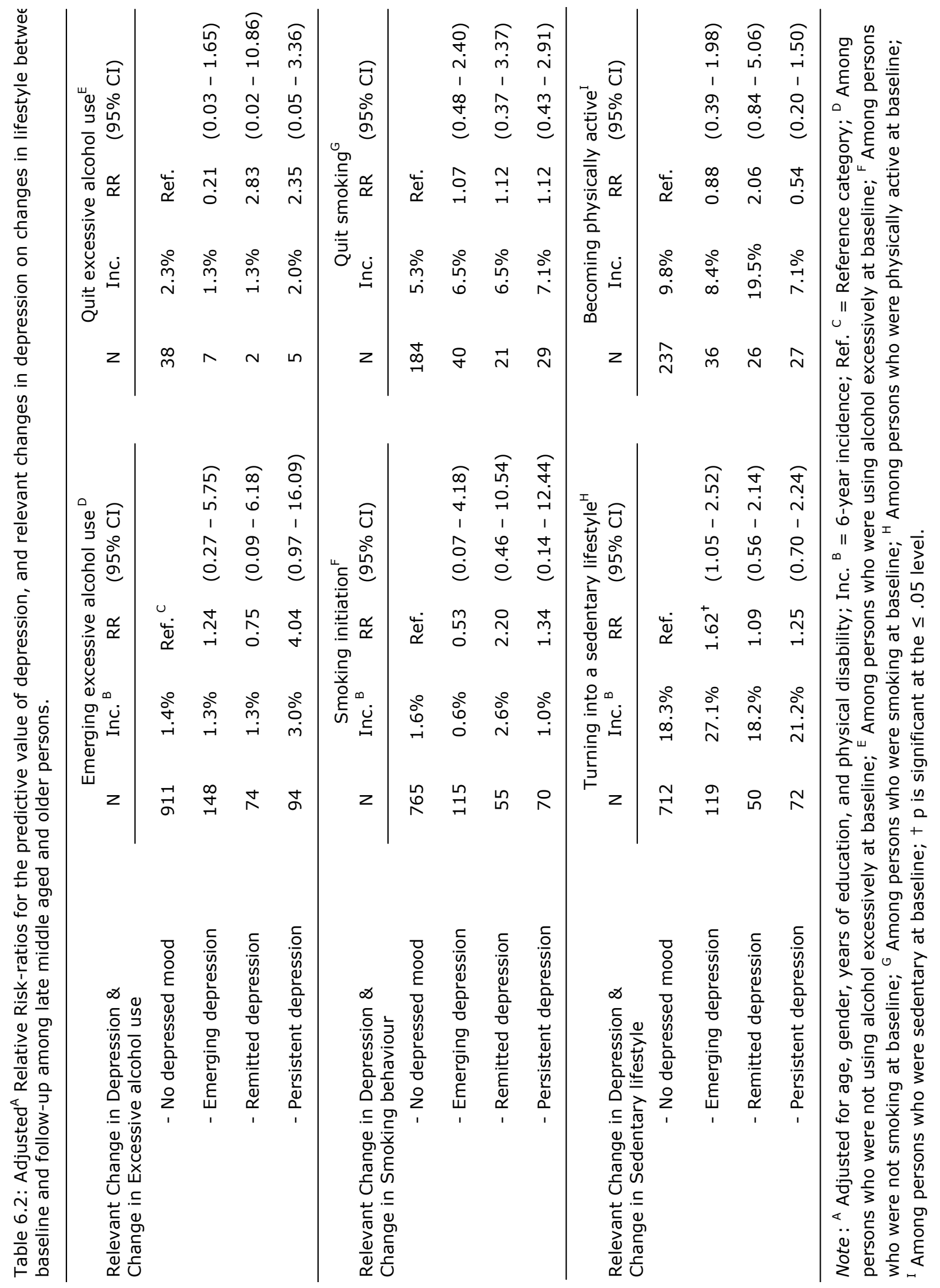


Figure 6.1: Change in number of cigarettes across depression groups among smokers over a six-year period $(\mathbf{N}=176) *$

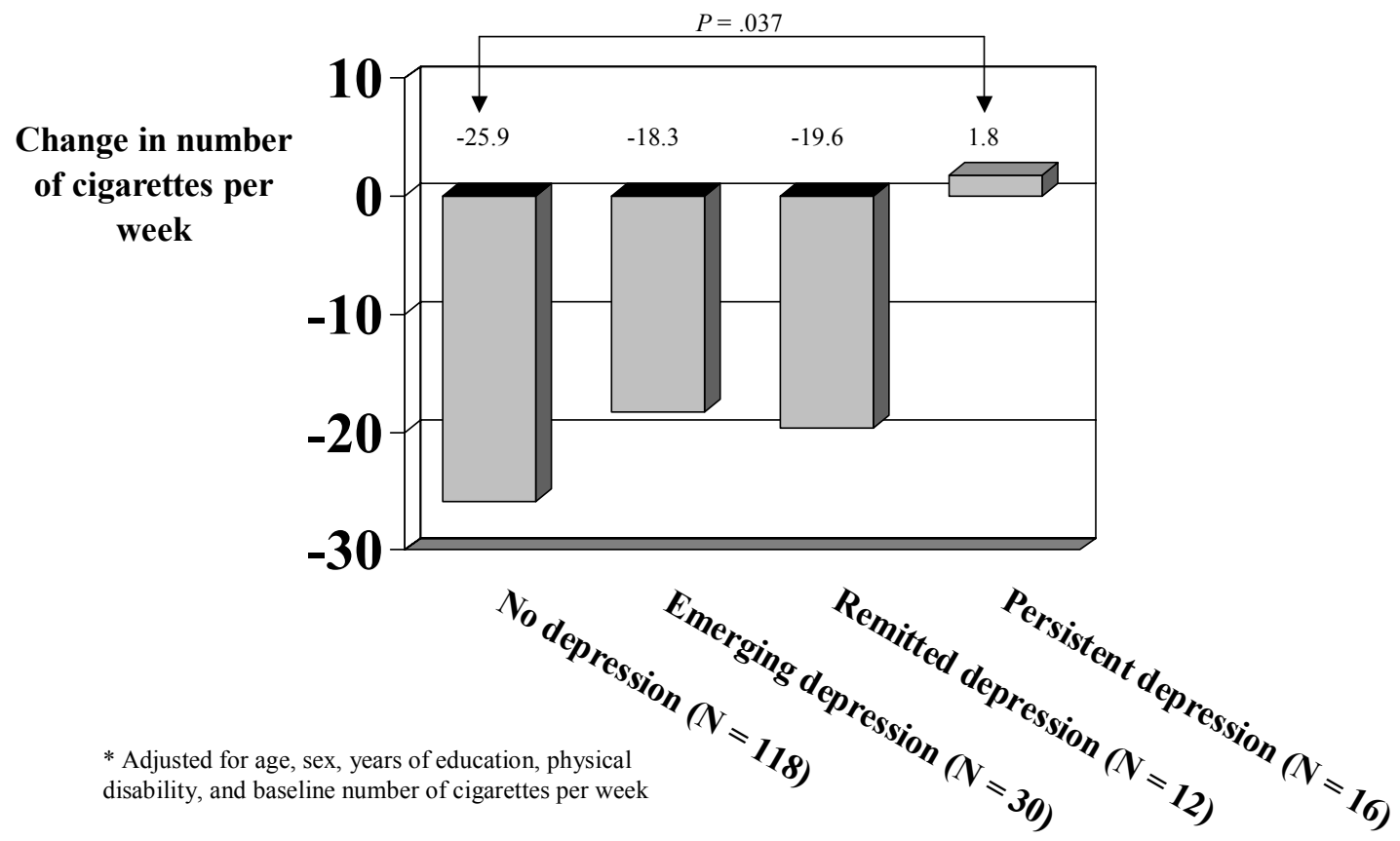

Figure 6.2: Change in minutes of physical activity across depression groups over a six-year period $(\mathbf{N}=1279) * *$

Change in minutes of physical activity per day
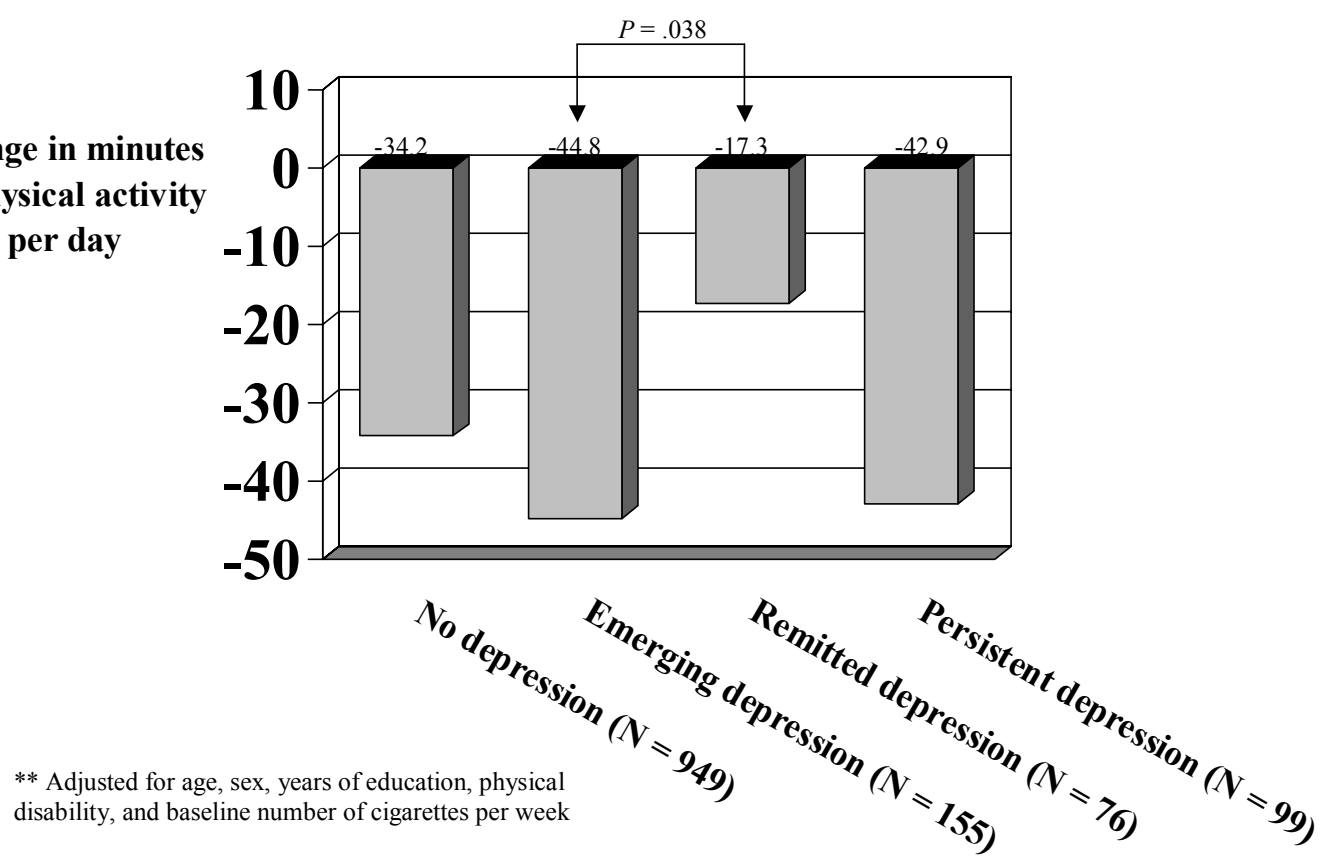
MANOVA demonstrated that persistent depression was associated with an increase in cigarette consumption of nearly two per week, while no depressed mood was associated with a decrease per week of nearly 26 cigarettes over a six-year period (Figure 6.1). The average decrease in cigarettes per week in the total - smoking - sample was $21.9(N=176 ; p$ $\leq .001)$. Analyses were adjusted for above-mentioned covariates and baseline cigarette consumption. In addition, an emerging depressed mood was associated with a nearly 45 minutes decrease in physical activity per day, while a remitted depressed mood was associated with a decrease of 'only' 17.3 minutes in physical activity per day over a six-year period (Figure 6.2). Analyses were adjusted for above-mentioned covariates and baseline minutes of physical activity. The average decrease in minutes of physical activity per day in the total sample was 33.5 minutes $(N=1279 ; p \leq .001)$. No multivariate analyses were performed for (change in) depression and change in alcohol use, for there was no continuous measure of alcohol use available.

\subsection{Discussion}

We studied the association between depression and lifestyle in a sample of Dutch late middle aged and older adults over a six-year period. We found a significant cross-sectional association between depression and smoking behavior at baseline, which was independent of chronic somatic disease status. Longitudinally, depression at baseline proved not to be predictive of changes in lifestyles later on. Although statistically non-significant, persistent depressed persons were at a four-fold likelihood of incident excessive alcohol use, compared to never depressed people. In addition, persons with an emerging depression were significantly more likely to concurrently adopt a sedentary lifestyle, irrespective of their somatic disease status, as there were no significant interaction effects, nor were there any confounding effects of chronic somatic disease status.

The fact that we found a cross-sectional association between depression and smoking is in concordance with most of the literature of the past decade [e.g., 15, 33]. MANOVA demonstrated that persistent depressed smokers, compared to never depressed smokers, seem unable or are less often motivated to decrease cigarette consumption over a six-year period. Here, 
longitudinal data support cross-sectional findings. One of the consequences of smoking is vascular disease. The association between depression and smoking may be one of the pathways through which depression and vascular disease are related. This is in support of the theory of vascular depression, in which there is a supposed link between cerebrovascular disease and manifestation of a specific subtype of depression arising in late life [e.g., 34].

Noteworthy is the apparent effect of depression on physical activity. People with an emerging depression tended to change more often to a sedentary lifestyle than people without a depression, while people with a remitted depression tended to become physically active compared to people without a depression (reference group). In addition, difference in change in minutes of physical activity is largest between the groups with emerging depression and remitted depression. It seems that our results and the literature are in line, regarding physical activity's antidepressant effect [e.g., 14, 35-37], but the inference of depression being a risk factor for simultaneous physical inactivity cannot be made on the base of our results.

A limitation of the present study is the considerable attrition (58.8\%). In addition, the fact that people who were lost to follow-up were more often male, older, and more likely to have a chronic disease, puts the generalization of the results at risk. However, if any, we believe that attrition would have an underestimating effect on our associations instead of an overestimation of reported associations. Moreover, Kempen and Van Sonderen [38] demonstrated that attrition's effect is more disturbing for descriptive results than for measures of (longitudinal) association.

Another limitation pertains to the fact that incidences of 'quit excessive alcohol use' and 'smoking initiation' are low, causing very small sub groups. Consequently, reliability of logistic regression coefficients regarding these variables is rather low. However, additional analyses of continuous data relieve that limitation regarding smoking. A last limitation pertains to the fact that most important results of this study were derived from cross-sectional analyses, or analyses of congruence of change. These analyses cannot disentangle the direction of association, and hence, results cannot be interpreted in any causal way. 
Summarizing, one can put that, in this study depression, although not referring to a clinical diagnosis, but rather to clinically relevant depressive symptoms, is associated with smoking behavior, irrespective of chronic somatic disease status. In addition, persistent depression tends to be associated with incident excessive alcohol use. The emergence of depression shows congruence with changing into a sedentary lifestyle, irrespective of chronic somatic disease status. However, no causal relation can be demonstrated, since the analyses relate to simultaneous changes. Our study showed consistent results from different designs. Depression was associated with smoking behavior cross-sectionally (Logistic regression), but change in depression was associated with change in smoking behavior (MANOVA) as well. Typically, this is one of the major advantages of a longitudinal study over a cross-sectional one.

We have shown that emergence of depression goes together with developing a sedentary lifestyle. Clearly, clinical practice can benefit from this line of study if further research can clarify whether treatment of depressive symptoms can prevent the development of sedentary lifestyles, so that both physical and mental health can be preserved. 


\subsection{References}

1. Copeland JR, Beekman AT, Dewey ME et al. Cross-cultural comparison of depressive symptoms in Europe does not support stereotypes of ageing. $\mathrm{Br}$ J Psychiatry 1999; 174: 322-9.

2. Beekman ATF, Penninx BWJH, Deeg DJH, Ormel J, Braam AW, Van Tilburg W. Depression and physical health in later life: results from the Longitudinal Aging Study Amsterdam (LASA). J Affect Disord 1997; 46: 219-31.

3. Mayou RA. Depressive mood and type of physical disorder and treatment. In: MM Robertson, CLE Katona (editors). Depressive mood and Physical Illness. London: Wiley; 1997: p. 21-38.

4. Cohen S, Rodriquez MS. Pathways linking affective disturbances and physical disorders. Health Psychol 1995; 14: 374-80.

5. Mayou RA, Sharpe M. Psychiatric illnesses associated with physical disease. Bailliere's Clin Psychiatry 1995; 1: 2.

6. Lebowitz BD, Pearson JL, Schneider LS et al. Diagnosis and treatment of depression in late life. Consensus statement update. JAMA 1997; 278: 1186-90.

7. Haynes RB, McKibbon KA, Kanani R. Systematic review of randomized trials of interventions to assist patients to follow prescriptions for medications. Lancet 1996; 348: 383-6.

8. Klatsky AL. Alcohol, coronary disease, and hypertension. Annu Rev Med 1996;47:149-60.

9. Francis K. Physical activity in the prevention of cardiovascular disease. Phys Ther. 1996;76:456-468.]

10. Penninx BWJH, Beekman ATF, Honig A et al. Depression and cardiac mortality: results from a community-based longitudinal study. Arch Gen Psychiatry 2001; 58: 221-7.

11. Jonas BS, Franks P, Ingram DD. Are symptoms of anxiety and depression risk factors for hypertension? Longitudinal evidence from the National Health and Nutrition Examination Survey I Epidemiologic Follow-up Study. Arch Fam Med 1997 Jan-Feb;6(1):43-9.

12. Perenboom RJM, Van Herten, LM, Boshuizen HC, Van de Water HPA. Trends in de gezonde levensverwachting in Nederland 1983-1994, met een verdeling naar de ernst van ongezondheid [Trends in healthy life-expectancy in the Netherlands 1983-1994, stratified by ill health]. In: PJM Van der Maas, PGN Kramers (editors). Volksgezondheid; Toekomstverkenning 1997, deel III Gezondheid en levensverwachting gewogen [Public health; future scenario 1997, Volume III Health and weighted life expectancy]. Maarssen: Elsevier; 1997: p. 53-77.

13. Katz IR. On the inseparability of mental and physical health in aged persons: lessons from depression and medical comorbidity. Am J Geriatr Psychiatry 1996; 4: 1-16.

14. Kempen GIJM, Verbrugge LM, Merril SS, Ormel J. The impact of multiple impairments on disability in community-dwelling older people. Age Ageing 1998; 27: 595-604.

15. Breslau N, Peterson EL, Schultz LR, Chilcoat HD, Andreski P. Major depression and stages of smoking. A longitudinal investigation. Arch Gen Psychiatry 1998; 55: 161-6. 
16. Anda RF, Williamson DF, Escobedo LG, Mast EE, Giovino GA, Remington PL. Depression and the dynamics of smoking. A national perspective. JAMA 1990; 264: 1541-5.

17. Deeg, D.J.H., Knipscheer, C.P.M., Van Tilburg, W., editors. Autonomy and Well- being in the Aging Population: Concepts and Design of the Longitudinal Aging Study Amsterdam. NIG Trendstudies No.7. Bunnik: Netherlands Institute of Gerontology; 1993.

18. Smit, J.H., de Vries, M.Z., Poppelaars, J.L. Data-collection and fieldwork procedures. In: D.J.H. Deeg, A.T.F. Beekman, D.M.W. Kriegsman, M. Westendorp-de Serière, editors. Autonomy and Well-being in the aging population II: Report from the Longitudinal Aging Study Amsterdam 1992-1996. Amsterdam: VU University Press; 1998: p. 9-20.

19. Penninx, B.W., Deeg, D.J.H., Van Eijk, J.Th. M., Beekman, A.T.F., Guralnik, J.M. Changes in depression and physical decline in older adults: a longitudinal perspective. J Affect Disord, 2000; 61: 1-12.

20. Radloff, L.S. The CES-D scale: A self-report depressive mood scale for research in the general population. App Psychol Meas, 1977; 1: 385-401.

21. Beekman, A.T., Deeg, D.J.H., Van Limbeek, J., Braam, A.W., De Vries, M.Z., Van Tilburg, W. Criterion validity of the Center for Epidemiologic Studies Depression scale (CES-D): results from a community-based sample of older subjects in The Netherlands. Psychol Med, 1997; 27: 231-5.

22. Kennedy, G.J., Kelman, H.R., Thomas, C. Persistence and remission of depressive symptoms in late life. Am J Psychiatry $1991 ; 148: 174-8$.

23. Statistics Netherlands. Health interview questionnaire. Heerlen, The Netherlands: Central Bureau of Statistics; 1989.

24. Visser, M., Launer, L. J., Deurenberg, P., Deeg, D. J. Total and sports activity in older men and women: relation with body fat distribution. Am J Epidemiol, 1997; 145: 752-61.

25. Caspersen, C.J., Bloemberg, B.P.M., Saris, W.H.M., Merrit, R.K., Kromhout, D. The prevalence of selected physical activities and their relation with coronary heart disease risk factors in elderly men: the Zutphen Study, 1985. Am J Epidemiol, 1991; 133: 107892.

26. Voorrips, L.E., Ravelli, A.C., Dongelmans, P.C., Deurenberg, D., Van Staveren, W.A. A physical activity questionnaire for the elderly. Med Sci Sports Exerc, 1991; 23: 974-9.

27. Van Sonsbeek, J.L.A. Methodische en inhoudelijke aspecten van de OESO- indicator betreffende langdurige beperkingen in het lichamelijk functioneren [Methodological and substantial aspects of the OECD indicator of chronic functional limitations]. Maandbericht Gezondheid [Statistics Netherlands], 1988; 88: 4-17.

28. Kriegsman DM, Deeg DJH, Van Eijk JThM, Penninx BWJH, Boeke AJ. Do disease specific characteristics add to the explanation of mobility limitations in patients with different chronic diseases? A study in the Netherlands. J Epidemiol Community Health 1997; 51: 676-85.

29. Aneshensel CS, Yokopenic PA. Tests for the comparability of a causal model of depression under two conditions of interviewing. J Pers Soc Psychol 1985; 49: 1337-48. 
30. Guccione AA, Felson DT, Anderson JJ et al. The effects of specific medical conditions on the functional limitations of elders in the Framingham Study. Am J Public Health 1994; 84: 351-8.

31. Midanik LT, Clark WB. The demographic distribution of US drinking patterns in 1990: description and trends from 1984. Am J Public Health 1994; 84: 1218-22.

32. Kriegsman DM, Penninx BWJH, Van Eijk JThM, Boeke AJ, Deeg DJH. Self-reports and general practitioners information on the presence of chronic diseases in communitydwelling elderly. A study of accuracy of patients' self-reports and on determinants of accuracy. J Clin Epidemiol 1996; 49: 1407-17.

33. Kandel DB, Davies M. Adult sequelae of adolescent depressive symptoms. Arch Gen Psychiatry 1986; 43: 255-62.

34. Baldwin RC, O'Brien J. Vascular basis of late-onset depressive disorder. Br J Psychiatry 2002; 180; 157-60.

35. Dunn AL, Trivedi MH, O'Neal HA. Physical activity dose-response effects on outcomes of depression and anxiety. Med Sci Sports Exerc 2001; 33 (Suppl): S587-97.

36. Camacho TC, Roberts RE, Lazarus NB, Kaplan GA, Cohen RD. Physical activity and depression: evidence from the Alameda County Study. Am J Epidemiol 1991; 134: 22031.

37. Singh NA, Clements KM, Singh MA. The efficacy of exercise as a long-term antidepressant in elderly subjects: a randomized, controlled trial. J Gerontol A Biol Sci: Med Sci 2001; 56: M497-504.

38. Kempen GIJM, Van Sonderen E. Psychological attributes and changes in disability among low-functioning, older persons: does attrition affect the outcomes? J Clin Epidemiol 2002, 55: 224-9.

\subsection{Acknowledgement}

The Longitudinal Aging Study Amsterdam is partly funded by the Ministry of Health, Welfare, and Sports of the Netherlands. 
CHAPTER $7^{*}$

\title{
Impact of depression on disablement in late middle aged and older persons
}

\author{
Results from the Longitudinal Aging Study Amsterdam
}

Coen H. van Gool, Gertrudis I.J.M. Kempen, Brenda W.J.H. Penninx, Dorly J.H. Deeg, Aartjan T.F. Beekman, Jacques Th.M. van Eijk

\begin{abstract}
The main pathway of the disablement process consists of four consecutive phases: Pathology (presence of disease / injury), Impairments (dysfunctions / structural abnormalities), Functional Limitations (restrictions in basic physical / mental actions), and Disability (difficulty doing Activities of Daily Life (ADL)). This study determines the presence of the main pathway of disablement in a cohort aged 55 years and older, and examines whether progression in the main pathway of disablement is accelerated in the presence of depression. Based on baseline (T1) and two three-year follow-up interviews (T2 \& T3) from the Longitudinal Aging Study Amsterdam (LASA) in a population-based cohort of 1110 Dutch persons, we first analysed the intermediate effect of the different consecutive phases of the disablement process by means of multiple regression, adjusted for covariates. Then, depression was used as interaction term in multiple regression analyses linking the consecutive phases of the disablement process. We found that Impairments mediated the association between Pathology and Functional Limitations, and that Functional Limitations mediated the association between Impairments and Disability. Depression significantly modified the associations between Pathology and subsequent Impairments, and between Functional Limitations and subsequent Disability. In sum, the main pathway of the disablement process was identified in our sample. In addition, we found an accelerating effect of depression, particularly in the early and late stages of the model. Reduction of depression may help slow down the process of disablement for persons who find themselves in those stages of the model.
\end{abstract}

Key words: disablement process, depressive symptoms, longitudinal studies.

\footnotetext{
${ }^{*}$ As published in Social Science \& Medicine 2005; 60 (1): 25-36.
} 


\subsection{Introduction}

$D$ ue to the aging of the population and the fact that improvements in medical technology will decrease the mortality of chronic diseases among patients, the prevalence of late middle aged and older people with chronic diseases will increase dramatically (Ruwaard \& Kramers, 1997; Van Eijk \& De Haan, 1998; World Health Organization \& Food and Agriculture Organization, 2003). Although long duration is typical for chronic diseases, there are differences in disease course and in disease severity, as well as in the physical and psychosocial burden they can impose on people (Rolland, 1987; Penninx, 1996; Kempen, Ormel, Brilman, \& Relyveld, 1997). Having a chronic disease and additional impairments may have consequences for the physical performance and adequacy of social and role functioning of an individual. This trajectory from disease to the inability of performing certain roles can be viewed as the disablement process (Verbrugge \& Jette, 1994). The main pathway of the disablement process consists of four consecutive phases: pathology (presence of disease) may lead to impairments (anatomic and structural abnormalities), which in turn may precipitate functional limitations (restrictions in basic physical and mental actions), which then may lead to disability (difficulty doing activities of daily life; cf. Figure 7.1; Verbrugge \& Jette, 1994; Lawrence \& Jette, 1996). There are risk factors, intra-individual factors, and extra-individual factors interacting with the main pathway during its entire course, potentially accelerating or slowing down the process of disablement. In practice, the associations between the four main phases are reciprocal and intertwining because of feedback loops, as, for example, disability may cause new, additional pathology (Verbrugge \& Jette, 1994).

Depressed medically ill patients are more likely to experience a higher burden of disease-specific symptoms than their non-depressed counterparts (Ciechanowski, Katon, \& Russo, 2000). Depressive symptoms have also been found to predict disability (Armenian, Pratt, Gallo, \& Eaton, 1998) and to influence functional recovery after fall-related injury in older persons (Kempen, Sanderman, Scaf-Klomp, \& Ormel, 2003). Other evidence suggests that depression and disability mutually contribute to the other's risk over time (Bruce, 2000; Geerlings, Beekman, Deeg, Twisk, \& Van Tilburg, 2001; Ormel, Rijsdijk, Sullivan, van Sonderen, \& Kempen, 2002). Considering the above, it 
Figure 7.1: The main pathway of the disablement process and influencing factors, adapted from Verbrugge and Jette (1994).
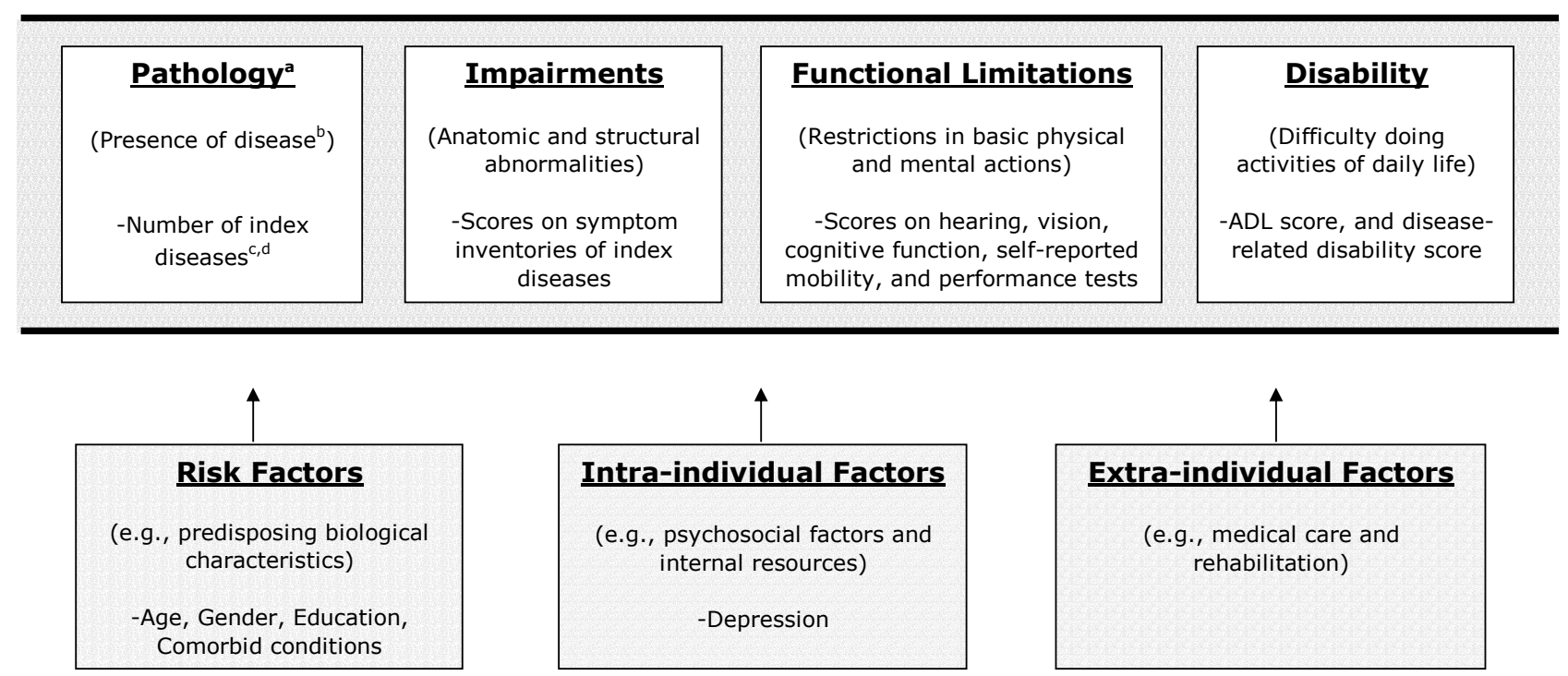

${ }^{a}$ The phases of the main pathway of the disablement process and influencing factors are underlined; ${ }^{b}$ Examples of the practical contents of the phases of disablement are between brackets; ${ }^{\mathrm{c}}$ The way the disablement phases were operationalised in the present study are in Italics; ${ }^{d}$ Index diseases include chronic non-specific lung disease (CNSLD), heart disease, (peripheral) arterial disease, diabetes, osteo- and rheumatic arthritis.

seems that people with chronic diseases carry a double burden when they experience depressive symptoms, as these may aggravate conditions (National Academy on an Aging Society, 2000). This can have adverse consequences for the course of their disablement process.

Although the associations between depression and the separate phases of disablement have been studied in different samples before, either crosssectionally (Kempen, Verbrugge, Merrill, \& Ormel, 1998; Kim, Kunik, Molinari, Hillman, Lalani, Orengo, et al., 2000), or longitudinally (Ormel, Vonkorff, Oldehinkel, Simon, Tiemens, \& Ustun, 1999) to date, the association between depression and phases of disablement has not been studied from a longitudinal perspective in a population-based sample.

Therefore, in this paper we focus on the following research objectives. First, can the main pathway of the disablement process be identified in a sample of Dutch late middle aged and older persons over a six-year period? And second, does depression, defined as an intra-individual factor influencing the main pathway, accelerate the process of disablement? In other words: are associations between two consecutive phases of the disablement process over a three-year period stronger for those who are depressed than for those who are not? 


\subsection{Methods}

\section{Design and Study population}

The Longitudinal Aging Study Amsterdam (LASA) is a cohort-study on predictors and consequences of changes in well-being and autonomy in the late middle aged and older population. Sampling, data collection procedures, and non-response have been reported in detail elsewhere (Van den Heuvel, Smits, Deeg, \& Beekman, 1996; Penninx, Deeg, van Eijk, Beekman, \& Guralnik, 2000). In short, a random sample, stratified by age and gender, was drawn from the population registers of 11 municipalities, divided over three geographic regions in the Netherlands. Initially, 3107 respondents, aged 55-85 years, were enrolled in the study. The baseline cycle took place in 1992 and 1993 (T1). After approximately three and six years, respondents were approached for first (T2) and second follow-up (T3), respectively (Lan, Deeg, Guralnik, \& Melzer, 2003). Between T1 and T3, 766 (24.6\%) respondents had died, $288(9.3 \%)$ could not be contacted (moved, etc.), $217(7.0 \%)$ refused participation, $102(3.3 \%)$ respondents were unable to participate due to cognitive or physical impairments, and 100 (3.2\%) respondents were excluded due to terminated interviews or shortened versions of the interview, leaving $1634(52.6 \%)$ respondents with valid data. We then selected respondents with no missing values on all relevant variables to monitor intra-individual changes in the disablement process. The largest subsequent attrition was on the composite variable of functional limitations, where 298 (9.6\%) respondents had one or more missing values. In addition, 226 (7.3\%) respondents had one or more missing values on other relevant variables, leaving, finally, a study sample of 1110 (35.7\%) healthy and (chronically) diseased respondents.

\section{Measurements}

In this study, the first phase of the disablement process, pathology, was based on number of self-reported diseases (Kriegsman, Penninx, van Eijk, Boeke, \& Deeg, 1996), ranged from 0 to 6 , and was assessed at all three data collection cycles. For a strict interpretation of Verbrugge \& Jette's main pathway of the disablement process (1994), we only included those chronic diseases, hereafter called index diseases, of which a symptom inventory was included in the medical interview. Respondents were asked whether or not 
they have a certain disease. The list of index diseases was summed and included chronic non-specific lung disease (CNSLD), heart disease, arterial disease, diabetes, osteo- and rheumatic arthritis. Reported diseases at baseline were checked with respondents' general practitioners. Cohen's Kappa's for concordance between patient and general practitioner compared to non-patient and general practitioner ranged from 0.31 for osteoarthritis, and 0.59 CNSLD, to 0.69 for heart disease, and 0.85 for diabetes (Kriegsman, Penninx, van Eijk, et al., 1996).

Impairments were assessed using symptom inventories of the index diseases at all three data collection cycles (Kriegsman, Deeg, van Eijk, Penninx, \& Boeke, 1997). The symptom inventory of CNSLD consisted of 8 questions about the frequency of coughing, coughing up phlegm, wheezing, shortness of breath, and the quality of the respondents' night's rest regarding the disease. Scores ranged from 0 to 11 , with higher scores indicating more CNSLD-related impairments. The symptom inventory of heart disease consisted of 5 questions about the frequency of chest pains, and how fast these pains disappear, swollen feet at getting up and going to bed, and the use of extra pillows at night. Scores ranged from 0 to 6 , with higher scores indicating more heart disease-related impairments. The symptom inventory of arterial disease consisted of 3 questions about pain experienced when walking, and whether this pain disappears when stopping walking. Scores ranged from 0 to 4 , with higher scores indicating more arterial disease-related impairments. The symptom inventory of diabetes consisted of 6 questions about the frequency of chest pains, pain experienced when walking, and whether this pain disappears when stopping walking. Scores ranged from 0 to 8 , with higher scores indicating more diabetes-related impairments. The combined symptom inventory of osteo- and rheumatoid arthritis consisted of 12 questions about the frequency of pain, stiffness, and swelling of joints, and the prevalence of arthritic symptoms in a list of joints. Scores ranged from 0 to 12, with higher scores indicating more arthritis-related impairments. Detailed information on disease-specific symptom inventories was published earlier (Kriegsman, Deeg, van Eijk, et al., 1997). Because the range of disease-specific symptom inventories was not equal across diseases, individual sum scores per symptom inventory were standardized using the formula in Figure 7.2. The impairments 
Figure 7.2: Formula used to standardize variables.

Individual or raw score on variable
Lower limit of (theoretical) score range of variable

(Theoretical) score range of variable

sum score thus ranged, theoretically, from 0 to 5, with higher scores indicating more impairments relating to the index diseases.

Functional limitations were assessed at all three data collection cycles using information on hearing, vision (Van Sonsbeek, 1988), cognitive functioning (Mini Mental State Examination (MMSE); Folstein, Folstein, \& McHugh, 1975), self-reported mobility (Van Sonsbeek, 1988), and physical performance tests (Magaziner, 1991). Questions regarding vision were 'Can you read the fine print in a newspaper without glasses?' and 'Can you recognize someone's face at a four meter distance without glasses?' (yes, without difficulty / yes, with some difficulty / yes, with much difficulty /no, I cannot). Questions regarding hearing were 'Can you understand a conversation between three or four persons without a hearing device?' and 'Can you hold a conversation with one person without a hearing device?' (yes, without difficulty / yes, with some difficulty / yes, with much difficulty /no, I cannot). Scores for hearing and vision, separately, ranged from 0 to 6 , with higher scores indicating more difficulty seeing or hearing. Cognitive function was assessed by the MMSE. After linear transformation of initial sum scores, scores ranged from 0 to 30 with higher scores indicating reduced cognitive function. Questions regarding self-reported mobility limitations were 'Can you go up and down a flight of 15 stairs without stopping?', and 'Can you walk for five minutes outside the house?', respectively (yes, without difficulty / yes, with some difficulty / yes, with much difficulty / yes, but only with help / no, I cannot). Scores were summed and ranged from 0 to 8 , with higher scores indicating more limitations in self-reported mobility. Physical performance tests included three subtests; walking six meters, five chair stands not using arms, and putting on and taking off a cardigan (Penninx, Deeg, van Eijk, et al., 2000). On the subtests, time needed was scored according to quartiles of the time required in the study sample, so that the fastest quartile scored 0 and the 
slowest quartile scored 3. Persons who were not able to perform a subtest scored 4 for that particular subtest. Overall functional limitations were computed by standardizing outcomes on vision, hearing, cognitive function, self-reported mobility, and performance subtests using the aforementioned formula in Figure 7.2, added up, and ranged from 0 to 7, with higher scores indicating more functional limitations.

Disability was assessed at all three data collection cycles using items of two self-reported disability measurement scales. The first was a disability scale that was previously validated in the Netherlands (Van Sonsbeek, 1988; Kriegsman, Deeg, van Eijk, et al., 1997). Respondents answered questions about difficulties in doing activities of daily living (ADL), such as, clipping their own toenails, dressing, and using transportation (yes, without difficulty / yes, with some difficulty / yes, with much difficulty / yes, but only with help / no, I cannot). Sum scores ranged from 0 to 12 , and higher scores indicated more disability. Furthermore, disability was assessed using a composite variable on self-report information to what extent respondents' disease(s) or health problem(s) limited their daily activities (adapted from Stewart, Hays, \& Ware, 1988). Respondents answered questions about 'Do health problems limit your daily activities?' (no / yes, somewhat / yes, very much), 'How long have health problems limited your daily activities?' (more / less than three months), 'How many days during the past month did you have to stay in bed due to (an) illness?' and 'How many days during the past month were you unable to do your daily activities due to (an) illness?' (none / 1-3 days / 4-7 days / >1 week, $<1$ month / all of the time). Scores ranged from 0 to 16 with higher scores indicating more disability. Both disability scores correlated 0.44 at baseline, and were then standardized using the aforementioned formula, added up, and ranged from 0 to 2 , with higher scores indicating more overall disability.

Depression was assessed using the Center for Epidemiologic Studies Depression (CES-D) scale at all three data collection cycles (Radloff, 1977). This 20-item self-report scale was designed for epidemiologic research purposes in the general population and has proven good psychometric qualities, for instance in the Netherlands (Beekman, van Limbeek, Deeg, Wouters, \& van Tilburg, 1994). Scores ranged from 0 to 60 , with higher scores 
indicating more depressive symptoms. We used the CES-D's widely accepted cut-off score of $\geq 16$ (Kennedy, Kelman, \& Thomas, 1990; Beekman, Deeg, van Limbeek, Braam, de Vries, \& van Tilburg, 1997; Penninx, Deeg, van Eijk, et al., 2000) to indicate clinically significant depressive symptoms, hereafter called depression.

Potentially confounding covariates are age, gender - derived from municipal registers -, and educational level. The latter was obtained through self-report, and ranged from 1 (did not finish elementary school) to 9 (finished university). Reported diseases that were not one of the index diseases were scored as comorbid conditions and ranged from 0 to 4 .

\section{Statistical Analyses}

Following attrition analyses, and descriptive sample analyses, we examined correlations within $\mathrm{T} 1$, and between $\mathrm{T} 1, \mathrm{~T} 2$, and $\mathrm{T} 3$ variables of the main pathway of the disablement process to gain insight in our suggested model.

Subsequently, we conducted multivariate linear regression analyses on separate phases of the main pathway of the disablement process to establish identification of our model (Figure 7.3). Specifically, part of the effect of 'Pathology $\mathrm{T} 1$ ' on 'Functional Limitations T3' is considered to go through 'Impairments $\mathrm{T}^{2}$ ' if the main effect, defined as the standardized regression coefficient, of 'Pathology $\mathrm{T} 1$ ' on 'Functional Limitations T3' (transitions ' 1 ' \& '4' in Figure 7.3) diminishes with at least $10 \%$, as a rule of thumb (Baron \& Kenny, 1986), when entering 'Impairments $\mathrm{T}^{2}$ ' in the regression model. This analysis is adjusted for covariates and 'change in Pathology between T1 and T3'. Similarly, part of the effect of 'Impairments T1' on 'Disability T3' goes through 'Functional Limitations $\mathrm{T}^{2}$ ' if the standardized regression coefficient of 'Impairments $\mathrm{T} 1$ ' on 'Disability T3' (transitions ' 3 ' \& ' 6 ' in Figure 7.3) diminishes with at least $10 \%$ when entering 'Functional Limitations $\mathrm{T} 2$ ' in the regression model. This regression analysis is adjusted for covariates and 'change in Impairments between T1 and T3'.

Verbrugge and Jette (1994) defined depression as an intra-individual factor influencing the main pathway. In order to test this assumption, we conducted multivariate linear regression analyses to examine the influence of 
Figure 7.3: Model for the analyses of the main pathway of the disablement process.

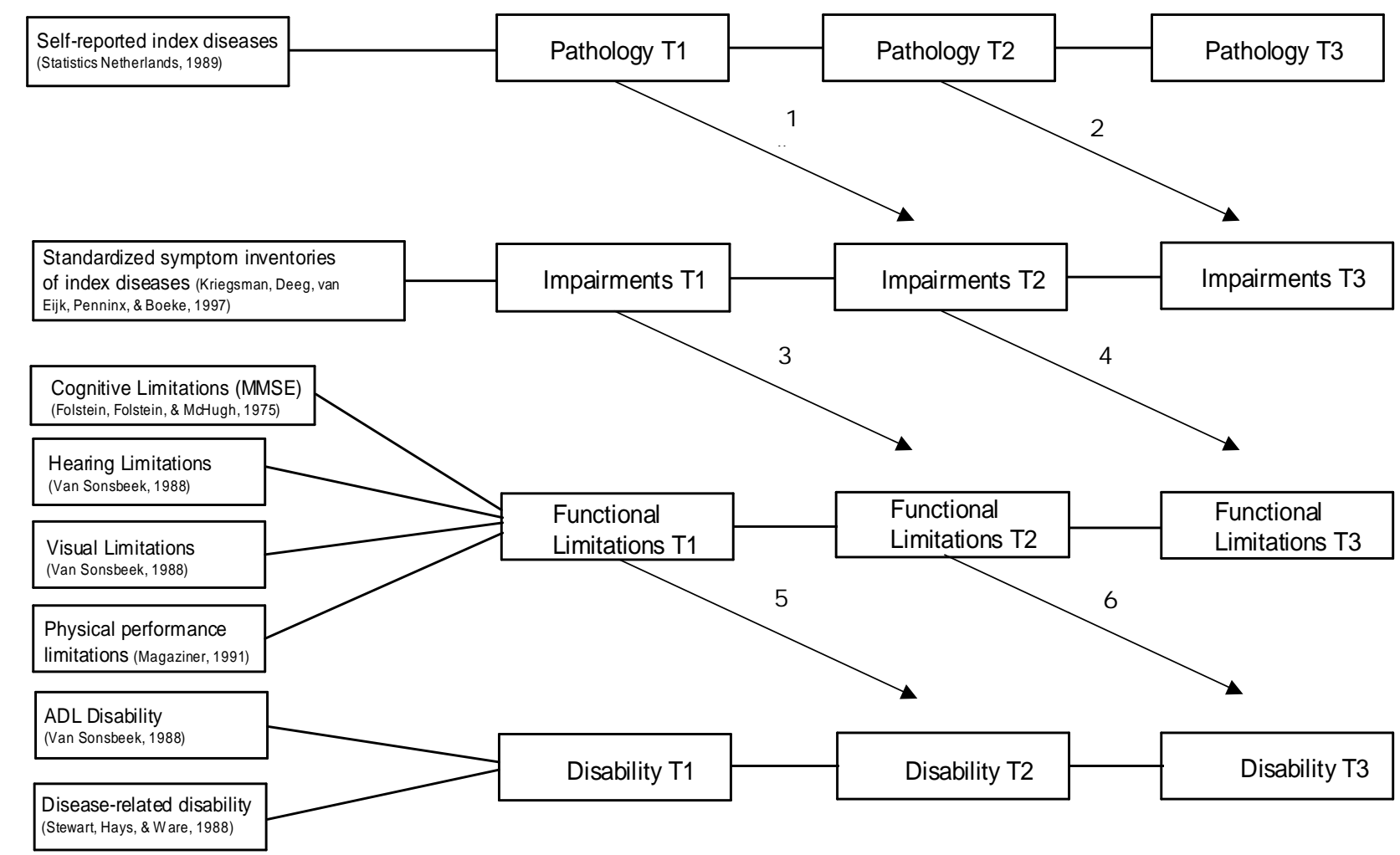

a Transitions (1) through (6) correspond with sequence of analyses of model identification, and analyses of interaction.

depression on associations between two consecutive phases in the disablement process. We wanted to rule out the advanced effects of depression and the independent variable on the dependent variable by including their change scores between two consecutive phases in the regression model. Thus, in regression analysis with 'I mpairments T2' as dependent variable and 'Pathology $\mathrm{T} 1$ ' as independent variable, we adjusted for covariates and 'change in Pathology between T1 and T2', and 'change in depression between T1 and T2'. Also, we entered 'depression T1' and the product term 'depression T1 X Pathology T1'. If this product term proves statistically significant, the association between Pathology T1 and Impairments T2 is different for depressed respondents at baseline compared to non-depressed respondents at baseline. We examined this for all consecutive phases of the main pathway of the disablement process (transitions ' 1 ' through ' 6 ' in Figure 7.3). The unstandardized regression coefficients of the significant interaction terms were explored in detail, in order to compare transitions with similar variables. The variance inflation factor (VIF) was used to measure collinearity in all regression models. 
Table 7.1: Baseline sample characteristics, stratified by non-depressed and depressed respondents at T1.

\begin{tabular}{|c|c|c|}
\hline \multirow[t]{2}{*}{ Characteristic } & \multicolumn{2}{|c|}{$\%$ of sample, or $M(S D)$ at baseline. } \\
\hline & $\begin{array}{l}\text { Non-depressed } \\
\text { Respondents } \\
(\mathrm{N}=1025,92.3 \%)\end{array}$ & $\begin{array}{l}\text { Depressed } \\
\text { Respondents } \\
(\mathrm{N}=85 ; 7.7 \%\end{array}$ \\
\hline -Age (range 55-85) & $66.5(7.4)$ & $67.8(8.5)$ \\
\hline -Gender ${ }^{b}$ & $50.0 \%$ & $65.9 \% *$ \\
\hline -Education ${ }^{c}$ & $57.6 \%$ & $55.6 \%$ \\
\hline -Comorbid Conditions (range $0-4$ ) & $0.4(0.7)$ & $0.8(0.8) * *$ \\
\hline -CES-D score (range 0-60) & $4.8(4.1)$ & $21.8(6.9)^{* *}$ \\
\hline -Pathology (range 0-6) & $0.6(0.7)$ & $0.8(1.0)^{*}$ \\
\hline -Impairments (range 0-5) & $0.15(0.27)$ & $0.37(0.53)^{* *}$ \\
\hline -Functional Limitations (range $0-6$ ) & $1.49(0.67)$ & $1.65(0.77)^{\dagger}$ \\
\hline -Disability (range 0-2) & $0.13(0.23)$ & $0.33(0.37)^{* *}$ \\
\hline
\end{tabular}

\subsection{Results}

Analyses of attrition demonstrated that respondents who were lost to follow-up were, at baseline, significantly older, and had more pathology, more impairments, more functional limitations, were more disabled, and were more depressed than the respondents included in the analytic sample (data not shown). Table 7.1 shows baseline characteristics of the study sample stratified by depressed mood status.

Correlation coefficients within $\mathrm{T} 1$ variables of the main pathway of the disablement process were for 'Pathology': 0.77 with 'Impairments', 0.21 with 'Functional Limitations', and 0.34 with 'Disability'. Correlation coefficients for 'Impairments' were: 0.20 with 'Functional Limitations', and 0.40 with 'Disability'. Finally, the correlation coefficient for 'Functional Limitations' with 'Disability' was 0.35 (all $p$ 's $<0.001$ ).

Table 7.2 shows the correlation coefficient matrix between T1 and T2, T2 and T3, and T1 and T3 variables of the main pathway of the disablement process. Correlations between same disablement phases at different data collection cycles were all positive and statistically significant (all $p$ 's $<0.001$ ) and ranged from 0.86 for 'Pathology $\mathrm{T}^{1}$ ' and 'Pathology $\mathrm{T} 2$ ' to 0.53 for 'Disability $\mathrm{T} 1$ ' and 'Disability $\mathrm{T} 2$ '. Correlations between different, but consecutive, disablement phases at consecutive data collection cycles were all positive and statistically significant (all $p^{\prime} \mathrm{s}<0.001$ ) and ranged from 0.66 
Table 7.2: Pearson correlation coefficient matrix between selected outcomevariables $(\mathrm{N}=1110)$.

\begin{tabular}{|c|c|c|c|c|c|c|c|c|c|}
\hline & & \multicolumn{4}{|c|}{ T2 } & \multicolumn{4}{|c|}{ T3 } \\
\hline & & Pathology & Impairments & $\begin{array}{l}\text { Functional } \\
\text { Limitations }\end{array}$ & Disability & Pathology & Impairments & $\begin{array}{l}\text { Functional } \\
\text { Limitations }\end{array}$ & Disability \\
\hline \multirow{4}{*}{$\mathrm{T} 1$} & Pathology & $0.86^{\mathrm{a}}$ & 0.63 & 0.22 & 0.32 & 0.69 & 0.57 & 0.16 & 0.31 \\
\hline & Impairments & 0.70 & 0.72 & 0.20 & 0.39 & 0.58 & 0.66 & 0.14 & 0.35 \\
\hline & Funct. Lim. & 0.18 & 0.16 & 0.59 & 0.29 & 0.16 & 0.19 & 0.58 & 0.29 \\
\hline & Disability & 0.39 & 0.44 & 0.33 & 0.55 & 0.35 & 0.38 & 0.28 & 0.50 \\
\hline \multirow{4}{*}{$\mathrm{T} 2$} & Pathology & & & & & 0.83 & 0.69 & 0.23 & 0.39 \\
\hline & Impairments & & & & & 0.66 & 0.79 & 0.23 & 0.45 \\
\hline & Funct. Lim. & & & & & 0.19 & 0.17 & 0.65 & 0.36 \\
\hline & Disability & & & & & 0.37 & 0.43 & 0.38 & 0.64 \\
\hline
\end{tabular}

${ }^{a}$ All correlations coefficients were statistically significant at the $P<.001$ level.

between 'Pathology $\mathrm{T}^{2}$ ' and 'Impairments $\mathrm{T} 3$ ' to 0.22 between 'Impairments T2' and 'Functional Limitations T3'.

Results of identification of our model of the disablement process are shown in Table 7.3, demonstrating, respectively, multiple linear regression analyses summaries of the association between 'Pathology $\mathrm{T} 1$ ' and 'Functional Limitations T3', and between 'Impairments T1' and 'Disability T3'. After inclusion of 'Impairments $\mathrm{T}^{2}$ ' in the regression model (model 1-4), the main effect of 'Pathology T1' on 'Functional Limitations T3' decreased 53.1\% (see footnote Table 7.3). After inclusion of 'Functional Limitations T2' in the regression model (model 2-4), the main effect of 'Impairments $\mathrm{T} 1$ ' on 'Disability T3' decreased $13.4 \%$ (see footnote Table 7.3 ). We consider this to be significant.

Significance levels of interaction terms between depression and disablement phase in their relation to two consecutive phases of disablement, and the unstandardized beta regression coefficients for non-depressed and depressed respondents are presented in Table 7.4 and 7.5, respectively. If an interaction term for a transition is statistically significant $(p<0.05)$, this indicates that the association between two consecutive phases of the disablement process is modified by depression (Table 7.4). In what way is revealed by stratified analyses (Table 7.5). Transitions ' 1 ' ' ' 2 ', ' 5 ', and ' 6 ' proved to be significantly modified by their interaction terms with depression. 
Table 7.3: Stepwise multiple linear standardized regression analyses summaries with dependent variables Functional Limitations T3 and Disability T3, respectively $(\mathrm{N}=1110)$.

\begin{tabular}{|c|c|c|c|c|c|}
\hline Model & Predictors & $\begin{array}{l}\text { Standardized Beta } \\
\text { Coefficients }\end{array}$ & Model & Predictors & $\begin{array}{l}\text { Standardized Beta } \\
\text { Coefficients }\end{array}$ \\
\hline \multirow[t]{4}{*}{1} & Age & $0.453 * *$ & \multirow[t]{4}{*}{1} & Age & $0.292 * *$ \\
\hline & Gender & -0.034 & & Gender & $0.073^{\dagger}$ \\
\hline & Education & $-0.139 * *$ & & Education & -0.043 \\
\hline & Comorbid Conditions & $0.102 * *$ & & Comorbid Conditions & $0.172 * *$ \\
\hline \multirow[t]{5}{*}{2} & Age & $0.443 * *$ & \multirow[t]{5}{*}{2} & Age & $0.245 * *$ \\
\hline & Gender & -0.039 & & Gender & 0.044 \\
\hline & Education & $-0.137 * *$ & & Education & -0.014 \\
\hline & Comorbid Conditions & $0.095 * *$ & & Comorbid Conditions & $0.130 * *$ \\
\hline & Pathology T1 & $0.099 * *$ & & Impairments T1 & $0.311 * *$ \\
\hline \multirow[t]{6}{*}{3} & Age & $0.437 * *$ & \multirow[t]{6}{*}{3} & Age & $0.392 \dagger$ \\
\hline & Gender & -0.041 & & Gender & 0.020 \\
\hline & Education & $-0.135 * *$ & & Education & $-0.139 * *$ \\
\hline & Comorbid Conditions & $0.092 * *$ & & Comorbid Conditions & $0.112 * *$ \\
\hline & Pathology T1 & $0.107 * * b$ & & Impairments $\mathrm{T} 1$ & $0.395 * * \mathrm{c}$ \\
\hline & $\Delta^{\mathrm{a}}$ Pathology T3-T1 & $0.061^{\dagger}$ & & $\Delta^{\mathrm{a}}$ Impairments T3-T1 & $0.327^{* *}$ \\
\hline \multirow[t]{7}{*}{4} & Age & $0.439 * *$ & \multirow[t]{7}{*}{4} & Age & $0.162 * *$ \\
\hline & Gender & -0.049 & & Gender & 0.013 \\
\hline & Education & $-0.133 * *$ & & Education & 0.017 \\
\hline & Comorbid Conditions & $0.087 *$ & & Comorbid Conditions & $0.106 * *$ \\
\hline & Pathology T1 & $0.057^{b}$ & & Impairments $\mathrm{T} 1$ & $0.358 * * \mathrm{c}$ \\
\hline & $\Delta^{\mathrm{a}}$ Pathology T3-T1 & 0.033 & & $\Delta^{\mathrm{a}}$ Impairments T3-T1 & $0.310 * *$ \\
\hline & Impairments T2 & $0.076^{\dagger}$ & & Functional Limitations T2 & $0.202 * *$ \\
\hline
\end{tabular}

${ }^{\mathrm{a}} \Delta$ Indicates a change score (new score minus old score); ${ }^{\mathrm{D}}$ After controlling for covariates, and after inclusion of the suspected intermediate variable - Impairments T2 -, the standardized Beta Pathology T1 diminished 46.7\% $(((0.107-0.057) / 0.107) \times$ $100 \%) ;{ }^{c}$ After controlling for covariates, and after inclusion of the suspected intermediate variable - Functional Limitations T2 the standardized Beta Impairments T1 diminished 9.4\% ( ((0.395-0.358) / 0.395) x 100\% );** P<.001;*P<.01; $+\mathrm{P}<.05 ;+\mathrm{P}<.10$.

Transitions ' 3 ' and ' 4 ' turned out not to be modified significantly by their interaction terms with depression.

The significant interaction terms regarding the effect of 'Pathology $\mathrm{T} 1$ ' on 'Impairments $\mathrm{T2}$ ', and 'Pathology $\mathrm{T2}$ ' on 'Impairments $\mathrm{T3}$ ' indicate that the impact of pathology on impairments is different for non-depressed respondents compared to their depressed counterparts. Analogously, the significant interaction terms regarding the effect of 'Functional Limitations $\mathrm{T} 1$ ' on 'Disability T2', and 'Functional Limitations T2' on 'Disability T3' indicate that the impact of functional limitations on disability is different for non-depressed respondents compared to their depressed counterparts.

Table 7.5 shows that depressed respondents had higher unstandardized beta regression coefficients on these significant associations compared to their 
Table 7.4: Statistical significancea of the interaction terms: 'depression $\mathrm{X}$ disablement phase' $(\mathrm{N}=1110)$.

\begin{tabular}{cllll}
\hline \hline Transition $^{\text {b }}$ & Independent Variable & Outcome Variable & Interaction term & $\begin{array}{r}\text { Significance of } \\
\text { Interaction }(P)\end{array}$ \\
\hline 1 & Pathology T1 & Impairments T2 & Pathology T1 X Depression T1 & .04 \\
2 & Pathology T2 & Impairments T3 & Pathology T2 X Depression T2 & $<.001$ \\
3 & Impairments T1 & Functional Limitations T2 & Impairments T1 X Depression T1 & $.57(\text { n.s. })^{\text {c }}$ \\
4 & Impairments T2 & Functional Limitations T3 & Impairments T2 X Depression T2 & .52 (n.s.) \\
5 & Functional Limitations T1 & Disability T2 & Functional Limitations T1 X Depression T1 & .002 \\
6 & Functional Limitations T2 & Disability T3 & Functional Limitations T2 X Depression T2 & $<.001$ \\
\hline \hline
\end{tabular}

${ }^{a}$ Controlled for age, gender, educational level, comorbid conditions, depression T1 or T2, depression change score T2 minus T1, or T3 minus T2, Independent Variable change score T2 minus T1, or T3 minus T2; ${ }^{\mathrm{D}}$ Transitions (1) through (6) are to be found in Figure $2{ }^{{ }^{c}}$ ( .s. ) = statistically not significant.

non- depressed counterparts. Although the difference in unstandardized beta regression regression coefficients between 'Pathology $\mathrm{T} 1$ ' and 'Impairments $\mathrm{T} 2$ ' was statistically significant, it was very small (transition ' 1 ' in Figure 7.3). The most striking discrepancy in unstandardized beta regression coefficients was found in the association between 'Functional Limitations $\mathrm{T} 1$ ' and 'Disability $\mathrm{T2}$ ' (transition ' 5 ' in Figure 7.3). For depressed respondents Functional limitations at T1 lead to almost twice as much Disability at T2 than Functional Limitations lead to disability for non-depressed respondents (unstandardized beta regression coefficients, respectively, 0.236 and 0.121 ). The variance inflation factor (VIF) was used to measure collinearity in all regression models. The highest VIF was 2.65 and therefore much lower than 10.0, and can be considered acceptable (Kleinbaum, Kupper, Muller, 1988).

Table 7.5: Unstandardized beta regression coefficients ${ }^{\mathrm{a}}$ of disablement phases on subsequent outcome variables, stratified by non-depressed and depressed respondents $(\mathrm{N}=1110)$.

\begin{tabular}{|c|c|c|c|c|}
\hline \multirow[b]{2}{*}{ Transition $^{\mathrm{b}}$} & \multirow[b]{2}{*}{ Independent Variable } & \multirow[b]{2}{*}{ Outcome Variable } & \multicolumn{2}{|c|}{ Unstandardized Beta Coefficient $(P)$} \\
\hline & & & $\begin{array}{l}\text { Non-depressed } \\
\text { Respondents }\end{array}$ & $\begin{array}{l}\text { Depressed } \\
\text { Respondents }\end{array}$ \\
\hline 1 & Pathology $\mathrm{T} 1^{\mathrm{c}}$ & Impairments $\mathrm{T} 2$ & $0.238(p<.001)$ & $0.249(p<.001)$ \\
\hline 2 & Pathology $T 2^{d}$ & Impairments T3 & $0.260(p<.001)$ & $0.345(p<.001)$ \\
\hline 5 & Functional Limitations T1 & Disability T2 & $0.117(p<.001)$ & $0.269(p<.001)$ \\
\hline 6 & Functional Limitations T2 & Disability T3 & $0.141(p<.001)$ & $0.295(p<.001)$ \\
\hline
\end{tabular}

${ }^{\text {a }}$ Controlled for age, gender, educational level, comorbid conditions, Independent Variable change score T2 minus T1, or T3 minus T2, and stratified by depressed mood status; ${ }^{b}$ Transitions (1) through (6) are to be found in Figure $2 ;{ }^{c}$ At T1 N non-depressed respondents with CES-D scores $\leq 15=1025 \& \mathrm{~N}$ depressed respondents CES-D scores $\geq 16=85{ }^{\mathrm{d}}$ At T2 $\mathrm{N}$ non-depressed respondents with CES-D scores $\leq 15=$ $1004 \& N$ depressed respondents CES-D scores $\geq 16=106$. 


\subsection{Discussion}

This paper aimed 1) to identify the main pathway of the disablement process in a sample of Dutch late middle aged and older persons over a 6-year period, and 2) to examine whether depression accelerates the process of disablement (i.e. whether associations between two consecutive phases of the disablement process are stronger for those who are depressed than for those who are not).

First, we found empirical evidence for the identification of the main pathway of the disablement process in our sample of Dutch late middle-aged and older persons. Associations between all disablement phases were positive and statistically significant, and the impact of prior disablement process variables decreased when the impact of intermediate phases were taken into account. Second, four of the six associations we examined in the main pathway were modified by depression, in the expected way. More specific, associations in the early and late phases of the process of disablement were modified by depression. This indicates acceleration in those transitions of the disablement process, at least partly, due to pre-existing depression.

Few other studies have used the disablement process to attain a comprehensive view on the course of a specific disease, e.g. arthritis (Guccione, 1994; Escalante \& Del Rincon, 2002), and pulmonary disease (Jette, Manago, Medved, Nickerson, Warzycha, \& Bourgeois, 1997). Generic, middle-aged and older adult population-based, longitudinal studies that consider the disablement process as a whole in their study are even more sparse (Femia, Zarit, \& Johansson, 2001; Peek, Ottenbacher, Markides, \& Ostir, 2003); those involving depression as well are, to our knowledge, lacking. Femia, Zarit, \& Johansson (2001) and Peek, Ottenbacher, Markides, \& Ostir (2003), however, found that the disablement process main pathway could be identified in a cross-sectional sample of the oldest-old Swedes, and in a longitudinal sample of the EPESE among older Mexican American adults, respectively. Moreover, both studies suggested that psychosocial experiences could greatly affect the disability experience. We found longitudinal support for their suggestion in the case of depression: the modifications by depression of the associations that we found, indicate acceleration in transitions of the disablement process due to pre-existing depression. The differences in effect between non-depressed and depressed persons, when transitions either from 
pathology to impairments, or from functional limitations to disability were analyzed, suggest that depression seems particularly at work in the early and late phases of the disablement process. The transition from impairments to functional limitations, however, was not significantly modified by depression. This can be due to the fact that, in our study with a heterogeneous sample, this is a transition from the disease-related construct of impairments, measured with disease-specific symptom inventories, to the more generic construct of functional limitations, measured with several generic instruments. Studies that use a more homogeneous sample, e.g. only participants with pulmonary disease (Jette, Manago, Medved, et al., 1997) in combination with the use of disease-specific instruments to assess functional limitations, may be more likely to find evidence of modification of the transition from impairments to functional limitations by depression.

In specific medical conditions, such as diabetes and heart diseases, depressive comorbidity is a predictor of worse course and outcome of those diseases (Depression Guideline Panel, 1993). How does this interaction have its effect on impairments? First, there could be a biological explanation. Inflammatory serum markers, such as C-reactive protein (CRP), and cytokine interleukin-6 (IL-6), were found to be elevated in depressed respondents compared to their non-depressed counterparts (Tiemeier, Hofman, van Tuijl, Kiliaan, Meijer, \& Breteler, 2003). Chronically elevated inflammatory serum markers are believed to negatively influence the course of a wide array of diseases, e.g., Alzheimer or substantial cognitive decline (Yaffe, Lindquist, Penninx, Simonsick, Pahor, Kritchevsky, et al., 2003), anemia (Tilg, Ulmer, Kaser, \& Weiss, 2001), arthritis (Wong, Toh, Wilson, Rowley, Karschimkus, Prior, et al., 2003), cancer (Repetto, Venturino, Fratino, Serraino, Troisi, Gianni, et al., 2003), heart disease (Stone, Mendall, Kaski, Edger, Risley, Poloniecki, et al., 2002), and lung disease (Mannino, Ford, \& Redd, 2003). The differential effect of pathology on impairments that we found for depressed respondents compared to their non-depressed counterparts may thus be a clinical manifestation of depression on the immunological level.

A second explanation for the stronger effect of pathology on impairments that we found for depressed respondents compared to their non-depressed counterparts may be that depressed physically ill respondents may suffer more 
from feelings of hopelessness, or be more pessimistic than non-depressed physically ill respondents that their physical symptoms will be effectively treated and, therefore, not report their physical symptoms to their GP's (cf. Schubert, Yokley, Sloan, \& Gottesman, 1995). These authors also suggest that depression may delay identification, treatment, and rehabilitation of coexisting physical illness, when the conditions are coincidental, thereby causing a discrepancy in impairments between depressed physically ill and nondepressed physically ill respondents. In addition, depressed physically ill respondents may be less likely to comply with their medical regimen (Carney, Freedland, Eisen, Rich, \& Jaffe, 1995; Ciechanowski, Katon, \& Russo, 2000), and less likely to adopt a healthy lifestyle (van Gool, Kempen, Penninx, Deeg, Beekman, \& van Eijk, 2003) compared to their non-depressed counterparts, thereby delaying treatment and rehabilitation as well. This also can lead to a discrepancy in impairments between depressed physically ill and nondepressed physically ill respondents.

The stronger effect of functional limitations on disability that we found for depressed respondents compared to their non-depressed counterparts may be a motivational manifestation of depression: depressed and functionally limited respondents may be less able or motivated to (try to) maintain a certain level of ability. Lamb (1996) found cross-sectional evidence for respondents with this frail profile of both depression and functional limitations to be more disabled than respondents with only a depressed profile, or respondents with only a functionally limited profile. Kempen, Steverink, Ormel, and Deeg (1996) found that depressed older adults scored lower on selfreported functional limitations than could be expected on the basis of performance-based functional limitations. Due to our use of a composite variable for functional limitations, composed of self-reported and performancebased measures of functional limitations, in our study this overestimation should be moderate. Moreover, does inaccurate self-estimation on functional limitations make the estimation any less valid for the depressed respondent itself?

Our study suffers from attrition during six years, much of which is caused by mortality. Only relatively healthy participants survived. Study dropouts were older, were more diseased, had more impairments and 
limitations, were more disabled and depressed. This could cause an underestimation of true interaction effects that we found between disablement phases and depression. Kempen \& Van Sonderen (2002), however, take the view that, although attrition may be responsible for inaccurate estimations of descriptive measures, attrition has less influence on measures of association. Another limitation pertains to our use of composite variables in each stage of the disablement process, instead of multiple separate variables. The latter approach would have conserved information contained in the separate variables, and would allow for better interpretation of the separate variables. However, this approach is beyond the scope of the paper, as it would obscure the comprehensiveness of our conceptual model.

Implications of our study are twofold. First, identification of the process of disablement could be regarded as an indication that the model can be used in future studies among population-based age groups similar to ours, to replicate our findings. Second, our results regarding the interactions between transitions of the main pathway of the disablement process and depression can be interpreted as an indication that prevention or treatment of depression can slow down the process of disablement, specifically transitions from pathology to impairments and from functional limitations to disability. Partial support for this interpretation comes from Von Korff, Ormel, Katon, \& Lin (1992), who report significant reductions in ADL disability scores in persons whose depression improved significantly, compared to non-significant reductions in ADL disability scores in persons whose depression did not, or did only moderately improve after 12 months.

Lastly, with our study results we hope to have contributed to the ongoing discussion (Charney, Reynolds, Lewis, Lebowitz, Sunderland, Alexopoulos, et al., 2003) regarding the consequences of late life mood disorders and the need to improve diagnosis and treatment of persons afflicted by those mood disorders. 


\subsection{References}

1. Armenian, H. K., Pratt, L. A., Gallo, J., \& Eaton, W. W. (1998). Psychopathology as predictor of disability: a population-based follow-up study in Baltimore, Maryland. American Journal of Epidemiology, 148, 269-275.

2. Baron, R. M., \& Kenny, D. A. (1986). The moderator-mediator variable distinction in social psychological research: conceptual, strategic, and statistical considerations. Journal of Personality and Social Psychology, 51 (6), 1173-1182.

3. Beekman, A. T., Deeg, D. J., Van Limbeek, J., Braam, A. W., De Vries, M. Z., \& Van Tilburg, W. (1997). Criterion validity of the Center for Epidemiologic Studies Depression scale (CES-D): Results from a community-based sample of older subjects in The Netherlands. Psychological Medicine, 27 (1), 231-235.

4. Beekman, A. T., van Limbeek, J., Deeg, D. J., Wouters, L., \& van Tilburg, W. (1994). A screening tool for depression in the elderly in the general population: the usefulness of Center for Epidemiological Studies Depression Scale (CES-D). Tijdschrift voor Gerontologie en Geriatrie, 25 (3),95-103.

5. Bruce, M. L. (2000). Depression and disability. In G. M. Williamson, D. R. Shaffer, \& P. A. Parmelee (Eds.), Physical Illness and Depression in Older Adults: a Handbook of Theory, Research, and Practice (pp. 11-29). New York: Kluwer Academic / Plenum Publishers.

6. Carney, R. M., Freedland, K. E., Eisen, S. A., Rich, M. W., \& Jaffe, A. S. (1995). Major depression and medication adherence in elderly patients with coronary artery disease. Health Psychology, 14 (1), 88-90.

7. Charney, D. S., Reynolds, C. F., 3rd, Lewis, L., Lebowitz, B. D., Sunderland, T., Alexopoulos, G. S., et al. (2003). Depression and Bipolar Support Alliance consensus statement on the unmet needs in diagnosis and treatment of mood disorders in late life. Archives of General Psychiatry, 60 (7), 664-672.

8. Ciechanowski, P. S., Katon, W. J., \& Russo, J. E. (2000). Depression and diabetes: impact of depressive symptoms on adherence, function, and costs. Archives of Internal Medicine, $60,3278-3285$.

9. Depression Guideline Panel (1993). Depression in primary care, Vol 1. Detection and diagnosis. Clinical Practice Guideline, Number 5. Rockville, MD, U.S. Department of Health and Human Services, Public Health Service, Agency for Health Care Policy and Research. AHCPR Publication No. 93-0550.

10. Escalante, A., \& Del Rincon, I. (2002). The disablement process in rheumatoid arthritis. Arthritis and Rheumatism, 47 (3), 333-342.

11. Femia, E. E., Zarit, S. H., \& Johansson, B. (2001). The disablement process in very late life: A study of the oldest-old in Sweden. The Journals of Gerontology. Series B: Psychological Sciences and Social Sciences, 56 (1), P12-23.

12. Folstein, M. F., Folstein, S. E., \& McHugh, P. R. (1975). Mini-mental state: A practical method for grading the cognitive state of patients for the clinician. Journal of Psychiatric Research, 12, 189-198. 
13. Geerlings, S. W., Beekman, A. T., Deeg, D. J., Twisk, J. W., \& Van Tilburg, W. (2001). The longitudinal effect of depression on functional limitations and disability in older adults: an eight-wave prospective community-based study. Psychological Medicine, 31 (8), 1361-1371.

14. Guccione, A. A. (1994). Arthritis and the process of disablement. Physical Therapy, 74 (5), 408-414.

15. Jette, D. U., Manago, D., Medved, E., Nickerson, A., Warzycha, T., \& Bourgeois, M. C. (1997). The disablement process in patients with pulmonary disease. Physical Therapy, 77 (4), 385-394.

16. Kempen, G. I. J. M., Ormel, J., Brilman, E. I., \& Relyveld, J. (1997). Adaptive responses among Dutch elderly: the impact of eight chronic medical conditions on health-related quality of life. American Journal of Public Health, 87 (1), 38-44.

17. Kempen, G. I. J. M., Sanderman, R., Scaf-Klomp, W., \& Ormel, J. (2003). The role of depressive symptoms in recovery from injuries to the extremities in older persons: a prospective study. International Journal of Geriatric Psychiatry, 18, 14-22.

18. Kempen, G. I., Steverink, N., Ormel, J., \& Deeg, D. J. (1996). The assessment of ADL among frail elderly in an interview survey: self-report versus performance-based tests and determinants of discrepancies. Journal of Gerontology Series B Psychological Sciences and Social Sciences, 51(5), 254-260.

19. Kempen, G. I., \& van Sonderen, E. (2002). Psychological attributes and changes in disability among low-functioning older persons: Does attrition affect the outcomes? Journal of Clinical Epidemiology, 55 (3), 224-229.

20. Kempen, G. I. J. M., Verbrugge, L. M., Merrill, S. S., \& Ormel, J. (1998). The impact of multiple impairments on disability in community-dwelling older people. Age and Ageing, 27, 595-604.

21. Kennedy, G. L., Kelman, H. R., \& Thomas, C. (1990). The emergence of depressive symptoms in late life: the importance of declining health and increasing disability. Journal of Community Health, 5, 93-104.

22. Kim, H. F., Kunik, M. E., Molinari, V. A., Hillman, S. L., Lalani, S., Orengo, C. A., Petersen, N. J.,Nahas, Z., \& Goodnight-White, S. (2000). Functional impairment in COPD patients: the impact of anxiety and depression. Psychosomatics, 41(6), 465-471.

23. Kleinbaum, D. G., Kupper, L. L., \& Muller, K. E. (1988). Applied regression analysis and other multivariable methods. Belmont, CA: Duxbury Press.

24. Kriegsman, D. M., Deeg, D. J., van Eijk, J. T., Penninx, B. W., \& Boeke, A. J. (1997). Do disease specific characteristics add to the explanation of mobility limitations in patients with different chronic diseases? A study in The Netherlands. Journal of Epidemiology and Community Health, 51 (6), 676-685.

25. Kriegsman, D. M., Penninx, B. W. J. H., Van Eijk, J. Th. M., Boeke, A. J., \& Deeg, D. J. H. (1996). Self-reports and general practitioners information on the presence of chronic diseases in community-dwelling elderly. A study of accuracy of patients' self-reports and on determinants of accuracy. Journal of Clinical Epidemiology, 49 (12), 1407-1417. 
26. Lamb, V. L. (1996). A cross-national study of quality of life factors associated with patterns of elderly disablement. Social Science and Medicine, 42 (3), 363-377.

27. Lan, T. Y., Deeg, D. J. H., Guralnik, J. M., \& Melzer, D. (2003). Responsiveness of the index of mobility limitation: Comparison with gait speed alone in the longitudinal aging study Amsterdam. Journal of Gerontology, 58A(8), 721-727.

28. Lawrence, R. H., \& Jette, A. M. (1996). Disentangling the disablement process. The Journals of Gerontology. Series B: Psychological Sciences and Social Sciences, 51 (4), S173-S182.

29. Magaziner, J. (1991). Hip fracture recovery study patient-proxy concordance study field manual.Baltimore, MD, USA: University of Maryland, School of Medicine.

30. Mannino, D. M., Ford, E. S., \& Redd, S. C. (2003). Obstructive and restrictive lung disease and markers of inflammation: data from the Third National Health and Nutrition Examination. American Journal of Medicine, 114 (9), 758-762.

31. National Academy on an Aging Society. (2000). Depression: A treatable disease. Challenges for the $21^{\text {st }}$ Century: Chronic and Disabling Conditions 9. http://www.agingsociety.org/profiles.htm.

32. Ormel, J., Rijsdijk, F. V., Sullivan, M., van Sonderen, E., \& Kempen, G. I. (2002). Temporal and reciprocal relationship between IADL/ADL disability and depressive symptoms in late life. The Journals of Gerontology. Series B: Psychological Sciences and Social Sciences, 57 (4), P338-P347.

33. Ormel, J., Vonkorff, M., Oldehinkel, A. J., Simon, G., Tiemens, B. G., \& Ustun, T. B. (1999). Onset of disability in depressed and non-depressed primary care patients. Psychological Medicine, 29 (4), 847-853.

34. Peek, M. K., Ottenbacher, K. J., Markides, K. S., \& Ostir, G. V. (2003). Examining the disablement process among older Mexican American adults. Social Science and Medicine, 57, 413-425.

35. Penninx, B. W., Deeg, D. J. H., Van Eijk, J. Th. M., Beekman, A. T. F., \& Guralnik, J. M. (2000). Changes in depression and physical decline in older adults: a longitudinal perspective. Journal of Affective Disorders, 61 (1-2), 1-12.

36. Penninx, B. W. J. H. (1996). Social support in elderly people with chronic diseases: does it really help? [doctoral dissertation]. Amsterdam: Vrije Universiteit.

37. Radloff, L. S. (1977). The CES-D scale: A self-report depressive mood scale for research in the general population. Applied Psychological Measurement, 3 (1), 385-401.

38. Repetto, L., Venturino, A., Fratino, L., Serraino, D., Troisi, G., Gianni, W., \& Pietropaolo, M. (2003). Geriatric oncology: a clinical approach to the older patient with cancer. European Journal of Cancer, 39 (7), 870-880.

39. Rolland, J. S. (1987). Chronic illness and the life cycle: a conceptual framework. Family Process, 26 (2), 203-21.

40. Ruwaard, D., \& Kramers, P. G. N. (1997). Volksgezondheid toekomst verkenning1997: de som der delen [Public health future scenario 1997: the sum of parts]. Bilthoven, The Netherlands: Rijksinstituut voor Volksgezondheid en Milieu (RIVM). 
41. Schubert, D. S., Yokley, J., Sloan, D., \& Gottesman, H. (1995). Impact of the interaction of depression and physical illness on a psychiatric unit's length of stay. General Hospital Psychiatry, 17 (5), 326-334.

42. Stewart, A., Hays, R., \& Ware, J. (1988). The Medical Outcome Study short form general health survey. Medical Care, 26, 724-733.

43. Stone, A. F., Mendall, M. A., Kaski, J. C., Edger, T. M., Risley, P., Poloniecki, J., Camm, A. J., \& Northfield, T. C. (2002). Effect of treatment for Chlamydia pneumoniae and Helicobacter pylori on markers of inflammation and cardiac events in patients with acute coronary syndromes: South Thames Trial of Antibiotics in Myocardial Infarction and Unstable Angina (STAMINA). Circulation, 106 (10), 1219-1223.

44. Tiemeier, H., Hofman, A., van Tuijl, H. R., Kiliaan, A. J., Meijer, J., \& Breteler, M. M. (2003). Inflammatory proteins and depression in the elderly. Epidemiology, 14 (1), 103107.

45. Tilg, H., Ulmer, H., Kaser, A., \& Weiss, G. (2002). Role of IL-10 for induction of anaemia during inflammation. Journal of Immunology, 169 (4), 2204-2209.

46. Van den Heuvel, N., Smits, C. H., Deeg, D. J., \& Beekman, A. T. (1996). Personality: A moderator of the relation between cognitive functioning and depression in adults aged 5585? Journal of Affective Disorders, 41 (3), 229-240.

47. Van Eijk, J. Th. M., \& De Haan, M. (1998). Care for the chronically ill: the future role of health care professionals. Patient Education and Counseling, 35 (3), 233-240.

48. Van Gool, C. H., Kempen, G. I. J. M., Penninx, B. W. J. H., Deeg, D. J., Beekman, A.T., \& van Eijk, J.T. (2003). Relationship between changes in depressive symptoms and unhealthy lifestyles in late middle aged and older persons: results from the Longitudinal Aging Study Amsterdam. Age and Ageing, 32 (1), 81-87.

49. Van Sonsbeek, J. L. A. (1988). Methodological and substantial aspects of the OECD indicator of chronic functional limitations. Maandbericht Gezondheid[Statistics Netherlands], 88, 4-17.

50. Verbrugge, L. M., \& Jette, A. M. (1994). The disablement process. Social Science and Medicine, 38 (1), 1-14.

51. Von Korff, M., Ormel, J., Katon, W., \& Lin, E. H. (1992). Disability and depression among high utilizers of health care: A longitudinal analysis. Archives of General Psychiatry, 49 (2), 91-100.

52. Wong, M., Toh, L., Wilson, A., Rowley, K., Karschimkus, C., Prior, D., Romas, E., Clemens, L., Dragicevic, G., Harianto, H., Wicks, I., McColl, G., Best, J., \& Jenkins, A. (2003). Reduced arterial elasticity in rheumatoid arthritis and the relationship to vascular disease risk factors and inflammation. Arthritis and Rheumatism, 48 (1), 81-89.

53. World Health Organization, \& Food and Agriculture Organization. (2003). Diet, nutrition and the prevention of chronic diseases. Report of a Joint WHO/FAO Expert Consultation. Geneva, Switzerland: World Health Organisation Technical Report Series, no. 916. 
54. Yaffe, K., Lindquist, K., Penninx, B. W., Simonsick, E. M., Pahor, M., Kritchevsky, S.,Launer, L., Kuller, L., Rubin, S., \& Harris, T. (2003). Inflammatory markers and cognition in well-functioning African-American and white elders. Neurology, 61 (1), 76-80.

\subsection{Acknowledgement}

The Longitudinal Aging Study Amsterdam is partly funded by the Ministry of Health, Welfare, and Sports of the Netherlands. 
CHAPTER 8

General conclusions and discussion 
$T_{\text {dem }}$

his dissertation examined several reciprocal associations between depression, health behavior, and the course of chronic disease, mainly among late middle aged and older persons, utilizing data from three different studies in the Netherlands and the United States. Following a brief synopsis of the main findings and conclusions of our study, the results are put in perspective, and some considerations regarding measurement instruments and research methodology used in this study are addressed. Finally, implications for public health and future research are outlined.

\subsection{Main findings and conclusions}

The research questions of our study can be summarized in the conceptual model that was presented in the introductory chapter (1). We will discuss our main findings using the arrows within this model (Figure 8.1).

Figure 8.1: Conceptual model of our study

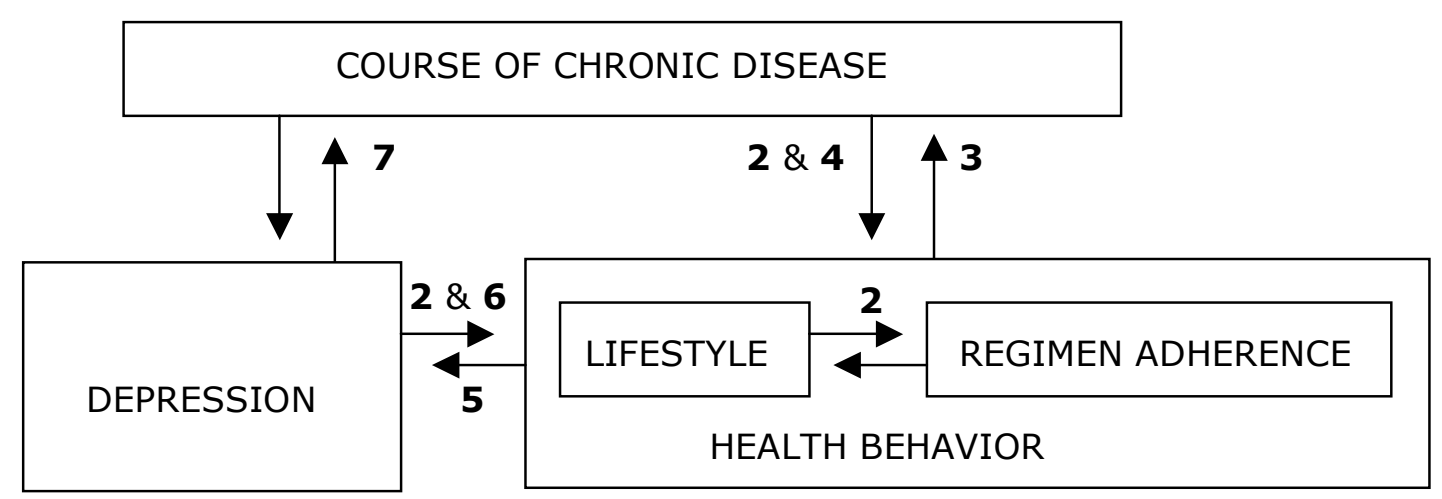

Note: The numbered arrows in the figure refer to the different chapters in this dissertation

\section{Determinants of regimen adherence to diet and exercise interventions} (Arrows 2)

In an exploration using demographic, health-related, and psychosocial information, we wanted to identify determinants of adherence to a diet and exercise regimen. Over the 18-month duration of the diet and exercise intervention study among at least overweight knee osteoarthritis patients aged $\geq 60$ years, predictors of adherence to both interventions appeared not to be associated with physical or mental health. For both interventions, high initial 
attendance to intervention sessions predicted intervention session attendance thereafter, indicating that persistence or motivation of persons seems to be crucial here. In addition, giving people a choice of where to do their exercise (either at home or at a research facility) and stimulating early intervention session attendance can be effective in improving long-term attendance to both interventions.

\section{Associations between regimen adherence and physical function and disability (Arrow 3)}

In overweight or obese patients with knee osteoarthritis (OA), higher exercise adherence - the extent to which persons attend intervention sessions and reported to have exercised at home - was found to be associated with greater improvements in physical function and in disability, though the latter to a lesser extent. Changes in the potentially explanatory variables pain and BMI modified these associations to some extent. Promoting adherence is clinically important when prescribing exercise regimen to overweight and obese older adults with knee OA. These regimens could also focus on decrease in pain and BMI.

\section{Chronic disease and lifestyle changes (Arrow 4)}

We examined prevalences of unhealthy lifestyles - smoking, excessive alcohol use, and being sedentary - and found that lifestyles varied over a six-year period and across chronic disease categories. Proportions of older persons who smoked decreased, while proportions of respondents with sedentary lifestyles increased. Older persons with incident cardiovascular disease were more likely to change lifestyles than persons in other chronic disease groups. Those persons who made healthy lifestyle changes - from unhealthy to healthy behavior - did not differ in experienced disease burden from those who persisted in their unhealthy behavior within chronic disease groups. Knowing whether (and why) a specific group of patients is inclined more than others to make healthy lifestyle changes might be important. This can be used to target health promotion strategies more effectively and enhance the effectiveness of self-management programs that aim at coping with chronic diseases. 
Ultimately, chronic disease groups who do not initiate more healthy lifestyles might be reached for intervention.

\section{Associations between lifestyle and depressed mood (Arrow 5)}

Excessive alcohol use predicted subsequent depressed mood, and $>30$ minutes of physical exercise per day predicted subsequent absence of depressed mood. Not being overweight for a longer period of time was predictive of subsequent absence of depressed mood. Adopting healthy lifestyles could be a way to 'break the negative cycle' and might be a starting point to prevent or to deal with depressed mood over time.

\section{Associations between depressed mood and lifestyle (Arrow 6)}

We examined whether symptoms of depression were associated with unhealthy lifestyles - smoking, excessive alcohol use, and being sedentary - and found that depressed persons were more likely to be smokers. A persistent depression was associated with an increase in cigarette consumption. Having an emerging depression was most likely to co-occur with persons becoming sedentary, and was associated with the largest decrease in minutes of physical activity per day. This effect was not modified or confounded by having chronic somatic disease. A persistent depression tended to be associated with incident excessive alcohol use. It should be clarified whether or not treatment of symptoms of depression can prevent the development of sedentary lifestyles.

\section{The process of disablement and depression (Arrow 7)}

We examined the main pathway of the disablement process - which was hypothesized to consist of four consecutive phases: pathology, impairments, functional limitations, and disability - and how depression affects this pathway. We found that impairments mediated the association between pathology and functional limitations, and that functional limitations mediated the association between impairments and disability, both in a time-dependent way, so that the main pathway of the disablement process could be identified in our study. In addition, we found an accelerating effect of depression, particularly in the early and late stages of the model. Reduction of depression may help slow down the 
process of disablement for persons who find themselves in particularly those stages of the model.

\section{Conclusions}

Transcending the findings of the separate studies, we can conclude that the course of chronic disease is accelerated under the presence of depression. However, we found that the disease's negative consequences on daily functioning can be restricted, as our study in patients with knee osteoarthritis demonstrated. Furthermore, for specific chronic diseases, the course of disease is associated differentially with lifestyle, and lifestyle changes. Healthy lifestyle changes, however, appeared not to be related with a relief of experienced disease burden. Other factors may be at work here.

When living a healthy lifestyle, the risk of a depression is relatively low. Still, should a depression emerge, a shift is likely to happen from being physically active to being sedentary. And when being persistently depressed, the risk of living unhealthy lifestyles is more prominent. In sum, in our study we found clear indications for an interrelationship between the concepts of course of chronic disease, depression, and health behavior among older persons.

\subsection{The prevalence of our key variables in perspective to other studies}

In order to put our findings in perspective, we briefly compare several prevalence figures from our findings with each other and with prevalence estimates of Statistics Netherlands (chapter $1 ;[1]$ ).

\section{Chronic conditions}

We tabulated the most prominent findings and ranked the studies beginning with the youngest, and probably healthiest sample (MAAS; 24 through 81 years), and ending with the sample assumed to be least healthy (ADAPT; 60 years and older plus all respondents were at least overweight and had knee OA; Table 8.1). As the study samples get older and 'unhealthier', the prevalence of heart disease increases - although different definitions of heart disease have been used - as does the prevalence of lung disease, and the proportion of respondents reporting 2 or more chronic conditions increases. 
The prevalence of musculoskeletal disorders among respondents in the ADAPT study was set to $100 \%$ as radiographic evidence of having knee OA was a study inclusion criterion.

Table 8.1: Comparison of prevalence figures (percentages) of several chronic conditions

\begin{tabular}{|c|c|c|c|c|c|}
\hline \multicolumn{6}{|c|}{ across studies } \\
\hline \multicolumn{2}{|l|}{ Study } & $\begin{array}{l}\text { MAAS }^{1} \\
\mathrm{n}=1186\end{array}$ & $\begin{array}{l}\mathrm{CBS}^{2} \\
\mathrm{n}=10110\end{array}$ & $\begin{array}{l}\operatorname{LASA}^{3} \\
\mathrm{n}=2184\end{array}$ & $\begin{array}{l}\text { ADAPT } \\
n=206\end{array}$ \\
\hline \multirow[t]{4}{*}{ Age } & $<55$ & 62.9 & 0 & 0 & 0 \\
\hline & $55-65$ & 19.4 & 44.8 & 24.4 & 37.4 \\
\hline & $65-75$ & 14.7 & 33.5 & 36.5 & 46.3 \\
\hline & $75+$ & 3.0 & 21.8 & 39.1 & 16.3 \\
\hline \multirow[t]{2}{*}{ Gender } & Male & 52.3 & 48.2 & 48.9 & 26.1 \\
\hline & Female & 47.7 & 51.8 & 51.1 & 73.9 \\
\hline \multicolumn{2}{|c|}{ Lung disease } & N.A. ${ }^{5}$ & 9.0 & 12.0 & 15.4 \\
\hline \multicolumn{2}{|c|}{ Heart disease } & N.A. & 9.6 & 29.2 & 64.6 \\
\hline \multicolumn{2}{|c|}{ Diabetes } & N.A. & 7.1 & 7.8 & 9.9 \\
\hline \multicolumn{2}{|c|}{ Musculo-skeletal disease(s) } & N.A. & 36.1 & 36.8 & 100 \\
\hline \multicolumn{2}{|c|}{$\geq 2$ chronic conditions } & 32.8 & 35.5 & 42.8 & $49.3^{6}$ \\
\hline
\end{tabular}

${ }^{1}$ Based on figures from chapter $5(n=1186) ;{ }^{2}$ Based on estimates from Statistics Netherlands (chapter $\left.1 ;[1]\right) ;{ }^{3}$ Based on figures from chapter $4 ;{ }^{4}$ Based on figures from chapter $2 ;{ }^{5}$ Not available; ${ }^{6}$ Besides knee osteoarthritis.

\section{Depression}

Although termed differently across our studies, respondents with scores $\geq 16$ on the CES-Depression scale were considered to have clinically relevant levels of depressive symptomatology. In chapter 5 we found that $14.3 \%$ of the study sample $(n=1186)$ of MAAS was depressed. In chapter 6 we were able to followup on depression in a sample of LASA over a six-year period $(n=1280)$. Proportion of depressed respondents increased from $13.8 \%$ at baseline to $20.3 \%$ at follow-up. These prevalences appeared to be in line with findings in a review of the literature on community prevalence of depression in later life [2], in which an averaged prevalence of all depressive syndromes deemed clinically relevant was found of $13.3 \%$. However, this averaged prevalence was 
calculated from the results of 28 community-based studies examining the prevalence of all depressive syndromes deemed clinically relevant among persons 55 years and older. These prevalences varied greatly: from $2.8 \%$ in Japan, to $35.0 \%$ in Hong Kong. In a study in which several European study centers collaborated to examine the extent of geographical variation in depression prevalences, using the same standardized assessment method (GMS-AGECAT), a 'European' depression prevalence was estimated at $12.3 \%$, with extreme prevalences of $8.8 \%$ in Iceland and $23.6 \%$ in Munich, Germany. These large differences across countries could be due to differences in religion, and urbanization, but not to differences in age [3].

The prevalences of $13.8 \%$ and $20.3 \%$ in chapter 6 are based on a cut-off score of 16 on depressive symptomatology measured by the CES-D [4]. Major depressive disorder (MDD), dysthymic disorder (DD), and subtreshold depressive disorders are included in this cut-off value. While the prevalence of MDD tends to decrease with age, the prevalence of other depressive disorders is more likely to increase [2]. So the apparent increase in prevalence could be due to selective survivorship (those with severe depression are less likely to grow old), an increase in the incidence of comorbid depressive symptomatology that goes with the increased risk of physical illness as people age (heart disease, dementia [4]), and/or the occurrence of life events.

As mentioned in chapter 7, depression and disability contribute to the risk of each other over time [5-7]. This could be explained by an overlap in somatic symptoms or concomitants of both concepts, such as decreased muscle mass. An underlying physical system failure, however, may at the basis of this overlap, causing both depression and disability.

\section{Smoking behavior}

In 2001, The Netherlands counted almost 16 million inhabitants; nearly 3.8 million of them (23.7\%) were 55 years or older. This last group was estimated to contain $22.8 \%$ smokers [1]. In our MAAS study sample (chapter 5 ) $26.6 \%$ smoked, which decreased after six years to $21.9 \%$ (17.7\% decrease). In our LASA study sample, $20.9 \%$ smoked and decreased after six years to $17.0 \%$ (18.7\% decrease). The percentage of respondents who smoked in the MAAS study sample is somewhat higher than the Statistics Netherlands estimate and 
the LASA study. This may be due to a lower averaged age (49.0), as well as a wider age range (24-81) in the MAAS study. In general, the percentage of respondents who smoke decreases with age [8].

\section{Alcohol use}

Statistics Netherlands estimated that the averaged number of alcoholic drinks in the Dutch older population ranges from 9.6 drinks per week among 55-64 year-olds to 6.0 among 75 year-olds and older [1]. In chapter 5 we found that respondents from our sample from the MAAS study $(n=1186)$ consumed approximately 6.1 alcoholic consumptions per week, which remained relatively stable with 6.2 alcoholic consumptions after six years. In chapter 4 we found that respondents from the LASA study $(n=2184)$ consumed 7.1 alcoholic consumptions per week on average.

Excessive alcohol use is termed differently internationally. Statistics Netherlands [1] used the same definition as we did: three or more alcoholic consumptions per day on average. Statistics Netherlands estimated that approximately $8 \%$ of all adults and $10.4 \%$ of the persons aged 55 years or older use alcohol excessively. From the MAAS study we learned that $6.7 \%$ used alcohol excessively, which increased to $8.2 \%$ after six years, among 24 to 81 -year olds. Our LASA study in chapter 6 shows that $4.1 \%$ of the respondents $(n=1280)$ drinks three or more alcoholic drinks per day on average. However, as this may have been quite a selective group of respondents (selective survivorship), their lifestyles might have been healthier than the lifestyles of those in the entire sample or in the population.

\section{Physical activity}

Statistics Netherlands estimates that the number of minutes physical exercise ranges from approximately 13 among 55 to 64 year-olds to less than 5 minutes among 75 year-olds and older [1]. Only sportive activities were taken into account, however. In chapter 5 the averaged number of minutes of physical exercise per day initially was 18.3. This decreased after six years to 10.6. However, this study sample was somewhat younger than the group of reference from the study from Statistics Netherlands. Respondents were considered having a sedentary lifestyle when their number of minutes of 
physical activity (this comprised not only all sportive activities, but light and heavy household chores as well) was in the lowest quartile of the baseline study sample. In chapter 4 we found that $25.0 \%$ of our initial sample $(n=2184)$ was physically active for less than 86 minutes per day on average. Hereafter, we followed-up on a study subsample $(n=1167)$ for six years and found that $20.6 \%$ was sedentary at the beginning, and $29.5 \%$ after six years. Among another, differently selected sample from the same study (LASA; chapter 6 ) we found that $25.5 \%$ of 1280 respondents were physically active for less than 84 minutes on average per day at study baseline. After six years this percentage increased to $35.2 \%$. Statistics Netherlands estimated that, in 2001, approximately $37.5 \%$ of all persons aged 55 and older did not conform to the recommendation of being (moderately intense) physically active for at least 150 minutes per week. Having a chronic condition does not automatically mean that the recommendation can not be met (chapter 4), as several of the chronic disease categories score above the recommendation, with respect to physical activity.

\section{Body Mass Index (BMI)}

Statistics Netherlands, as well as numerous other institutions, defines overweightness as having a BMI, or Quetelet index, of $\geq 25[1,5]$. It is estimated that among 55 year old and older people, $54.9 \%$ are at least overweight [1]. These percentages increase with age until approximately 70 years, and decrease thereafter [8]. However, another study showed that these overweight cut-off levels are somewhat unreliable, as respondents who fluctuate in bodyweight may be unjustly categorized as overweight [9]. Therefore, the ADAPT study as well as the MAAS study utilized more strict overweight cut-off levels - i.e. $\geq 28$, and $\geq 27.3$ for women and $\geq 27.8$ for men, respectively. According to our more conservative measure of being overweight, $33 \%$ of our MAAS study sample $(n=1186)$ was overweight at study initiation. After six years $39.7 \%$ was overweight. In absolute numbers, the MAAS study sample's BMI increased from an averaged 26.5 at baseline to 27.0 after six years, among 24 to 81 year old respondents. Statistics Netherlands estimated that the BMI of the general population increased from 24.9 in 2000 to 25.1 after three years, among 20 to 70 year old people [1]. 


\subsection{Validity of the study}

By discussing the extent to which potential threats to the internal and external validity apply to our study, we evaluate the adequacy of the overall research design of our study and of the adjustments we made to avoid potential bias in our study.

\section{Threats to internal validity}

Internal validity of a study refers to the extent to which the study findings actually apply to the study respondents [10], or 'did we use the correct study design?'. Grossly, threats to the internal validity of our study can lead to overor underestimation of effects or associations, or to a switch in effect parameters, and can be categorized into instrumentation bias, selection bias, and confounding [10].

\section{Instrumentation bias}

In general, research using self-reported measurements is cheap, easy to administer, and is not bothered by, for example, inter-rater variability. Downside of self- reported measurements can be the risk of acquiescence, inaccurate recollection, and answers to questions being socially desirable. These distortions of effect sizes due to erroneous measurement of variables can lead to information bias.

In chapter $5,37.4 \%$ of the respondents from the MAAS study $(n=1186)$ reported at follow-up to have never smoked. However, cross-tabulating these data with baseline findings showed that 38 of these respondents reported to have smoked formerly and 1 respondent reported to have been a current smoker at baseline. Perhaps due to (some of) the earlier mentioned risks, approximately 39 persons were either mistaken at baseline or at follow-up, or both! In the other two categories of the smoking behavior variable a similar process of misclassification may have occurred. However, this may not emerge from the data as evident as the increased percentage of persons who reported never to have smoked. Whether or not this misclassification in the smoking behavior variable was random is difficult to determine, but it may have been a source of information bias. 
A final source of information bias when using self-reported instrumentation is the possibility that the state a person is in, influences the rating of a person on other variables, also called reactivity. The state a person is in, is susceptible to fluctuation and can be misleading, as it can be mistaken for a trait, which is a more stable characteristic of persons. Often, it is this stable trait that researchers are looking for, and not the state a person is in. For example, persons who feel somewhat depressed while filling out a questionnaire on self-perceived health or activities of daily living, can easily feel different a couple of days later. In the meantime, these persons may well have scored lower on self-perceived health or activities of daily living than might have been expected on the basis of performance-based measures [11]. In our study, this may have caused some overestimation of variability within respondents.

\section{Selection bias}

As we already briefly stipulated in previous chapters, large prospective observational studies, particularly those who involve older persons, have the disadvantage of being susceptible to study attrition due to morbidity and mortality. Several of the studies in this dissertation used data from large prospective longitudinal studies with at least two moments of measurement. Typically in longitudinal research among older persons in the general population, more and more respondents become ill and/or move to nursing homes and the relatively healthy respondents are likely to remain in the ultimate study samples, especially when follow-up measurements are (several) years apart. Then statistical power diminishes and study attrition is selective; the remaining study sample is no longer representative of the study population. This endangers the reliability of study results, and generalization of study findings should be done with caution. The above described selection bias could have affected our study as well. The effect it had would be the effect of underestimation of intragroup changes, as persons who dropped out due to morbidity or mortality may have gone through physical changes faster than the persons who are still in the study sample [12]. This means that, in our study, associations might have been stronger when (more) persons with bad health were included in the study sample. Kempen and van Sonderen acknowledge 
the effect of attrition on intragroup changes [13]. However, they suggest that attrition is of less influence when measures of association are the focus of study.

Another source of study attrition that may cause selection bias, stems from the selection of respondents once they have commenced participation in interview cycles. Longitudinal studies that only include respondents with valid measurements may suffer from incompleteness of interviews or questionnaires, also called item nonresponse. Without the use of imputation strategies, it may lead to decreased sample sizes, decreased statistical power, and inaccurate effect estimations. When using imputation strategies, it is possible that the imputed value underestimates true variability, potentially leading to a distortion of power in hypothesis testing, and inaccurate effect estimations. The studies in this dissertation that examined change were affected by incompleteness of measurements by reasons of item nonresponse. In only one occasion, however, in chapter 4 , we chose to use imputation methods to replace missing values on physical activity measures, which were missing by reasons of item nonresponse.

In all, selection bias may have bothered some of our study results and may have lead to some underestimation of the associations that we found. Therefore, we call for a cautious interpretation of the conclusions of the affected chapters.

\section{Confounding}

A final concern regarding the internal validity refers to potential confounders which may lead to spurious associations between the independent and dependent variables of a study. Strictly speaking, confounders are both associated with the independent and dependent variables, but are no part of a causal sequence between independent and dependent variable. In our study we have both attempted to identify potentially confounding variables, by means of correlation analyses, and subsequently, to avoid the negative consequences of confounding, by controlling these potentially confounding variables in statistical analyses. We have done this for the variables which we deemed potentially confounding and which also were available to us. For example, in chapter 2 we suggest that session attendance in the initiation 
phase is a very strong predictor of session attendance in a later stage of the intervention. It may well be possible, that psychosocial and/or motivational variables, which we did not incorporate in our study, are largely responsible for this strong association. Therefore, some reservations should be made regarding the comprehensiveness of adjustments in statistical analyses to avoid confounding, as there might have been confounding variables that were unavailable to us to identify in analyses, or were unknown to us.

\section{Threats to external validity}

External validity of a study refers to the potential generalizability of findings to other study populations and other settings [14]. For example, we have no reasons to believe that study outcomes would be different if the ADAPT study was replicated among $\geq 60$ year old, at least overweight, knee osteoarthritis patients in the Netherlands. This indicates good external validity. However, our use of slightly different age groups across studies comprises the extrapolation of results across studies. Finally, it is worth mentioning that good internal validity can be regarded as a 'conditio sine qua non' for good external validity. Nevertheless, good internal validity is no guarantee for good external validity.

\section{Causal inferences}

In this study we tried to use the strongest models of analyses as possible. In several studies, this lead us to perform analyses at three different levels: cross-sectional, longitudinal, and congruence of change. The results from analyses done with models of congruence of change are - despite covering changes in variables over time - limited in their power to make causal inferences. As this method relates change in one variable to change in the other, using panel data, one can not ascertain which change preceded the other. The same goes for the results from analyses done with cross-sectional models. Associating the levels of two variables, measured at the same time, does not allow for causal inferences. Still, the analyses with the greatest predictive power involve multiple moments of measurement and try to predict the level of a variable (e.g., level of depressive symptomatology in 2000) with the change in another variable (e.g., change in physical activity between 1994 and 2000), which precedes the moment of measurement of the variable one 
wants to predict. Examples of such analyses can be found in chapters 3, 4, 5, and 6.

\subsection{Study implications}

Keeping the abovementioned methodological considerations in mind, comments are made with respect to public health relevance, and recommendations are made for future research.

\section{Public health relevance}

The surplus value of our research over other studies is derived from disentangling and quantifying the separate associations between the interrelated concepts of course of chronic disease, depression, and health behavior. Our results indicate that unhealthy lifestyles and depressive symptomatology contribute to each other's risk over time. The fact that both unhealthy lifestyles as well as clinically relevant depressive symptomatology are prevalent in the older population, plus the fact that both eventually cause increased morbidity and mortality, emphasizes the public health relevance. Opportunities for the prevention of the emergence of clinically relevant depression as well as the treatment of symptoms of depression may be sought in manipulating lifestyles. The prevention of becoming sedentary (or even better: promotion of vigorous physical activity), the maintenance of a healthy weight, and the cessation of both smoking and excessive alcohol use might contribute to the prevention of the emergence of clinically relevant depression as well as the treatment of symptoms of depression. And what's more, these behaviors can safely be strived for, regardless of their potential effect on depression, as these are beneficial for one's health anyway. We hypothesize, though, that adopting and maintaining these healthy behaviors over time lead to lower levels of depression, and, through these lowered levels of depression, might lead to less chronic disease burden [15]. Also, when these healthy lifestyle changes take place and/or are maintained as part of a selfmanagement program, perceived control over and coping with the consequences of a chronic disease may be improved, also potentially resulting in less chronic disease burden [16]. 
When changing one's lifestyle, for instance by starting to exercise daily for a certain amount of minutes, it appears imperative to ensure adherence to one's own lifestyle regimen. For it is adherence to a lifestyle regimen, in this case actually exercising every day, that beneficially influences the course of certain chronic diseases, for example osteoarthritis. In order to make regimen adherence somewhat easier to achieve, these exercise regimens need not be located at gyms, but can easily be located at home, or at public places, such as shopping or community centers. In the United States some communal exercise programs are held in these indoor centers. Participants of these programs walk vigorously through the shopping malls, in groups. Not only have these programs demonstrated to be beneficial for several physical parameters, such as lower extremity muscle force, psychosocial parameters have also been shown to improve through these programs, for example symptoms of depression and quality of life $[17,18]$. Social group effects might be responsible for this, together with increased self-satisfaction [18], resulting in enhanced feelings of social support and self-efficacy and thereby improving psychosocial parameters [19].

From a governmental point of view, the discouragement of unhealthy lifestyles (smoking, excessive alcohol use, and being sedentary) is done through television commercials, newspaper advertisements, but also through banning smoking in certain public spaces, increasing taxes on tobacco products, and limiting the availability of both alcohol and tobacco products for certain age groups. The promotion of healthy lifestyles (daily physical activity, healthy body composition, moderate alcohol use) is also done through television commercials, and newspaper advertisements. Lately, more and more health management organizations have begun to reimburse expenses that their customers make while leading a healthy lifestyle, thereby promoting these healthy lifestyles. For example, costs of nicotine patches may be reimbursed for those who wish to quit smoking, costs of visits to a certified dietician may be reimbursed for those who wish to return to a healthy weight. However, the promotion of healthy, but especially the discouragement of unhealthy lifestyles is an arduous mission, for, while national health care should remain cost-effective, at the same time a balance must be sought in respecting the personal freedom of people, and the importance of all people - 
not just specific age groups - understanding either the benefits of healthy lifestyles and the risks of unhealthy lifestyles.

Low socio-economic status (SES) has been found to be a risk factor for chronic diseases [8], accelerated mobility decline [20], and more unhealthy lifestyles [8]. Hence, future lifestyle interventions, which seek to promote healthy behavior in the community, might benefit from an approach that differentiates in SES status of the target population. Also, (public) health care and opportunities for healthy lifestyles should remain easily accessible for people from all SES categories.

\section{Future research}

Regarding the treatment of symptoms of depression, whether or not lifestyle interventions should be done in persons who are under medical treatment for their depressive symptomatology is indistinct. Beneficial effects of physical exercise (initiation) on depressive symptomatology are well documented $[21,22]$. Far less clear are potential effects of smoking cessation and quitting excessive alcohol use on depressive symptomatology. In the medical treatment of depression some side effects have been reported that are unfavorable for adopting healthy lifestyles, such as weight gain, lethargy, postural hypotension, and nausea [23]. These might diminish after adopting healthy lifestyles.

However, depressed persons are likely to suffer from tiredness and lethargy, independent from their medication. Therefore, a first challenge in future intervention research may be to reach and motivate depressed persons to participate, and to motivate them to continue participation in longitudinal research. Then, future research could examine 1 ) whether or not the extent to which persons adhere to these lifestyle interventions matters for the improvement in symptoms of depression (a suggested dose-response effect), or that the success of counteracting depressive symptomatology is dependent on the accumulation of knowledge, skills, or a certain amount of (pre-existing) healthy behavior (a suggested threshold effect)? Future research could also clarify 2) whether or not lifestyle interventions are effective in reducing symptoms of depression; 3) whether these can be incorporated in the existing therapies to treat depression; and 4) whether or not lifestyle interventions are 
equally effective in persons with minor depression or major depressive disorder, either in combination or without medical treatment, or cognitive behavioral therapy for depressive symptomatology. Some preliminary studies among older persons with minor depression yield promising results for the effectiveness of a physical activity intervention on symptoms of depression [22].

With respect to our finding of depression being an accelerator in the process of disablement, it needs clarification whether this effect of depression is disease-specific. In other words, does depression affect persons with lung disease differently as compared to persons with osteoarthritis, for example, regarding their advancement in the main pathway of the disablement process. Although some studies identified the main pathway of the model of disablement among different chronic diseases [24,25], to date no study has compared the influence of depression on the course of different chronic diseases in the same sample. This will require prominent longitudinal research.

Unraveling the association between change in disease-related impairments and changes in lifestyle also requires longitudinal research. The relevance for this can also be seen in terms of the disablement process. When studying the advancement of respondents with chronic diseases in the main pathway of the disablement process, it is important to know whether lifestyle changes cause either an improvement or aggravation in disease-related impairments or are caused by an improvement or aggravation in diseaserelated impairments. Moreover, when studying aspects of disablement, a need exists for greater conceptual clarity and concordance regarding disablement outcomes. Certain similar concepts are defined and operationalised differently across studies. For example, the concepts of the main pathway of Verbrugge and Jette's model of the disablement process were adapted from Nagi's initial model of disablement $[26,27]$. In turn, this was not too different from the International Classification of Diseases and Handicaps of the World Health Organization [28]. All of these models use similar concepts that slightly differ. This is detrimental for good comparison of study results and limits comparability across studies. 


\subsection{References}

1. Statistics Netherlands. Health Interview Questionnaire. Heerlen, The Netherlands: Statistics Netherlands, 1989.

2. Beekman AT, Copeland JR, Prince MJ. Review of community prevalence of depression in later life. Br J Psychiatry. 1999 Apr;174: 307-11.

3. Copeland JR, Beekman AT, Dewey ME, et al. Cross-cultural comparison of depressive symptoms in Europe does not support stereotypes of ageing. $\mathrm{Br}$ J Psychiatry 1999; 174: 322-9.

4. Beekman AT, Deeg DJ, Smit JH, et al. Dysthymia in later life: a study in the community. J Affect Disord. 2004 Sep;81(3):191-9.

5. Bruce ML. Depression and disability. In GM Williamson, DR Shaffer, PA Parmelee (Eds.), Physical Illness and Depression in Older Adults: a Handbook of Theory, Research, and Practice. New York: Kluwer Academic / Plenum Publishers, 2000: pp. 11-29.

6. Ormel J, Rijsdijk FV, Sullivan M, van Sonderen E, Kempen GI. Temporal and reciprocal relationship between IADL/ADL disability and depressive symptoms in late life. J Gerontol B Psychol Sci Soc Sci 2002; 57: P338-347.

7. Geerlings SW, Beekman AT, Deeg DJ, Twisk JW, van Tilburg W. The longitudinal effect of depression on functional limitations and disability in older adults: an eight-wave prospective community-based study. Psychol Med 2001; 31 (8), 1361-1371.

8. Nationaal Kompas Volksgezondheid. Bilthoven, The Netherlands: RIVM, 2002.

9. Williamson DF, Kahn HS, Remington $\mathrm{PL}$, et al. The 10-year incidence of overweight and major weight gain in US adults. Arch Intern Med 1990; 150: 665-72.

10. Bouter LM, van Dongen MC. Epidemiologisch onderzoek. Opzet en interpretatie. Houten/Antwerpen: Bohn Stafleu Van Loghum, 2000.

11. Kempen GI, Verbrugge LM, Merril SS, Ormel J. The impact of multiple impairments on disability in community-dwelling older people. Age Ageing 1998; 27: 595-604.

12. Deeg DJ. Attrition in longitudinal population studies: Does it affect the generalizability of the findings? 1: An introduction to the series. J Clin Epid 2002; 55 (3): 213-15.

13. Kempen GI, van Sonderen E. Psychological attributes and changes in disability among low-functioning older persons: does attrition affect the outcomes? J Clin Epidemiol 2002; 55 (3): 224-29.

14. Polit DF, Hungler BP. Nursing Research Principles and Methods. Philadelphia PA: Lippincott, 1999.

15. Lebowitz BD, Pearson JL, Schneider LS, et al. Diagnosis and treatment of depression in late life.

Consensus statement update. JAMA 1997; 278: 1186-90.

16. Lorig KR, Holman HR. Self-management education: History, definition, outcomes, and mechanisms. Ann Behav Med 2003; 26: 1-7.

17. Penninx BW, Rejeski WJ, Pandya J, et al. Exercise and depressive symptoms: a comparison of aerobic and resistance exercise effects on emotional and physical function in older persons with high and low depressive symptomatology. J Gerontol B 
Psychol Sci Soc Sci 2002; 57: P124-32.

18. Rejeski WJ, Mihalko SL. Physical activity and quality of life in older adults. J Gerontol A Biol Sci Med Sci 2001 Oct;56 Spec No: 2:23-35.

19. Toobert DJ, Strycker LA, Glasgow RE, Barrera M, Bagdade JD. Enhancing support for health behavior change among women at risk for heart disease: the Mediterranean Lifestyle Trial. Health Educ Res 2002 Oct;17(5): 574-85.

20. Koster A, Bosma $\mathrm{H}$, Kempen GI, et al. Socioeconomic inequalities in mobility decline in chronic disease groups (asthma/COPD, heart disease, diabetes mellitus, low back pain): only a minor role for disease severity and comorbidity. J Epidemiol Community Health 2004; 58(10): 862-9.

21. North TC, McCullagh P, Tran ZV: Effect of exercise on depression. Exerc Sport Sci Rev 1990; 18: 379-415.

22. Lawlor DA, Hopker SW. The effectiveness of exercise as an intervention in the management of depression: systematic review and meta-regression analysis of randomised controlled trials. BMJ 2001 Mar 31;322(7289):763-7.

23. Berkow R. The Merck manual - Second home edition. Whitehouse Station, NJ: Merck Research Laboratories, 1999.

24. Escalante A, Del Rincon I. The disablement process in rheumatoid arthritis. Arthritis and Rheumatism 2002; 47 (3): 333-42.

25. Jette DU, Manago D, Medved $E$, et al. The disablement process in patients with pulmonary disease. Physical Therapy 1997; 77 (4): 385-94.

26. Verbrugge LM, Jette AM. The disablement process. Soc Sci Med 1994; 38 (1): 1-14.

27. Nagi SZ. Some conceptual issues in disability and rehabilitation. In: Sussman MB, editor. Sociology and rehabilitation. Washington, D.C: American Sociological Association, 1965: 100-13.

28. World Health Organization (WHO). International Classification of Impairments, Disabilities, and Handicaps. Geneva, Switzerland: WHO, 1980. 
CHAPTER 9

Summary (Samenvatting) 


\subsection{Introduction}

Th CHAPTER 1 we discuss the central focus of this dissertation, which is the

$\mathcal{I}$ interrelation between depression, health behavior, and the course of chronic disease among late middle-aged and older adults. Health behavior was defined as to include lifestyle - smoking, alcohol use, physical activity, and body composition - and regimen adherence. From a public health perspective, unraveling this interrelation is important for several reasons. First, chronic diseases, depression, and unhealthy lifestyles are prevalent in the general population. Chronic diseases and depression are even more prevalent in late middle aged and older persons. Second, some of these concepts have been suggested to contribute to each other's risk, eventually leading to increased burden of disease for patients, higher prevalences of diseases in the community, and a higher burden for national health care. Primary objective of this study was to clarify these reciprocal associations, using data from the (large) longitudinal studies of LASA, MAAS, and ADAPT. Forthcoming paragraphs will elaborate on this. Results may provide insights into determinants of the abovementioned associations that are amenable to change. These determinants could potentially be used in intervention research, and may therefore be relevant for clinical practice. Finally, outcomes may contribute to improvements in public health policy and to cost-effective health care.

\subsection{Reciprocity between depression, health behavior, and chronic disease}

\section{Determinants of attendance to diet and exercise interventions}

Determinants of compliance to lifestyle regimens are not well understood. Attendance to intervention sessions is crucial for persons to acquire knowledge and skills regarding the core elements of an intervention, and can be seen as a prerequisite of intervention compliance. Therefore, in CHAPTER 2, we explored demographic, health-related, and social determinants of attendance to diet sessions and exercise sessions in the Arthritis, Diet, and Activity Promotion Trial. The results pertain to 206 persons of 60 years or older who had knee osteoarthritis and were - at least - overweight. They were asked to participate in a dietary weight loss intervention, an exercise intervention, or a combination 
of both (double intervention randomization) over the duration of 18 months. Being randomized into a single intervention and attending sessions in the early phase of the interventions both predicted high attendance to sessions in the later phase of the interventions. Ultimately, determinants of attendance to diet sessions and exercise sessions differed. Giving persons a choice to do their exercises at least partly at home and stimulating attendance to sessions early in the intervention may be effective in enhancing long-term attendance to diet and exercise interventions.

\section{Associations between regimen adherence and physical function and disability} For patients with knee osteoarthritis (knee OA) adherence to a prescribed physical exercise regimen is important to preserve physical function. Concurrently though, adherence to a prescribed regimen in general tends to diminish with the duration of the regimen. We therefore examined, in CHAPTER 3 , whether high adherence to an 18-month physical exercise regimen improved physical performance and self-reported disability among 134 persons of 60 years or older who had knee OA and were - at least - overweight. These persons of the Arthritis, Diet, and Activity Promotion Trial were asked to exercise for one hour - three days per week. Results indicated that higher exercise adherence was associated with improvements in physical performance in a dose-response kind of way. High initial adherence to the exercise regimen was associated with improvements in self-reported disability, but not in the long run. To a certain extent these associations could be explained by modifiable variables, such as pain and body mass index (BMI). Thus, promoting exercise regimen adherence seems justified when prescribing one to overweight older adults with knee OA, and thereby also focusing on improvements in pain and BMI.

\section{Chronic disease and lifestyle changes}

In CHAPTER 4 we theorized that lifestyle changes might be indicated in some instances to prevent chronic diseases from worsening and to maintain physical and social functioning. In 2184 persons of the Longitudinal Aging Study Amsterdam, we examined differences in lifestyles, and lifestyle changes after six years, stratified by prevalent and incident chronic disease categories. Lastly 
we tested whether changes in disease-related impairments differed between persons who made a healthy lifestyle change and those who did not, within the same chronic disease category. Results indicated that some differences in lifestyles could be attributed to differences in background variables, such as age, gender and educational level. Overall, proportions of persons who smoked decreased, while the proportion of persons who reported to be sedentary increased. Respondents who developed cardiovascular disease during the study were more likely to change lifestyles than other chronic disease categories. Lifestyle changes appeared not to occur under the influence of the emergence or worsening of disease-related impairments. If our findings are replicated in future studies, health promotion strategies may be targeted more effectively, and patient groups who do not initiate more healthy lifestyles might be reached for intervention.

\section{Associations between lifestyle and depressed mood}

A complex of physical, psychological, and socio-environmental factors is assumed to cause depressed mood, which is defined as clinically relevant levels of depressive symptomatology along the depressive spectrum. It is not unequivocally clear how lifestyles, as an example of these socio-environmental factors, and depressed mood are associated over time. In CHAPTER 5, we focused on the question: do healthy lifestyles protect against depressed mood in 1186 persons of the longitudinal Maastricht Aging Study? No cross-sectional associations between lifestyles and depressed mood were found. Excessive alcohol use predicted the presence of depressed mood after six years, while exercising more than 30 minutes per day and not being overweight for six years were associated with absence of depressed mood after six years. We concluded that adopting healthy lifestyles might be a starting point to prevent or to deal with depressed mood over time.

\section{Associations between depressed mood and lifestyle}

In CHAPTER 6 we theorized that the way in which depressed mood might trigger or worsen chronic diseases might go through unhealthy lifestyles. Mental health improvements in chronically diseased persons could possibly intervene in the downward spiral of depressed mood, unhealthy lifestyles, and 
deterioration of chronic disease. In 1280 community-dwelling persons from the Longitudinal Aging Study Amsterdam we examined associations between depressed mood and unhealthy lifestyles. Results indicated that depressed persons were likely to smoke, and persistently depressed people increased their cigarette consumption. Having an emerging depressed mood was likely to co-occur with change to a sedentary lifestyle, and the largest decrease in minutes of physical activity. Chronic diseases did not moderate the effects of depressed mood on unhealthy lifestyles. Clinical practice can benefit from this line of research if future research can elucidate whether treatment of depressive symptomatology can prevent unhealthy lifestyle changes.

\section{The process of disablement and depression}

The main pathway of the disablement process consists of four consecutive phases: pathology (presence of disease or injury), impairments (dysfunctions or structural abnormalities), functional limitations (restrictions in basic physical or mental actions), and disability (difficulties in doing activities of daily life). In CHAPTER 7 we determined the presence of the main pathway of the disablement process, and determined whether progression along the main pathway of disablement is accelerated in the presence of depressed mood in 1110 persons from the community-based Longitudinal Aging Study Amsterdam. We analyzed intermediate effects of different consecutive disablement phases, and depression was used as an interaction term while linking the consecutive disablement phases. We concluded that the main pathway of the disablement process could be identified in our sample, and that depression accelerated progression in the disablement process, particularly in the early and late stages of the model. Reduction of depression may help slow down the process of disablement for persons who find themselves in those stages of the model.

\subsection{Conclusions}

In CHAPTER 8 we summarize the principal findings of the study, and we put our findings in perspective. Furthermore, methodological considerations are made regarding internal and external study validity. We conclude with study implications, which are relevant to public health, and make recommendations for future research. Although hypothesized before, we conclude that adopting 
and maintaining healthy behaviors over time may lead to lower levels of depression, and to less chronic disease burden. However, the promotion of healthy, but particularly the discouragement of unhealthy lifestyles in the community is an arduous undertaking, for a balance must be sought in respecting the personal freedom of persons and the importance of all persons - not just specific age groups - understanding either the health benefits of healthy lifestyles and the health risks of unhealthy lifestyles, while trying to make national health care cost-effective. Future research should elucidate: 1 ) whether the extent to which persons adhere to their lifestyle regimens matters for the improvement in depressive symptomatology, 2) whether lifestyle interventions are effective in the treatment of depressive symptomatology, 3) whether lifestyle interventions are equally effective in persons with minor depression or major depressive disorder, and 4) whether lifestyle interventions can be incorporated in the existing treatment of depressive symptomatology. Also, whether or not the influence depression has on the course of chronic diseases is disease-specific, deserves further attention.

\subsection{Inleiding}

Tn HoofdSTUK 1 wordt het centrale thema van dit proefschrift besproken; de samenhang tussen depressie, gezondheidsgedrag, en het beloop van chronische ziekten onder ouderen. Gezondheidsgedrag was zo gedefinieerd dat het leefstijl - dus roken, alcohol gebruik, en lichaamsbeweging - en therapietrouw omvatte. Vanuit het oogpunt van maatschappelijke gezondheidszorg is het om meerdere redenen van belang dat deze samenhang wordt onderzocht. Ten eerste, depressie, ongezonde leefstijlen, en chronische ziekten zijn veelvoorkomend in de gewone bevolking, zelfs nog meer in de oudere bevolkingslagen. Ten tweede, in eerder onderzoek is gesuggereerd dat deze concepten bijdragen aan elkaar's risico, wat uiteindelijk kan leiden tot toegenomen ziektelast, hogere prevalenties, en hogere uitgaven voor de nationale gezondheidszorg. Het voornaamste doel van deze studie was het verhelderen van de wederkerige, onderlinge samenhang, met behulp van gegevens van de (grote) longitudinale studies LASA, MAAS, en ADAPT. In de hierop volgende paragrafen zullen daar verder op ingaan. De resultaten kunnen nieuwe inzichten verschaffen in de veranderbare determinanten van de 
hierboven genoemde samenhang. Deze determinanten kunnen wellicht in interventie onderzoek toegepast worden en zijn daarom van belang voor clinici. Ten slotte kunnen de uitkomsten bijdragen aan verbeteringen in gezondheidszorg beleid en aan een meer kosten-effectieve gezondheidszorg.

\subsection{Wederkerigheid van depressie, gezondheidsgedrag, en chronische ziekte}

\section{Determinanten van deelname aan dieet- en bewegingsinterventies}

Determinanten van de mate waarin leefstijladvies wordt opgevolgd zijn onduidelijk. Het bijwonen van interventie bijeenkomsten wordt verondersteld cruciaal te zijn om kennis en vaardigheden aangaande de kernelementen van de interventie op te doen, en kan daarom worden opgevat als een 'sine qua non' voor de mate waarin aan een interventie gevolg wordt gegeven. In HOOFDSTUK 2 hebben we daarom demografische, gezondheidsgerelateerde, en sociale determinanten van het bijwonen van bijeenkomsten van dieet- en bewegingsinterventies geëxploreerd in de Arthritis, Diet, and Activity Promotion Trial. De resultaten hebben betrekking op 206 personen van 60 jaar of ouder met tenminste overgewicht en die osteoartritis aan de knie hadden. Zij waren gevraagd deel te nemen aan een 18 maanden durende dieetinterventie, bewegingsinterventie, of aan een interventie die beiden combineert. Ingedeeld worden in een 'enkele' interventie en het veelvuldig bijwonen van bijeenkomsten in het vroege deel van de interventie voorspelden het veelvuldig bijwonen van bijeenkomsten in het latere deel van de interventie. Uiteindelijk bleken determinanten van het bijwonen van bijeenkomsten van de dieet- en bewegingsinterventies te verschillen. Personen keuzevrijheid geven waar ze hun bewegingsoefeningen kunnen doen en het stimuleren van het bijwonen van interventie bijeenkomsten in het vroege deel van de interventie zijn wellicht effectief in het verhogen van het bijwonen van dieet- en bewegingsinterventie bijeenkomsten.

\section{Het opvolgen van bewegingsadvies en lichamelijk functioneren} Voor patiënten met osteoartritis aan de knie is het van belang een voorgeschreven bewegingsadvies op te volgen ten einde lichamelijk functioneren te behouden. Het opvolgen van advies neemt gewoonlijk af 
naarmate de tijd verstrijkt dat het advies geldt. We hebben daarom bekeken, in HoOFDSTUK 3, of het goed opvolgen van een 18 maanden durend bewegingsadvies lichamelijk functioneren op prestatietaken en zelfgerapporteerde invaliditeit verbeterde bij 134 personen van 60 jaar of ouder met tenminste overgewicht én osteo-artritis aan de knie. Deze deelnemers aan de Arthritis, Diet, and Activity Promotion Trial werden gevraagd drie dagen per week een uur lang oefeningen te doen. De resultaten gaven aan dat naarmate men trouwer het bewegingsadvies opvolgde de verbeteringen qua lichamelijk functioneren op de prestatie-taken groter waren. Het initieel goed opvolgen van het bewegingsadvies leidde tot korte-termijn verbeteringen in zelfgerapporteerde invaliditeit, maar niet gedurende de lange termijn. Deze associaties zijn tot op zekere hoogte te verklaren door tussenkomst van wijzigbare variabelen, zoals pijn en body mass index (BMI). Vandaar dat het promoten van het opvolgen van bewegingsadvies zinvol is wanneer een dergelijk bewegingsadvies wordt voorgeschreven aan oudere personen met overgewicht én osteoartritis aan de knie dat zich tegelijkertijd richt op verbeteringen in pijn en BMI.

\section{Chronische ziekte(s) en leefstijl veranderingen}

In HOOFDSTUK 4 veronderstelden we dat leefstijl veranderingen in sommige gevallen geïndiceerd zijn om te voorkomen dat bepaalde chronische ziekte(s) verergeren, en om een bepaald niveau van fysiek en sociaal functioneren te behouden. Bij 2184 personen van de Longitudinal Aging Study Amsterdam hebben we de verschillen in leefstijl onderzocht, en de veranderingen hierin na zes jaar, en presenteren dat per prevalente en incidente chronische ziektecategorie. Tot slot bekeken we of veranderingen in ziekte-gerelateerde klachten verschillend waren tussen personen die hun ongezonde leefstijl veranderden en diegenen dat niet deden, binnen een en dezelfde chronische ziektecategorie. De resultaten gaven aan dat sommige verschillen in leefstijl toegeschreven konden worden aan verschillen in achtergrond variabelen, zoals leeftijd, geslacht en opleiding. Over het algemeen namen proporties van mensen die rookten af, terwijl de proportie van mensen met een sedentaire leefstijl toenam. Veranderingen in leefstijl lijken niet samen te hangen met het optreden of verergeren van ziekte-gerelateerde klachten. Wanneer resultaten 
van toekomstig onderzoek een zelfde richting in wijzen, kunnen mogelijk de programma's ter bevordering van de gezondheid effectiever worden ingezet om zo patiënten groepen, die geen gezonde leefstijlveranderingen vertonen, te bereiken voor interventies.

\section{Samenhang tussen leefstijl en neerslachtigheid}

Verondersteld wordt dat een complex van fysieke, psychologische, en sociaalen omgevingsgerelateerde factoren neerslachtigheid veroorzaken. Neerslachtigheid wordt gedefinieerd als klinisch relevante niveau's van depressieve symptomatologie langs het langs het spectrum van depressie. Het is evenwel niet duidelijk hoe leefstijl - een sociaal- en omgevingsgerelateerde factor - en neerslachtigheid over tijd met elkaar gelieerd zijn. In HOOFDSTUK 5 richtten we ons op de vraag of 'n gezonde leefstijl beschermt tegen neerslachtigheid bij 1186 personen die deelnamen aan de longitudinale Maastricht Aging Study. Er werden geen cross-sectionele verbanden tussen leefstijl en neerslachtigheid gevonden. Excessief alcohol gebruik voorspelde de aanwezigheid van neerslachtigheid zes jaar later, terwijl het meer dan 30 minuten fysiek actief zijn per dag en het niet hebben van overgewicht verband hielden met de afwezigheid van neerslachtigheid na zes jaar. Geconcludeerd werd dat het aannemen van een gezonde leefstijl een begin kan zijn in het voorkomen van neerslachtigheid of in het succesvol omgaan met neerslachtigheid over de tijd.

\section{Samenhang tussen neerslachtigheid en leefstijl}

In HOOFDSTUK 6 theoretiseerden we dat de manier waarop neerslachtigheid chronische ziekten kan uitlokken of verergeren, deels zou gaan via het hebben van een ongezonde leefstijl. Verbeteringen in de mentale gezondheid van mensen met een chronische ziekte zou wellicht kunnen ingrijpen op de neerwaartse beweging van neerslachtigheid, het hebben van een ongezonde leefstijl, en verslechtering van chronische ziekte. We onderzochten de samenhang tussen neerslachtigheid en een ongezonde leefstijl bij 1280 personen die deelnamen aan de Longitudinal Aging Study Amsterdam. De resultaten gaven aan dat neerslachtige personen vaker rookten, en dat aanhoudend neerslachtige personen het aantal sigaretten dat ze roken, opvoerden. Het opkomen van een periode van neerslachtigheid gebeurde vaak 
samen met het veranderen naar een sedentaire leefstijl, en de grootste afname in minuten die besteed worden aan fysieke activiteit. Chronische ziekten hadden geen invloed op de samenhang tussen neerslachtigheid en het hebben van een ongezonde leefstijl. De klinische praktijk kan van dit soort onderzoek profiteren wanneer toekomstig onderzoek kan uitwijzen of de behandeling van depressieve symptomatologie de verandering naar ongezonde leefstijlen kan verhinderen.

\section{Neerslachtigheid en het proces van invalidering bij chronische ziekte} Het belangrijkste traject in het proces van invalidering bestaat uit vier opeenvolgende fasen: pathologie (aanwezigheid van ziekte of verwonding), klachten (disfuncties of structurele abnormaliteiten), functionele beperkingen (beperkingen in basaal fysieke of mentale taken), en invaliditeit (hinder bij het uitvoeren van alledaagse activiteiten). In HOOFDSTUK 7 hebben we getracht aan te tonen: 1) de aanwezigheid van het belangrijkste traject van het proces van invalidering onder 1110 deelnemers aan de Longitudinal Aging Study Amsterdam, en 2) dat het voortschrijden in het belangrijkste traject in het proces van invalidering wordt versneld onder aanwezigheid van neerslachtigheid. We analyseerden intermediërende effecten van verschillende opeenvolgende fasen van het proces van invalidering op elkaar, en neerslachtigheid werd gebruikt als interactieterm, terwijl we de opeenvolgende fasen van het proces van invalidering aan elkaar probeerden te koppelen. Geconcludeerd werd dat het belangrijkste traject van het proces van invalidering in onze steekproef geïdentificeerd kon worden, en dat neerslachtigheid het voortschrijden in het proces van invalidering daadwerkelijk versneld, vooral in de vroege en late fase van het model. Het tegengaan van neerslachtigheid zou het voortschrijden in dit proces van invalidering wellicht kunnen vertragen voor personen die zich in deze fasen van het model bevinden.

\subsection{Conclusies}

In HOOFDSTUK 8 vatten we de meest in het oog springende bevindingen van onze studie samen en plaatsen ze in perspectief. Daarnaast worden er methodologische afwegingen gemaakt met betrekking tot de interne en 
externe validiteit van de studie. We sluiten af met de implicaties van ons onderzoek die relevant zijn voor het veld van maatschappelijke gezondheidszorg, en doen aanbevelingen voor toekomstig onderzoek. Hoewel er al over is getheoretiseerd, concluderen wij dat het aannemen en handhaven van gezonde gedragingen over de tijd leidt tot lagere niveau's van depressie en tot minder ziektelast. Toch is het bevorderen van een gezonde leefstijl, maar meer nog het afraden van een ongezonde leefstijl, op gemeenschaps- of nationaal niveau een hachelijke onderneming. Hierin moet namelijk een evenwicht worden gevonden in het respecteren van iemands persoonlijke keuzevrijheid en het belang dat iedereen - dus niet slechts enkele leeftijdsgroepen - op de hoogte is van de gezondheidsvoordelen van een gezonde leefstijl en van de gezondheidsrisico's van een ongezonde leefstijl, en ondertussen de kosten van de gezondheidszorg zo laag mogelijk houden. Toekomstig onderzoek zou kunnen verduidelijken: 1) of gezonde leefstijl interventies, i.h.b. fysieke activiteit voorschriften, moeten worden uitgevoerd onder personen die medicijnen gebruiken voor hun depressieve symptomatologie; 2 ) of de mate waarin personen zich houden aan hun leefstijl advies van invloed is op de mate waarin de depressieve symptomatologie afneemt; 3 ) of leefstijl interventies effectief zijn in de behandeling van depressieve symptomatologie; 4) of de effectiviteit van leefstijl interventies verschilt tussen personen met een maiore depressieve stoornis en personen met klachten van neerslachtigheid; en 5) of leefstijl interventies deel kunnen gaan uitmaken van de reeds bestaande behandelingstrategieën. Of de invloed, die depressieve symptomatologie heeft op het proces van invalidering, al dan niet ziektespecifiek is, ten slotte, zou ook verduidelijking behoeven. 


\section{Acknowledgement (Dankwoord)}

$A$ llereerst zou ik graag mijn (co-)promotores willen bedanken. Jacques, "In der beschränkung zeigt sich erst der Meister", of, zoals ik duidelijk heb hopen te maken in de verdediging, "Weniger ist mehr". Ik heb je manier van leiding geven over dit project erg kunnen waarderen. Losjes in tijden waarop het lekker liep, en kordaat in tijden waarin voortgang even op zich lieten wachten, maar immer in overleg, en immer met het doel dat ik er zelf beter / wijzer van werd. Ruud, ik vond het prettig om samen met jou 'aan de grenzen van het weten' te werken. Het was voor mij erg fijn om te weten dat ik bij je aan kon kloppen als me iets niet duidelijk was (hoe klein ook). Ook voor jou geldt dat je goed aanvoelde wanneer ik bijsturing kon gebruiken en wanneer niet. Brenda, ik had me geen betere co-promotor kunnen wensen. Niet alleen ben je (terecht) altijd erg kritisch geweest op hetgeen ik je toestuurde - wat de kwaliteit van de artikelen heeft verhoogd -, maar jullie (samen met Wout, Dino, en Mila) hebben me ook gastvrij ontvangen in North Carolina. Je hebt mede de voorwaarden geschapen voor twee heel fijne werkbezoeken aan de VS en voor dat alles ben ik je erg dankbaar! Jacques, Ruud, en Brenda, ik hoop dat we onze samenwerking nog een tijdlang kunnen voortzetten!

Dorly en Martin, als co-auteur van een (aantal) artikel(en) en lid van de oppositiecommissie hebben jullie bijgedragen aan het bereiken van deze dag, waarvoor veel dank. Ook de overige leden van zowel de oppositie- als de beoordelingscommissie wil ik heel hartelijk danken voor hun inzet.

De afgelopen jaren heb ik plezierig gewerkt en genoten van de ongedwongen sfeer bij de sectie Medische Sociologie. Ik wil graag alle collega's bedanken die mijn verblijf aangenaam hebben gemaakt: $m$ 'n kamergenoten Godelief en Esther, de dames van het secretariaat, en alle andere -al dan niet juniore- medewerkers.

Gelukkig was er naast het werk genoeg tijd en ruimte voor ontspanning. Ik heb me altijd kunnen uitleven bij het hockeyteam, bij Balans, bij Edilibre, bij de OVSE, en bij Equilibre. Dank, dat jullie dat tolere(e)r(d)en. 
My dear American and Italian friends, Hal and Heidi, Graziano, and Matteo, I believe we found exactly the right balance between work and leisure. Foosball, hiking trips, and DAC at Ziggy's (Hell yeah!). That's what made my working visits worthwhile. Thanks!

Beste Les en Koen. Onze uitstapjes naar Marmaris, Kreta, Charleston, en Kopenhagen zorgden voor de broodnodige ontspanning, evenals de stapavonden in Tilburg en Utrecht. Ik zie al weer uit naar onze volgende bestemming, waar ook ter wereld!

Pap, mam (ja, ik ben nu klaargekomen met 't onderzoek), Margot en Willem, en Sander bedankt voor jullie onbetaalbare, niet aflatende en onvervangbare steun gedurende de afgelopen vijf jaar. Bovendien zijn er maar weinig promovendi die zich gesteund weten door meer dan twee paranimfen! En lieve Kim, ik weet niet wat (en wanneer!) er van mijn 'buukske' zou zijn geworden als je niet in mijn leven was verschenen. Bedankt voor je begrip en geduld (als we weer eens door een congres/werkbezoek/weekendtripje niet bij elkaar konden zijn). Bedankt ook voor je belangstelling, je vriendschap, en dank voor nog onnoemelijk veel meer, maar wat niet in woorden is uit te drukken. Bedankt!

Hier wil ik het voorlopig bij laten... 


\title{
About the author
}

\begin{abstract}
Con van Gool was born on November 12, 1974 in Goirle. He spent his childhood in Berkel-Enschot, and went to Cobbenhagen College in Tilburg where he completed secondary school. After his graduation, he began a study in Psychology at Tilburg University in September 1993. From March through October 1999 he performed his internship at the Center for the Sudy of Giftedness at the Radboud University in Nijmegen, where he was trained in psychodiagnostic research, and performed literature research on "Underachievement in gifted adolescents". Concurrently he finished his Master's thesis on "Self-image and quality of life in asthmatic children" in close collaboration with his supervisors from Tilburg University and the University Hospital Maastricht. At graduation in March 2000, he received his Master's degree in the free track, in which he combined the Health Psychology track and the Child Psychology track, as well as his certificate of competence in psycho-diagnostic research from the Dutch Institute of Psychologists.

In August 2000 he was employed on a PhD programme, on which this dissertation is based, by the Section of Medical Sociology of the department Health Care Studies, Universiteit Maastricht. During his PhD traineeship he followed numerous methodological and statistical courses. In 2001 he was awarded a Fulbright Visiting Scholar grant in order to conduct research at Wake Forest University, North Carolina in the United States. Also, in 2004 he was awarded a Prof. G. Kootstra Fellowship from the Faculty of Medicine of the Universiteit Maastricht. During this fellowship he will be working on the preparation of postdoctoral research regarding the interaction of biomedical and behavioral mechanisms in the process of physical decline in old age.
\end{abstract}


